\title{
MODIFICATIONS TO THE COACHING BEHAVIOUR ASSESSMENT SYSTEM
}

\author{
A thesis submitted to \\ the Faculty of Graduate Studies and Research \\ in Partial Fulfilment of the requirements for the degree \\ Masters of Arts
}

by

Gregory Thompson

Department of Psychology

Carleton University

July 2008

(C) 2008 Gregory Thompson 
Library and

Archives Canada

Published Heritage

Branch

395 Wellington Street

Ottawa ON K1A 0N4

Canada
Bibliothèque et

Archives Canada

Direction du

Patrimoine de l'édition

395 , rue Wellington

Ottawa ON K1A 0N4

Canada
NOTICE:

The author has granted a nonexclusive license allowing Library and Archives Canada to reproduce, publish, archive, preserve, conserve, communicate to the public by telecommunication or on the Internet, loan, distribute and sell theses worldwide, for commercial or noncommercial purposes, in microform, paper, electronic and/or any other formats.

The author retains copyright ownership and moral rights in this thesis. Neither the thesis nor substantial extracts from it may be printed or otherwise reproduced without the author's permission.
Your file Votre référence ISBN: 978-0-494-51969-1 Our file Notre référence ISBN: 978-0-494-51969-1
In compliance with the Canadian

Privacy A'ct some supporting forms may have been removed from this thesis.

While these forms may be included in the document page count, their removal does not represent any loss of content from the thesis.
AVIS:

L'auteur a accordé une licence non exclusive permettant à la Bibliothèque et Archives Canada de reproduire, publier, archiver, sauvegarder, conserver, transmettre au public par télécommunication ou par l'Internet, prêter, distribuer et vendre des thèses partout dans le monde, à des fins commerciales ou autres, sur support microforme, papier, électronique et/ou autres formats.

L'auteur conserve la propriété du droit d'auteur et des droits moraux qui protège cette thèse. $\mathrm{Ni}$ la thèse ni des extraits substantiels de celle-ci ne doivent être imprimés ou autrement reproduits sans son autorisation.

\section{Canadä}


Modifications to the CBAS

\begin{abstract}
This study sought to improve the reliability and provide evidence of validity for the Coaching Behaviour Assessment System (CBAS) by expanding the behavioural dimensions of the measure. Self-report questionnaires were given to 144 girls and 121 boys, aged 11-16 $(M=14.65)$ twice during a season of competitive soccer in Ottawa, Ontario. Validity was demonstrated by Structural Equation Modelling, by favourable comparisons between the principal component structure of the modified CBAS and the Coaching Feedback Questionnaire, and by correlations between mCBAS and selected dimensions of the Physical Self-Description Questionnaire. Pearson correlations between test and retest data, and Cronbach's alpha provide evidence of reliability. Future research must add behaviours to better predict the impact of coaching behaviours on adolescent athlete psychosocial development.
\end{abstract}


Modifications to the CBAS

\section{Acknowledgement}

This study is dedicated to Mark Hearn, whose inspiration and dedication to excellence in the realm of sport coaching was seminal to my interest in this topic. Mark possessed the rarest combination of talents which made him perfectly suited for coaching adolescents: He was an excellent communicator and teacher, had an immense understanding of the game, and cared and respected his players as well as any parent could wish. His leadership and commitment allowed many children to succeed and enjoy the very highest level of athletic competition. 
Table of Contents

Title Page

Abstract ii

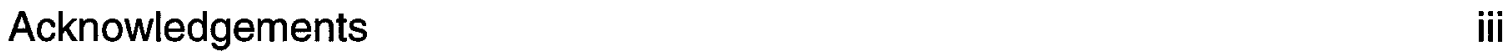

Table of Contents iv

List of Tables vi

List of Figures viii

$\begin{array}{ll}\text { Introduction } & 1\end{array}$

$\begin{array}{ll}\text { Purpose of study } & 3\end{array}$

$\begin{array}{ll}\text { Theoretical model } & 4\end{array}$

What is CBAS? $\quad 4$

What does CBAS measure?

$\begin{array}{ll}\text { Developmental process } & 6\end{array}$

$\begin{array}{ll}\text { Research findings } & 8\end{array}$

Strengths and limitations of CBAS 13

$\begin{array}{ll}\text { Self-esteem } & 24\end{array}$

Restatement of purpose \& expectations regarding results 29

$\begin{array}{ll}\text { Pilot study } & 32\end{array}$

$\begin{array}{ll}\text { Method } & 40\end{array}$

$\begin{array}{ll}\text { Results } & 45\end{array}$

Exploratory Factor Analysis $\quad 45$

Confirmatory Factor Analysis $\quad 51$

iv 
Modifications to the CBAS

Coaching Feedback Questionnaire

Gender Differences

Predictive Validity

Discussion

References

107

Appendices

117 


\section{Modifications to the CBAS}

List of Tables

Table 1: Factor analysis structure using varimax rotation reported by Smith,

Smoll \& Curtis (1978).

Table 2: Principal component analysis results using varimax rotation reported by

Smoll, Smith, Barnett \& Everett (1993).

Table 3: Principal-axis factor analysis using varimax rotation reported by Allen \& Howe (1998).

Table 4: Principal-axis factor analysis results using varimax rotation reported by Amorose \& Horn (2000).

Table 5: Principal component factor analysis results using varimax rotation reported Smith, Fry, Ethington \& Li (2005).

Table 6: Pilot principal component matrix rotated to the varimax criteria (all subjects).

Table 7: Pilot study orthogonal factor structures for female athletes.

Table 8: Pilot study orthogonal factor structures for male athletes.

Table 9: Principal component matrix rotated to the varimax criteria for $\mathrm{T} 1$ data (all subjects).

Table 10: Principal component analysis rotated to the varimax criteria for T2 data (all subjects).

Table 11: Pearson correlations between the T1 and T2 mCBAS dimensions. 93 Table 12: Goodness-of-Fit statistics summary for the hypothesised model using T2 data. 
Table 13: Principal component matrix for CFQ items rotated to the varimax criteria (all subjects).

Table 14: Pearson correlations between the mCBAS and the CFQ dimensions.97

Table 15: Means and standard deviations of T1 mCBAS behaviours (all subjects, genders separate).

Table 16: ANOVA summary for T1 and T2 mCBAS and Self-Concept dimensions comparing gender.

Table 17: Principal component matrix of mCBAS results at $\mathrm{T} 1$ rotated to the varimax criteria for female subjects only.

Table 18: Principal component matrix of mCBAS results at $\mathrm{T} 1$ rotated to the varimax criteria for males subjects only.

Table 19: Principal component matrix of mCBAS results at T2 rotated to the varimax criteria for female subjects only.

Table 20: Principal component matrix of mCBAS results at T2 rotated to the varimax criteria for males subjects only.

Table 21: Pearson correlations between the T1 and T2 mCBAS dimensions for female subjects.

Table 22: Pearson correlations between the T1 and T2 mCBAS dimensions for male subjects.

Table 23: Pearson correlations between the original CBAS, the CFQ and the mCBAS dimensions. 
List of Figures

Figure 1. Smoll \& Smith's model of adult leadership behaviours

Figure 2. Structure of Self-concept (Shavelson, Hubner \& Stanton, 1976).

Figure 3: Graphic representation of the proposed dimensions structure of mCBAS behaviours applied to T2 behaviours 
Modifications to the Coaching Behaviour Assessment System

In the last forty years there has been a dramatic increase in the participation of youth in sport. As the level of involvement of youth in sport increases, so too does the interest in the effects these activities have on the minds and bodies of the players. It is generally believed that participation in sport has a variety of benefits for children and adults. These conceptions find much acceptance in the scientific literature. The physical (Bell, 1996; Dishman, 1988; Paffenburger \& Hyde, 1988; Siscovick, LaPorte \& Newman, 1985; Martin \& Dubbert, 1982), social (Bell, 1996; Deci \& Ryan, 1985; Hunter, Grenier \& Brink, 2001; Weinberg, Tenenbaum, McKenzie, Jackson, Anshel, Grove \& Fogarty, 2000), and psychological benefits (Bell, 1996; Frederick \& Ryan, 1993; Kleiber and Kirshnit, 1991; Koivula, 1999; Miller and Levy, 1996; Richman and Shaffer, 2000; Ryan, Frederick, Lepes, Rubio \& Sheldon, 1997; Senkfor \& Williams, 1995) of sport participation have been well chronicled. However, there is also evidence that the quality of the individual experience varies and for some individuals there may even be negative outcomes associated with sports participation (Bowker et al., 2003; Delaney \& Lee, 1995; Richman \& Shaffer, 2000). As the popularity of sport participation increases, the potential for these accumulated outcomes, whether positive or negative, also rise.

As a natural function of the increasing number of young people participating in athletics there is an ever increasing number of parent volunteers. Much of the controversy surrounding youth sport involves these adults and the role that they play as coaches, managers, referees and spectators (D'Alessio, 
1991; Singer, 1972). There is general agreement that many of the outcomes for the children reside in the relationship between the adults and the players (Martens, 1987; Smith, Smoll \& Curtis, 1978), and the most important adultadolescent relationship in sport is that between the coach and the player. The coach-athlete relationship is usually confined to the athletic setting and by degrees becomes more intense as players progress from recreational to the highest levels of competitive sport. This therefore suggests a higher level of psychological involvement at the competitive level and perhaps a greater psychological impact on the players as well (Feltz, 1978; Martens \& Gould, 1979; Scanlon, 1988).

Through the coach's eyes, his/her primary goals are to improve the physical condition, skill level and game strategies of the players, which in turn improves the performance of the athlete in competition. But it is also becoming apparent that a coach's behaviour can impact the personality and social development of adolescent players (Weiss, 1987; Smoll \& Smith, 1989). It has been suggested that the coach's role as a teacher of the technical aspects of sport is not as important with regard to the overall effect on the player as is the personal relationship with the player (Singer, 1972). For it is the coach's goals, priorities, attitudes, values, behaviours and processes which determine whether the outcomes for the players are favourable or not (Smoll \& Smith, 1989).

The ability to assess the coach's impact on the psychosocial development of their athletes becomes increasingly more critical as research delving into these issues question the notion that sport participation is universally beneficial 
for children. To that end, a variety of assessment devices have been developed to address the coach's behaviour, each with a different focus and with different attributes. The purpose of this study is to improve and build upon one of these behaviour measurement devices. In particular, this study will contribute to the further development of an assessment device designed to measure the nature of the performance feedback the coach provides, and the effect that this feedback has on the self-perceptions of elite adolescent athletes.

Purpose of the Study

The purpose of the present study was to modify the Coaching Behaviour Assessment System (CBAS), an existing measure of coaching behaviour, by expanding the behavioural dimensions of the measure, improve reliability, provide evidence of construct validity, and examine gender variations in the factor structure. Such refinements will allow for a closer examination of the impact that coaching behaviour has on elite adolescent athlete self-perceptions by improving the predictive value of the measure.

Towards that end, a complete analysis of the methodology behind the development of CBAS was undertaken. The theoretical underpinnings and model created by the originating authors were evaluated followed by a discussion of what CBAS is, what it is intended to study and the direction the developmental process has been taking. The study focussed on the positive and negative attributes of CBAS and its descendant, the Coaching Feedback Questionnaire (CFQ), and implemented improvements which will continue to progress the development of CBAS. Justification for the study focussed on the 
positive and negative consequences that sport coaches have on the selfperceptions and psychosocial development of young athletes.

\section{Theoretical Model}

CBAS is described conceptually as a cognitive-mediational model of adult leadership behaviours in sport. The cognitive-mediational model proposes that the behaviour demonstrated by the coach is processed cognitively by the athlete, thus mediating the evaluative pressure on the child's self-perceptions (Smith, Smoll \& Curtis, 1978). The cognitive-mediational model is based on three core elements - (1) the coaches' behaviour, (2) the player perceptions and recall, and (3) the players' evaluative reactions (see Figure 1). The model includes a variety of factors which influence the core elements. These take into account the many situational and individual difference variables effecting the coach/player relationship and the outcomes from that relationship. The ultimate effects of the coach's behaviour is on the players' evaluative reactions and psychosocial development. The players' evaluative reactions include the attitudes about the coach, the sporting experience and the players' teammates; and the psychosocial development includes their self-esteem, global physical selfconcepts, and physical self-perceptions. This relationship is mediated by the meanings the player attaches to the coach's behaviour.

\section{What is CBAS?}

The Coaching Behaviour Assessment System (CBAS) was developed by Smith, Smoll, \& Hunt, (1977) to investigate the type of feedback behaviours that youth athletes received in response to the quality of their athletic performances. 
The CBAS is a systematic behavioural assessment device originally designed to code all coaching behaviours within the natural settings of practice and competition. The method initially employed direct, third party observation by trained research staff but was expanded to include how the coaches thought they had behaved, and how the players perceived the coach to have behaved (Smith, Smoll \& Curtis, 1978). Original research subjects were children and young adolescents aged 8-15 year of age. The main interest was the type, frequency and quality of the coaches' feedback to the young athletes and to determine the effects of those behaviours on the self-perceptions, psychosocial development and attitudes of the athletes (Smith, Smoll \& Hunt, 1977; Smith, Smoll \& Curtis, 1978). In other studies specific study criterion variables have included player global self-esteem (D'Alessio, 1991; Smith, Smoll \& Curtis, 1978), athlete self-perceptions of athletic or sport competence (Horn, 1985), and the impact the coach's gender has had on coaching behaviour tendencies (Millard, 1999).

\section{What Does CBAS Measure?}

CBAS is divided into reactive and spontaneous classes of behaviours (see Appendix A). The reactive behaviours are those for which the coach responds immediately to a player or team performance success or mistake, and are subdivided into responses to desirable, undesirable behaviours (mistakes or failures) and misbehaviours. Spontaneous behaviours are initiated by the coach without recent antecedent player or team performance stimulus and are subdivided into game related and game irrelevant behaviours. 


\section{Developmental Process}

The assessment system was started by observing soccer coaches during practice and games. Observers with tape recorders recorded the play by play in a time sampling procedure. Behavioural descriptions were then transcribed and the content analysed. From this procedure an initial set of behaviours were determined and the researchers returned to the field to observe coaches in other sports. The intent was to ensure that the list of behaviours were comprehensive, that individual coaching differences were discernable and that the coding system could be easily used in the field setting (Smith, Smoll \& Hunt, 1977; Smith, Smoll, Hunt, Curtis \& Coppel, 1978).

Studies initially included observations of the coaches' behaviours, the coaches' self-perceptions of their own behaviours and the players' perceptions of the coach's behaviours. Surveys were conducted verbally after the season was over in the coach or players' home. Observer data was compared to the coach's self-perceptions, and the perceptions of the player. There was little correlation between the coach's self-perceptions and their overt coaching behaviours (as observed by third party assessors). However, there was consistently a significant relationship between the players' perceptions and observations of coaching behaviours (Smith, Smoll, Hunt, Curtis \& Coppel, 1978). As a result, little use is made of the coach's perceptions in subsequent research, and current research uses only the players' perceptions of the coach's behaviour (Allen \& Howe, 1998; Amorose \& Horn, 2000; Smith, Fry, Ethington \& Li, 2005).

Over the course of the history of the CBAS, several modifications have 
been made to the list of the behaviours included. Reinforcement ${ }^{1}$ was subdivided into two components - simple positive reinforcement for successful performance called Reinforcement, and a positive reinforcement behaviour plus technical instruction or Technical Instruction with Reinforcement (Horn, 1985; D’Alessio, 1991; Black \& Weiss, 1992; Solomon et al., 1998; Amorose \& Horn, 2000). This was a result of educational and developmental research which found that performance-contingent feedback improved the self-perceptions of competence, control and expectations of future success in young children (Horn, 1985).

The largest overhaul of CBAS was initiated by Allen \& Howe (1998), and continued to its present form by Amorose \& Horn (2000) and Smith et al., (2005). This overhaul focussed on creating a pencil and paper questionnaire from what had been entirely verbal. The wording of the questions were rearranged, several behaviours were dropped and two questions per behaviour were included. The name for this questionnaire was the Coaching Feedback Questionnaire (CFQ), but the theoretical foundation, nature of the questionnaire and its intended use remain consistent with the CBAS origins.

CFQ included only eight behaviours. Seven of the original behaviours remained - Reinforcement, Non-reinforcement, Mistake-contingent Encouragement, Ignoring Mistakes, Mistake-contingent Technical Instruction, Punishment, and Punitive Mistake-contingent Technical Instruction. The eighth behaviour was the subsequently favoured Technical Instruction with

\footnotetext{
${ }^{1}$ See Appendix B for detail description of all behaviours discussed in this study.
} 
Reinforcement.

Research Findings

The Smith and Smoll research group identified three types of coaching behaviours through factor analysis: (1) supportive behaviours such as Reinforcement, General Encouragement and Mistake-contingent Encouragement; (2) instructional behaviours which include General Technical Instruction and Mistake-contingent Technical Instruction; and (3) negative coaching behaviours - Punishment, Non-reinforcement, and Punitive Mistakecontingent Technical Instruction. Generally, studies have associated the supportive coaching behaviours and the instructive coaching behaviours with higher levels of player self-esteem, both at a global and domain specific levels (Black \& Weiss, 1992; D'Alessio, 1991; Horn, 1985; Kenow \& Williams, 1999; Smith, Smoll \& Curtis, 1978; Smith \& Smoll, 1990; Smoll, Smith, Barnett \& Everett, 1993). The negative coaching behaviours were associated with lower levels of both (D'Alessio, 1991; Allen \& Howe, 1998).

Some findings have seemingly contradicting conclusions. D'Alessio (1991) found that the coaching behaviours which had the greatest impact on the players' self-esteem were the punitive and the instructional behaviours. The instructional behaviours were positively correlated with self-esteem, and the punitive behaviours were significantly negatively related to self-esteem. In contrast, Smith, Smoll \& Curtis (1978) concluded that global self-esteem was correlated with supportive behaviours and not to the instructional coaching behaviours. An important distinction between these two studies is the 
competitive level of the players. D'Alessio's subjects were varsity or competitive athletes and the subjects in Smith, Smoll and Curtis's study were recreational athletes. This may suggest that recreational and elite level athletes react differently to the various coaching behaviours. Supportive behaviours appear salient at the global level to the recreational athletes but not to the competitive athletes. It may be that instructive coaching behaviours are salient to both, and negative coaching behaviours were salient to only the competitive athletes.

Evidence is also available that coaching behaviours impact feelings of sport competence (self-esteem at a domain specific level). Several studies have found that players who played for coaches who demonstrated higher levels of instructive behaviours had higher feelings of sport competence (Black \& Weiss, 1992; Smith, Smoll and Curtis, 1978).

In another study, Horn (1985) investigated novice junior female high school baseball players, and found that those who received more frequent positive reinforcement (a supportive behaviour) or no reinforcement in response to desirable performances (a negative coaching behaviour) scored lower in perceived sport competence. Players who received more punishment in response to performance errors had higher perceptions of sport competence. Horn suggests that this is owing to the fact that the Reinforcement statements given were more often unconditional and therefore unrelated to a players' skill level, or were more generalized and non-specific. Excessive praise for a task easily achieved or for a skill of which the entire group is capable may convey negative information about an athlete's competence. In fact, in Horn's 
preliminary work, more praise and less punishment was given to the athletes the coaches themselves deemed to be the low ability players than were given to the high ability athletes.

Conversely, the use of criticism was more often a direct response to a specific error in skill and usually contained skill-relevant information. Horn concluded that coaches must provide encouragement plus information on how to improve after the incorrect execution of a skill, and must provide praise plus technical information following successful execution of a task to have a positive impact on self-esteem. It must be noted that Horn also concluded that although there is no empirical evidence of a causal relationship between coaching behaviours and player self-perception, results do 'reinforce the notion' that the feedback from the adults in a performance situation did seem to have an effect on the child's self-perceptions of their ability (Horn, 1985).

In a study of competitive swimmers, Black and Weiss (1992) concluded that adolescent athletes seemed to prefer coaches who gave more praise and information following desirable performances. These athletes reported that coaches who displayed more supportive and instructional behaviours and less criticism reported higher levels of perceived sport competence. Athletes in this study ranged from novice to elite level swimmers.

Another study to examine the relationship between coaching behaviours and sport competence was done with competitive, adolescent, female field hockey players 14 to 18 years of age. Results indicate that perceived sport competence was positively correlated with Reinforcement and Technical 
Instruction with Reinforcement, and negatively correlated with Mistake-contingent Encouragement and Mistake-contingent Technical Instruction (Allen \& Howe, 1998).

There is also evidence that male and female athletes are affected differently by a coach's behaviour. In Black and Weiss's study (1992) of the coaching behaviour preferences of adolescent competitive swimmers, it was discovered that the girls, but not the boys, enjoyed the sport more if the coaches were more supportive and instructive after successful performances. Smoll and Smith (1989) found that among elementary school basketball players, girls perceived coaches as giving more support and less punishment and technical instruction than did the boys. Girls liked the supportive behaviours more and had a greater dislike for the negative behaviours than did the boys.

In summary, research into the effects of coaching behaviours indicates that coaching behaviours are related to self-esteem - both global (D'Alessio, 1991; Smith, Smoll \& Curtis, 1978; Smith \& Smoll, 1990; Smoll, Smith, Barnett \& Everett, 1993) and domain-specific (Black \& Weiss, 1992; Horn, 1985; Smith, Smoll \& Curtis, 1978; Allen \& Howe, 1998). However, results varied as a function of the competitive level of the athletes. Global self-esteem was positively correlated with supportive and instructive coaching behaviours in studies of recreational athletes (Smith, Smoll \& Curtis, 1978; Smith \& Smoll, 1990; Smoll, Smith, Barnett \& Everett, 1993), whereas, a study using competitive athletes concluded that global self-esteem was negatively correlated with punitive or negative coaching behaviours, and positively correlated with instructional 
behaviours but not supportive behaviours (D'Alessio, 1991). Perceptions of domain specific self-esteem, or sport competence, was also generally positively correlated with supportive coaching behaviours (Allen \& Howe, 1998; Black \& Weiss, 1992; Horn, 1985) and negatively correlated with negative coaching behaviours (Allen \& Howe, 1998; Horn, 1985), but here too, sufficient contradiction exists within the body of the available literature to suggest that the competitive level of the athlete may be a confounding variable.

Considerable differences also exist between the studies cited with regard to the gender of the subjects, and with the specific outcome variable in question. The subjects in the studies conducted by Smith, Smoll and colleagues (Smith, Smoll \& Curtis, 1978; Smith \& Smoll, 1990; Smoll, Smith, Barnett \& Everett, 1993) and D'Alessio (1991), in which global self-esteem was the outcome variable, all were male. In the studies in which sport competence was the outcome variable, the subjects were either female (Horn, 1985; Allen \& Howe, 1998) or a combination of male and female subjects (Black \& Weiss, 1992). Yet despite these possible contradictions, the nature of the feedback clearly influences the self-perceptions of youth athletes and thus warrants the continued research into the study of the coach/athlete relationship in youth sport. Further development of the CBAS is central to future research in this area and so justifies this study. The purpose of this study is to advance the utility of CBAS and to this end, control of the competitive level of the athletes was established by having only elite athletes as subjects. Furthermore, the suggestion of gender differences has necessitated that responses be evaluated along this dimension 
as well.

Strengths and Limitations of CBAS

This section explores the strengths and limitations of CBAS in four parts. The first deals with a summary of the strengths of CBAS. The second section deals with the reliability and validity limitations of the questionnaire. The third section discusses the problems the questionnaire has dealing with the quality and the contingency of the feedback behaviours, and the final section discusses behaviour categories that are missing.

\section{Strengths}

The CBAS has numerous strengths. The first of these is the conceptual model upon which CBAS is based. The conceptual model, called a cognitivemediational model, was developed from the outset of the development process (figure 1). This model allows for two way interactions between the core elements, considers causal and moderator relationships, and includes the impact of individual and situation specific difference variables on each of the core elements (Chelladurai \& Riemer, 1998).

The developmental process was a rigorous empirical analysis, and reassessment and refinements have been ongoing through the efforts of many researchers (Allen \& Howe, 1998; Amorose \& Horn, 2000; Black \& Weiss, 1992; Horn, 1985; Smith, Fry, Ethington \& Li, 2005). This measurement device was designed specifically for the assessment of the impact of coaches on the selfperceptions of youth athletes, and is focussed on the feedback behaviours of coaches in response to player performance in practice and game conditions. 
The device is considered a wide spectrum coding system of coaching behaviours and as such is considered comprehensive (Chelladurai \& Riemer, 1998). The face validity of CBAS is widely accepted (Chelladurai \& Riemer, 1998), and CBAS is considered the principal measurement device when the psychosocial development of child athletes are the outcome variables (Horn, 2002).

The predictive value of CBAS has been repeatedly supported empirically as coaching behaviours have been shown to correlate with player self-esteem (D'Alessio, 1991; Smoll, Smith, Barnett \& Everett, 1993; Smith, Smoll \& Curtis, 1979; Smith, Zane, Smoll \& Coppel, 1983; Smith \& Smoll, 1990), feelings of sport competence (Allen \& Howe, 1998; Black \& Weiss, 1992; Horn, 1985), and levels of intrinsic motivational climate (Amorose \& Horn, 2000; Smith, Fry, Ethington \& Li, 2005).

Reliability and validity limitations

Reliability is the level of consistency provided by a measurement device. Mathematically speaking, reliability is the ratio of the true score variance for a test item and the total variance possible for the same test item (Cohen \& Swerdlik, 1988). The original method for collecting data consisted of asking players single, carefully worded questions for each behaviour category. This single question per behaviour requires that internal consistency estimates be done on a single giving of this device, and suggests the need for a test-retest approach to explore reliability, but to date such studies have not been done.

Validity of a measure is an assessment derived from relevant information 
concerning the suitability of inferences drawn from the test results, or how adequately the target construct is actually measured. To demonstrate a level of construct validity, an underlying dimensional structure is necessary, but as yet, a repeatable dimensional structure has not been found for CBAS. The original authors provide two separate attempts to find the structural dimensions for CBAS. In the first, Smith, Smoll \& Curtis (1978) studied male recreational baseball players aged 8-15 years of age, and the effects of coaching behaviours on self-esteem. Data was gathered post-season using a survey questionnaire consisting of one question per behaviour. All of the twelve original behaviours were considered. The factor structure was determined using a factor analysis performed on the coaching behaviour responses provided by the players, and suitable factors identified by setting a minimum Eigenvalue of 1.0 and a varimax rotation. Three factors, explaining $45.6 \%$ of the total variance were identified: (1) the degree to which the coach used supportive behaviours; (2) the degree to which the coach used negative behaviours; and (3) the degree to which the coach responded to mistakes with technical instruction versus the tendency to ignore mistakes (see Table 1). It was concluded that the degree to which the coach used supportive and instructive coaching behaviours correlated with player self-esteem. Evidence to indicate reliability and validity of the CBAS measure was not provided.

Another study was done with male, recreational baseball players, 10-12 years of age to detect the effects of coaching behaviours on player self-esteem (Smoll et al., 1993). The same 12 behaviours with one question per behaviour in 
a verbal survey format was used as was done by Smith et al (1978). A principal components analysis on the behaviour responses was conducted and the factors identified with an Eigenvalue minimum threshold of 1.0 and a varimax rotation. Two factors were found to explain $53.1 \%$ of the total variance: (1) the degree to which the coach was supportive and technically instructive versus the degree to which they perceived their coach to provide negative behaviours; and (2) the degree to which the coach demonstrated Mistake-contingent Technical Instruction and Keeping Control (Table 2). The study concluded that players who played for coaches who demonstrated more of the supportive and instructive coaching behaviours had self-esteem improvements over the season and that the other players did not.

Similarities between the factor structures of these two studies are limited to the inclusion of three common behaviours in factor 1 - General Encouragement, Reinforcement and General Technical Instruction. Dissimilarities are numerous and provide no evidence of construct validity. More recent studies have attempted to address reliability and construct validity for the CBAS (as stated earlier - see page 10). Allen \& Howe (1998) initiated an overhaul process which proceeded to development of the Coaching Feedback Questionnaire (CFQ). The initial offering of CFQ increased the number of questions per behaviour to three and created a questionnaire in a written format to study the effects of coaching behaviours on the self-perceptions of sport competence of female, adolescent field hockey players. Several of the original CBAS behaviours were dropped (Organization, General Encouragement, 
Keeping Control, General Communication, General Technical Instruction), and several behaviours added (Non-verbal Reinforcement, Non-verbal Punishment, Technical Instruction with Reinforcement, Success-contingent Technical Instruction without Praise, and Mistake-contingent Technical Instruction plus Encouragement). Behavioural responses were analysed using exploratory principal-axis factor analysis with an Eigenvalue threshold of 1.0 and a varimax rotation. Internal consistency estimates were calculated using Cronbach's alpha coefficient with four of seven orthogonal factors achieving the minimum criteria $(\geq 0.70)$. The four factors accounted for $41.5 \%$ of the total variance (Table 3 ) and were: (1) supportive and instructional responses to mistakes, (2) reinforcement and instruction in response to good performances, (3) punishment, and (4) technical instruction. The resultant factor structure is not similar to the factor structure of either Smith et al. (1978), or Smoll et al. (1993), and so construct validity is not evident. Therefore, the similarities of these two research articles marginally advance the reliability of CBAS but not construct validity.

Amorose \& Horn (2000) continued the overhaul process with a study of the perceptions of the coach's behaviour among male and female university athletes engaged in a variety of sports. This version of CFQ was identical to the Allen \& Howe (1998) device in that it retained the same eight behaviours and was a written questionnaire. It differed in that there were only two questions for each coaching behaviour rather than three as had been the case in the Allen \& Howe study. This study was the first to name the questionnaire as the Coaching Feedback Questionnaire. 
An exploratory principal-axis factor analysis was conducted on the response data. Appropriate factors were determined with a minimum Eigenvalue of 1.0 and a varimax rotation. Three factors, providing $49.8 \%$ of the variance were identified: (1) supportive and instructional feedback, (2) negative feedback, and (3) Non-reinforcement and Ignoring Mistakes (Table 4). Evidence of internal consistency was provided by the Cronbach's alpha coefficient as all factors exceeded the minimum $(\geq 0.70)$. Difficulties with the factor dimensions include the loading of single Mistake-contingent Technical Instruction questions on factor 1 and 2, and the cross loading of both Non-reinforcement questions on factors 1 and 3. Evidence of construct validity is not present as comparisons to earlier dimensional structures are too dissimilar.

Smith, Fry, Ethington \& Li (2005) continued the development of the CFQ in a study of the effect of feedback behaviours on the team motivational climate as perceived by female high school varsity basketball players. The same pencil and paper, eight behaviour questionnaire was used as in Amorose \& Horn (2000) with two questions per behaviour. The responses were analysed with a principal components factor analysis, with a minimum Eigenvalue threshold of 1.0 and a varimax rotation. Three factors which accounted for $52.8 \%$ of the total variance were segregated (table 5): (1) supportive behaviours, (2) Punishment, and (3) Ignoring Mistakes. Each of the three factors exceeded the minimum internal consistency reliability criteria (Cronbach's alpha 20.70 ). So, here again evidence of internal consistency is provided. The only concern to the original author is the cross loading of Technical Instruction with Reinforcement on factors 
one and two. Some evidence is available for construct validity due to the similarity of the factor structures derived by this article and that provided by Amorose \& Horn (2000).

In conclusion, progress has been made with regard to the reliability and construct validity of CBAS from the original author's research to the most recent studies using CFQ. Evidence for internal consistency is provided by the steadily improving Cronbach's alpha coefficient for the orthogonal factors by the most recent attempts. A degree of construct validity is demonstrated by the similarity of the factor structures of the most recent two articles. But more effort is required to establish confidence in the reputation of the CBAS as the principal measurement device of its kind in the study of the psychosocial development of child athletes.

\section{Quality and contingency of behaviours}

The predictive value of CBAS is dependent on its ability to capture the entire range of potential behaviours that may impact the self-perceptions of players, and convey in its wording the essence of the meaning those behaviours are intended to impart. The subjects must be able to readily understand the abstract meaning imparted by the question and then associate it to recalled feedback behaviour. This next section will discuss the potential for aligning of behaviours into unexpected categories due to the underlying meaning or quality of the behaviour, or due to non-contingent feedback, and discuss the potential for missing behaviours.

There is concern that the quality of the behaviours is not taken into 
account by CBAS. These may be verbal, but may also be non-verbal, and are imparted to the player in ways which only the player may perceive (Horn, 2002). The potential for sarcasm in a coach's encouraging response to player performance is an example. Players may interpret encouragement given in a sarcastic manner as a negative response to their performance (Smoll, Smith, Curtis \& Hunt, 1978). The feedback requires interpretation, and defies consistent placement into the higher order categories of supportive or negative coaching behaviours.

The contingency and appropriateness of certain behaviours is also cited as a source of difficulty for consistent predictive association of behaviours with superordinate categories. The results and interpretation of Horn's (1985) study are important to appreciate (discussed earlier, see page 9). The results suggested that the players' self-perceptions of sport competence increased with increased levels of punitive coaching behaviours directed at them. In contrast, sport competence was lower in athletes who reported more praise directed their way. This counter intuitive result is explained by the coaches' use of noncontingent or inappropriate use of supportive and punitive behaviours. The author concluded that coaches used positive reinforcement more often with less competent athletes as a way of motivation rather than criticism. They were also more demanding of the higher skilled athletes, providing less praise and more critical assessments after errors of skill or performance. The athletes deciphered these tendencies and parsed the real meaning of these behaviours thus rendering praise a negative skill clue, and criticism a positive skill clue (Black \& 
Weiss, 1992; Horn, 1985).

Thus it is important that a questionnaire addressing the feedback behaviours of coaches and the impact those behaviours have on the selfperceptions of their athletes be concerned with the quality and intensity of the behaviour, and with the contingency and appropriateness of the behaviour.

Missing behaviours

The CBAS is considered a feedback questionnaire measuring the coach's responses to player performance, and as such, it is considered by some to be comprehensive (Chelladurai \& Riemer, 1998). The CBAS is reputed to consider a wide range, if not all, of the behaviours of the coach in practice and game situations (Chelladurai \& Riemer, 1998; Smith \& Smoll, 1990). However, many behaviours are not addressed by CBAS.

Significant differences have been found between game and practice behaviours, and some of the game behaviours demonstrated to effect player self-perceptions are not considered by CBAS (Wandzilak, Ansorge \& Potter, 1988). The differences between a coach who is composed on the sidelines, and a coach who is often agitated, emotionally demonstrative, and anxious is a case in point. Whether the outburst is directed toward the subject or someone else on the field, players do make critical self-assessments of their performance as a result of having witnessed these behaviours (Baker, Cote \& Hawes, 2000; Kenow \& Williams, 1992; Kenow \& Williams, 1999; Williams et al., 2003). It is therefore important to consider the emotional state demonstrated by the coach on the sidelines as witnessed by players during games. 
Reinforcement may take the form of a thumbs up or a pat on the back. Rolling of the eyes or shaking of the head may also be the extent of a punishment behaviour. Analysis of the wording of the player perceived version of the questionnaire demonstrates that unspoken behaviours are not addressed (Horn, 2002; Martens, 1987). Body language, facial expressions and gestures are all sources of communication which may be directed to an athlete. Indeed, it is speculated that such non-verbal mechanisms may actually account for up to $70 \%$ of pertinent communication (Martens, 1987). Such subtle skill relevant clues directed toward the players should also be considered in a measurement device designed to predict player self-perceptions.

Decisions made by the coach about the athletes' ability are often communicated non-verbally. This type of communication between player and coach, whether public or private, may include clues about the coach's confidence in the player's individual abilities in relation to others. These may be demonstrated in preferential treatment of favoured athletes at the expense of the others, or in providing differential playing time to specific players. CBAS also does not address these behaviours. It is therefore necessary to consider preferential treatment and playing time as a behaviour which may contribute to a player's self-perceptions.

In summary, the strengths of CBAS include a detailed working model and a rigorous development process. The clear focus on the coach's feedback behaviour to the performance of youth athletes in game and practice situations heighten the utility of CBAS. CBAS incorporates a comprehensive spectrum of 
potential behaviours and its predictive value has been repeatedly empirically supported. In the study of psychosocial development of youth in sport, CBAS has become the principal measurement device of its kind.

Despite these strengths and ongoing refinements, areas in need of improvement remain. More evidence to support reliability is required, and a track record of studies verifying the construct validity of CBAS is not available. Another area which needs improvement is its predictive validity. The saliency and understandability of the questions for the athletes needs to be improved, and the breadth of the behavioural spectrum needs to be expanded to include additional game related and non-verbal behaviours which may influence the psychosocial development of youth athletes and hence improve predictive utility of CBAS.

In the present study, evidence of reliability is sought for CBAS by employing a test-retest procedure to compare factor structures, and by calculation of Cronbach's coefficient alpha for an estimation of internal consistency. Support for the measure's validity is advanced in four ways: (I) by scrutinizing the wording of the questions in an effort to provoke better understandability and thereby provide a more consistently repeatable dimensional structure (construct validity); (ii) by expanding the set of behaviours to include the coach's composure during games, the amount of playing time allowed individual players, and the coach's non-verbal skill level references or clues subtly communicated to the players about the quality of their play (not considered in prior versions of CBAS or CFQ); (iii) by comparison of the factor structures of the modified Coaching Behaviour Assessment System (mCBAS) 
and the Coaching Feedback Questionnaire (CFQ) (concurrent validity); and (iv) attempt to find proof of the success of this process by evaluating the strength of the correlations between the global, domain and domain specific indices of selfesteem and the coaching behaviour dimensions (predictive validity). Such refinements will allow for a closer examination of the impact of coaching behaviour on adolescent psychosocial development by increasing the predictive value of CBAS.

\section{Self-esteem}

In this section the foundations of research and theory on self-esteem will be traced through several authors. A working definition and a developmental model will be detailed and subsequently expanded and explored. This will be followed by a discussion of a theoretical model of self-concept and the supporting and related research. The section will be concluded with a discussion of the relationship between global physical self-concept, global self-esteem and sports competence.

Coopersmith defined self-esteem as

"the evaluation which the individual makes and customarily maintains with regard to himself: it expresses an attitude of approval or disapproval and indicates the extent to which an individual believes himself to be capable, significant, successful and worthy. In short, self-esteem is a personal judgement of worthiness that is expressed in the attitudes the individual holds towards himself. It is a subjective experience which the individual conveys to others by verbal reports and other overt expressive behaviour" (Coopersmith, 1967; p. 5).

Global self-esteem is typically consistent over time but varies across different situations or environments which Coopersmith calls 'areas of 
experience' (academic, athletic, musical, etc.). The sum of these areas of experience is Global Self-esteem. He states that the concept of self-esteem is multidimensional and deals with different aspects of the individual's environment or circumstances and the capabilities that the individual ascribes to him/herself in each (Coopersmith, 1967).

Susan Harter explored self-esteem from a theoretical perspective. She theorized that there are links between significant others, perceptions of competence and psychosocial growth which she expounds in her competence motivation theory. Within this theory, Harter put forward a developmental model which assesses the changes that occur to an individual's self-esteem and hence to the individual's self-concept as an individual grows through childhood and adolescence. The evaluative feedback from others, as perceived by the child, effects the child's perceptions of competence in the endeavour. Children who imagine that they receive relatively more positive evaluations for their performance will develop a higher regard for their abilities. As the higher regard for their abilities continues to grow, so too does their sense of control over the environment within which they perceive themselves to be competent. This in turn leads to other attributes and behaviours such as intrinsic motivation, high selfesteem, low performance anxiety and persistence with improving skills (Harter, 1999).

Harter also makes a distinction between the individual's overall sense of self-worth or Global Self-esteem and domain specific feelings of competence. Global Self-esteem is defined as an overall judgement about one's worth as a 
person. It is not effected by the sum of the parts of other facets of one's selfconcept, but is a unity of itself, separate from other competency domains.

In Harter's set of self-esteem domains there are eleven competencies which have been identified in adults: intelligence, sense of humour, job competence, morality, athletic ability, physical appearance, sociability, intimate relationships, nurturance, adequacy as a provider and household management. Each of these matures at different stages as the child develops from childhood and only a few are identified in children or adolescents. Harter's results led her to conclude that during middle childhood self-esteem and domain concepts take on meaning. By the age of 12 , children clearly differentiate five of the adult domains of self-esteem: scholastic competence, athletic competence, peer social acceptance, behavioural conduct and physical appearance. Also, as adolescence progresses, additional domains emerge and greater discrimination is possible. Adolescents begin to differentiate three more domains - close friendship, romantic appeal and job competence. Its also at this time that Global Self-esteem takes on meaning. In Harter's opinion, self-esteem is the mediator of affect and motivation and therefore, has a major impact on an adolescent's mood and energy level (Harter, 1987).

Shavelson, Hubner \& Stanton (1976) expressed dissatisfaction with the progress made in the study of self-concept. There were many different definitions for self-concept and many different measurement instruments being used. As a result there was difficulty comparing results between studies. In order to enable researchers to empirically study the construct of self-concept, they 
proposed a unifying definition and a multifaceted, hierarchical model (Shavelson, Hubner \& Stanton, 1976).

They defined self-concept as self-perceptions formed through the interpretation of the stimulus within the individual's environment. These selfperceptions are influenced by the significant people in one's life, the various rewards and feedback from one's actions and the attributes associated with one's behaviour and accomplishments. The shape of the model is pyramidal with Global Self-esteem at the apex supported by several gradually expanding levels below (see Figure 2). Each subsequent supporting level contributes to, but does not entirely determine, the superordinate concept. Academic, social, emotional and physical domains lie just beneath the global self-concept (self-esteem) and are supported further by domain specific levels. At the base of the hierarchy is specific, situational, personal behaviour which contributes to inferences about one's self in a broader sense.

The model is described as multifaceted because many separate subareas or facets contribute to the perception of the self. Concepts higher in the pyramid are more stable than subordinate levels but are also more generalized. Descending the pyramid, the self-concept becomes more situation specific and increasingly more malleable. Self-concepts become more complex with age and the individual makes comparisons between his/her self perceptions, other people and their ideal based upon it (Shavelson, Hubner \& Stanton, 1976).

The Shavelson model led initially to the development of the Self Description Questionnaire series of self-concept measurement devices (SDQ) 
from which the Physical Self-Description Questionnaire (PSDQ) was developed (Marsh et al., 1994). The PSDQ was designed to measure physical self-concept and was consistent with the multidimensional hierarchical self-concept model put forward by Shavelson, Hubner \& Stanton (1976). It had eleven specific components: strength, body fat, activity, endurance/fitness, sport competence, coordination, health, appearance, flexibility, Global Physical Self-concept, and Global Self-esteem.

Marsh (1998) used the model to study the differences between elite youth athletes and their non-athlete counterparts. The athletes in the study generally had a more positive physical self-concept than non-athletes (Marsh, 1998). Follow up studies demonstrated that elite athletes (versus non-athletes) attached higher importance to athletic competence, demonstrated higher overall feelings of physical ability, and generally had higher self-concept scores (Marsh \& Jackson, 1986). Higher self-perceptions of Sport Competence was one of the areas which specifically differentiated elite athletes from non-elite athletes (Fox \& Corbin, 1989; Marsh \& Jackson, 1986; Marsh \& Shavelson, 1985).

In the present study, self-esteem is conceptualized as both a global construct (Global Self-esteem), a domain construct (Global Physical Selfconcept) and as a series of domain specific competencies or subdomains of physical self-concept which includes appearance, athletic competence and a variety of physically related areas. As this thesis centres on elite athletes, the measures of self-esteem which are included in this study are Global Selfesteem, Global Physical Self-concept and Sport Competence. 
In summary, the section starts with Coopersmith's definition of selfesteem and continues with a discussion of Harter's developmental theory of selfesteem, multiple domains and global sense of self-esteem. Shavelson, Hubner \& Stanton (1976) attempted to unify the self-concept research community by creating a hierarchical, multifaceted model and definition for self-concept. Further refinements in the methodology led to the development of the PSDQ measurement device for the empirical study of Global Physical Self-concept (domain) and its domain specific self- concepts and the individual and collective impacts of these on Global Self-esteem.

There is empirical support for the model in the form of clear differentiations between the subdomains of physical competence, physical appearance, and the nonphysical domains of academic, emotional and social self perceptions (Marsh, 1997; Marsh \& Shavelson, 1985).

Restatement of Purpose and Expectations Regarding Results

It is the intention of this study to improve the reliability and provide evidence for the construct validity of the Coaching Behaviour Assessment System with the ultimate goal to improve the ability to predict the effects of a coach's behaviour on the self-perceptions of elite, adolescent athletes. Specifically, the following four hypotheses are tested.

(1) Provide proof of reliability in two ways. The modified CBAS (see Appendix $\mathrm{C}$ ) is a one item per behaviour questionnaire and this heterogeneity of items suggests that a test-retest comparison of the factor structures would be most appropriate. However, the potential volitility of the coach-player relationship 
within the win-at-all-costs context of elite sport, and the variable nature of the adolescent mood may confound such an approach and suggests that an internal consistency estimate of reliability may be prudent as well. Therefore, a test-retest comparison of the factors structures and internal consistency estimates of reliability are both conducted towards providing evidence of reliability of mCBAS.

(2) Strengthen the body of evidence that the Coaching Behaviour Assessment System has validity. This is done by careful attention to wording to ensure the athletes clearly understand the intended meaning of each question, and by expanding the set of questions to include game and skill clue behaviours not considered in previous versions of CBAS. The stability and repeatability of the CFQ factor structure has benefited by more concise wording and attention to the intended meaning of its questions (Allen \& Howe, 1998; Amorose \& Horn, 2000; Smith et al., 2005). This same attention to the wording of the modified CBAS questions and the addition of new behaviours added to CBAS in this study are expected to improve the repeatability and stability of the principal component structure of the modified CBAS. In addition, further evidence of the validity of CBAS is advanced by a favourable comparison between the component structures of mCBAS and CFQ results garnered in this study.

(3) Provide evidence of predictive validity of the measure by evaluating the correlations between the coaching and self-concept dimensions provided by factor analyses. It is expected that by expanding the set of behaviours to include additional game and skill clue behaviours the predictive value of CBAS will be improved. The additional set of behaviours include the coach's composure on 
the sidelines during games, the amount of playing time allowed the subject, and subtle clues the coach may have communicated to the players about their quality of play. The inclusion of additional behaviours is hypothesised to increase the explained variance of the impact of a coach's behaviour on the self-perceptions of elite youth athletes. Non-verbal behaviours and sideline composure of the coach are expected to be salient to the players, and therefore impact their selfperceptions. Higher domain specific self-esteem (Sport Competence) is expected for players who perceive more playing time, and who perceive preferential treatment for themselves by their coach. The perception of an emotionally demonstrative, highly anxious coach during games is expected to be negatively correlated with Sport Competence (Kenow \& Williams, 1992).

Subtle clues concerning a player's relative skill level and value to the team will also impact the self-perceptions of players. The impact of Negative Skill Clues are expected to have a negative impact on the Global Self-esteem, and the impact of Positive Skill Clues are expect to have a positive impact on the Global Self-esteem of the recipient players (Smith \& Smoll, 1990; Smoll, Smith, Barnett \& Everett, 1993).

(4) As evidence suggests gender differences exist, separate factor analysis are run for boys and girls to lend further support for construct validity. The mCBAS factor structures are expected to reveal differences between the sexes. This is based on reports of differences in responses by the genders to individual behaviours and resultant impacts on their self-perceptions (Black \& Weiss, 1992; Smoll \& Smith, 1989). The exact nature of gender specific factor 
structures have not previously been examined so there are no precise expectations beyond the hypothesis that there are measurable differences between the factors structures of the male and female athletes.

Taken together, such modifications allow for a closer examination of the impact of coaching behaviour on adolescent psychosocial development by increasing the reliability, the construct validity and the predictive validity of CBAS. All behaviour categories included in the modified CBAS are hypothesised to be significant to the players and therefore to load in the factor solution. Elite adolescent athlete self-perceptions which are expected to be effected by these coaching behaviours are Global Self-esteem, global physical self-esteem, and Sport Competence.

Pilot Study

The purpose of the pilot study was to evaluate the efficacy of the additional coaching behaviours. To this end, a series of additional questions were created, added to the existing CBAS questionnaire and included as a single questionnaire for use in a pilot study. The following section discusses this process with particular emphasis on the impact the pilot results have had on the final modified CBAS questionnaire that will be used in the main portion of this study, and how several of the hypotheses stated above were strengthened.

\section{Participants}

Participants were adolescent boys and girls ( male $=42$, female $=42$ ) playing club soccer in the various competitive soccer leagues in Ottawa, Ontario, Canada. There were 28 participating teams in clubs which represent the 
communities of Kanata and Gloucester within the city of Ottawa in the Eastern Regional Soccer League (ERSL) or Ontario Youth Soccer League (OYSL); and all under the auspices of the Ontario Soccer Association (OSA). Participants ranged in age from 11 to 17 years.

Player selection for these teams is based upon age and soccer ability. These clubs were chosen because of the competitive nature of their teams and due to the willingness of the club executive and head coaches to participate. The team head coaches were volunteer or professional coaches, and were selected by the club based upon their experience, qualifications within the game and their willingness to undertake the coaching task for their respective team.

\section{Procedure}

Letters of introduction and parent permission forms were given to each player after a practice during the summer league schedule of 2005. Players were asked to have their parents fill out the permission forms at home and return them to the researcher at a subsequent team practice or game. Players then logged onto the research web site to answer the questionnaires provided. In order to ensure anonymity each player was provided a unique participant number. This portion of the pilot project was part of a longitudinal study conducted by Dr. Anne Bowker at Carleton University.

\section{Instruments}

The original version of the Coaching Behaviours Assessment System (CBAS) was developed and modified by Smith, Smoll and their associates (Smith and Smoll, 1989) and included 12 behaviours to allow for young athletes 
to assess their recollection of their coach's behaviours. Eleven questions were added to the original twelve CBAS behaviours to explore the saliency of the behaviours to adolescent competitive athletes. These additional questions were created from anecdotal evidence and informal discussions with players, coaches and parents. These additional behaviours were Technical Instruction with Reinforcement (D’Alessio, 1990; Horn, 1985; Allen \& Howe, 1998), Less Playing Time, More Playing Time, Equal Playing Time, Preferential Playing Time, Player Specific Uneven Playing Time, Positive Skill Clues, Negative Skill Clues, Emotional Sideline Behaviour, Composed Sideline Behaviour, Nurturing behaviour, and degree to which the player likes the coach's treatment. Wording of the added questions were consistent with that of the original CBAS questions and the new questions were added to the original CBAS questionnaire to create a single, 23 item, pilot questionnaire (see Appendix D, Pilot CBAS, items nos. 13-23).

The players were asked to read a description of the behaviour and indicate on a seven point scale how often they remembered their head coach eliciting that behaviour. The Likert scale goes from 1 (never) to 7 (almost always).

Results

The intention of the pilot study was to ascertain the saliency of the behavioural items through principal component analysis, and to determine the dimensions along which the coaching behaviours pattern themselves. To this end, a principal component analysis was performed with a varimax rotation. The 
number of factors chosen was based on consideration of Kaiser's criterion, the scree plot and theoretical considerations. Only those items which demonstrated consistent loadings within the chosen factor solutions (all subjects, male and female structures) were included in the modified CBAS questionnaire for use in the main study.

Preliminary analysis suggested eliminating several items. Review of the wording and the intent of the Less Playing Time and More Playing Time items were deemed subordinate behaviours to Negative Skill Clues and Positive Skill Clues respectively. A plateau or step in the shape of the of the scree plot curve supported this contention, so these questions were dropped and the concept of more and less playing time entrenched in the wording of the superordinate item as an example of a type of clue that might communicate a negative or positive skill clue (see Appendix C, modified CBAS, question 14 and 15).

Analysis of the factor solutions revealed that the items Preferential Playing Time and Player Specific Uneven Playing Time did not load consistently on any factor and, due to its apparent redundancy in light of the decision to drop the less and more playing time items, this item was also eliminated from the modified CBAS questionnaire. The item 'the degree to which the player liked the coach's treatment' did not refer to a single behaviour but to a composite evaluation of the coaches treatment as perceived by the player, so it too was discarded.

Organization is one of the original CBAS behaviours, but is excluded from further study because it has not been correlated with any adolescent self-perception, and it does not load consistently with any set of behaviours in the pilot study. 
Also of particular note was the exclusive pairing, and persistently high loadings of Composed Sideline Behaviour and Emotional Sideline Behaviour together on the same factor. This suggested the need to add another or other questions to fully flesh out a dimension which was separate from other factors in this study (C. Davis, personal communication). To that end, a question was added: The Emotional sideline behaviour is divided into two separate behaviours, one in which the emotional component is directed toward the players on the field and another in which the emotional component is directed toward the officials (see Appendix C, modified CBAS, questions 16 and 17). Identical wording is used for both.

The factor solution selected was determined using principal component analysis, a varimax orthogonal rotation and an initial analysis using the Kaiser's criterion with eigenvalues greater than 1.0 . The final solution was identified by forcing a maximum number of five factors due to theoretical considerations (previous research results) and the scree plot. The five factors, explaining $64.2 \%$ of the total variance were identified as: (1) the degree to which the coach used supportive behaviours; (2) the degree to which the coach used instructive behaviours; (3) the degree to which the coach was composed on the sidelines during games (Game Behaviours); (4) the degree to which the coach used negative behaviours; and (5) the degree to which the coach communicated skill clues to the players (see Table 6).

Factor solutions for the separate genders was determined using principal component analysis with varimax orthogonal rotation, and suitable factors 
identified by setting a maximum of three factors. The factor solution for the female athletes explains $55.1 \%$ of its variance, and the factors are identified as: (1) the degree to which the coach used supportive and instructive behaviours; (2) the degree to which the coach used negative behaviours and communicates skill clues; and (3) the degree to which the coach was composed on the sidelines during games (see Table 7). The factor solution for the male athletes explained $57.9 \%$ of the total variance and the factors were identified as follows: (1) the degree to which the coach used supportive behaviours; (2) the degree to which the coach used negative behaviours and is composed on the sidelines; and (3) the degree to which the coach used instructive behaviours (see Table 8).

Of particular note within the gender factor structures was that the same five group of items found separately in the pooled factor structure were located as discrete units in each of the separate gender structures. The location of these five distinct groups within the solutions presented suggested the behaviour categories have different degrees of saliency for each gender. The first factor of the female solution included the instructional and supportive coaching behaviours together in contrast to that of the male structure which loaded these two categories on separate factors. The gender structure solutions also differed in the location of the degree of sideline composure. The female structure isolated this dimension on factor 3 , whereas the males' solution located the degree of sideline composure with the negative coaching behaviours on factor 2. A third difference was the location of the skill clues category. In the female structure this category loaded with the negative coaching behaviours on factor 2 , whereas in 
the male solutions these behaviours did not load on any factor.

The pilot project has thus aided in strengthening the hypothesis regarding the reliability and the construct validity of the measure. Previous studies using CBAS and CFQ have indicated separate and distinct categories of behaviours. The distinctness of these categories was reinforced in the results of the present pilot study and supports the contention that the Supportive, Negative and Instructive behavioural categories are indeed separate and distinct behavioural dimensions.

The pilot study also strengthened the hypothesis that additional behaviours, not considered by the original authors of CBAS, must be included into the modified CBAS questionnaire. The factor structures of the results of the pilot study demonstrated the degree of saliency of these behaviours to the adolescent athlete. Therefore, the items Sideline Composure or Game Behaviours and Skill Clues are confirmed as separate and distinct categories by the results of the pilot study, and warrant inclusion into the mCBAS due to the import of the categories to the athletes.

The results of the pilot study also supported the contention that different factor structures exist for each gender. The resultant factor solutions suggested that for the female athletes the Supportive and Instructive Coaching Behaviours were closely associated, the Negative Behaviours and the Skill Clues were closely associated, and Game Behaviours were distinct from the other categories on a separate dimension. For the male athletes the Supportive and Instructive Coaching Behaviours were isolated from each other on separate dimensions, 
and the Negative Behaviours were closely associated with the coach's degree of composure on the sidelines. The Skill Clues dimension did not load on the male athlete factor solution and suggests that it may not be salient to the male athletes to the degree found in the female factor structure.

Therefore, based on the pilot study, the main study is expected to confirm the following four hypotheses. First, that evidence of reliability of the modified Coaching Behaviour Assessment System will be demonstrated by test-retest and internal consistency estimates. Secondly, that construct validity for CBAS items will be provided by repeatable and stable factor solutions, and by favourable comparison with a parallel measurement device; thirdly, that consistent and repeatable gender differences will be demonstrated for the modified CBAS; and finally that the ability of the modified CBAS to predict self-concept issues for elite adolescent athletes will be provided (predictive validity). 


\section{Method}

\section{Participants}

Participants were adolescent girls $(N=144)$ and boys $(N=121)$, aged 1116 years $(M=14.65)$, who played club soccer in the various competitive soccer leagues in Ottawa, Ontario, Canada. The participating teams were associated with clubs within the city of Ottawa in the Ottawa Carleton Soccer League (OCSL) or the Eastern Regional Soccer League (ERSL); or Ontario Youth Soccer League (OYSL); or represent the city of Ottawa within the Super Y League (USA), and all under the auspices of the Ontario Soccer Association (OSA).

\section{Procedure}

Letters of introduction and permission forms were given each player after a practice during the summer league schedule of 2006. Players were asked to fill out the permission forms at home and return them to the researcher at a future team practice. Players subsequently did the questionnaires together during two later team events.

Instruments

\section{Time 1}

The modified version of the Coaching Behaviours Assessment System (mCBAS) was used to allow young athletes to assess their recollection of their coach's behaviours (see Appendix C). Questions included in the questionnaire were based on the results of the pilot project. The additional questions added 
were directed at the behaviours associated with Technical Instruction with Reinforcement, non-verbal clues about the individual player's skill level, and the degree of sideline composure during games.

The players were asked to read a description of the behaviour and indicate on a seven point scale how often they remembered their head coach eliciting that behaviour. The Likert scale goes from 1 (never) to 7 (almost always).

The Coaching Feedback Questionnaire (CFQ) was also given to the players at Time $1(\mathrm{~T} 1)$. The CFQ is a version of CBAS originally modified by Allen \& Howe (1998), and continued in its present form by Amorose \& Horn (2000) and Smith et al., (2005). The theoretical foundation of CFQ, the behavioural items and its intended use remain consistent with the CBAS origins. The wording of the questions of CFQ have been changed to facilitate the conversion to a paper and pencil style questionnaire from what had been a verbal, interview style questionnaire (see Appendix E).

The players were given a list of examples of the type of feedback their coach might have given them during a practice or game. They were asked to read a description of the behaviour and indicate on a five point scale how typical the behaviour was of the kind of feedback their coach might have given them. The Likert scale goes from 1 (not at all typical) to 5 (very typica). Comparison of the CFQ responses with the mCBAS test results are expected to provide additional evidence of the validity of mCBAS through comparison of the principal component structures and Pearson correlations between the items and 
dimensions of each.

Time 2

After a period of time ( $M=21.94$ days, range $=13-50$ days $)$ the original players were retested using the same modified version of the Coaching Behaviour Assessment System (mCBAS) used in T1. A test-retest comparison of the results using Pearson correlations and Cronbach's coefficient alpha calculations on the underlying factors formed the basis of the estimate of reliability of the device.

The Physical Self-Description Questionnaire (PSDQ) was also given to the players at Time 2 (T2). The measure was developed by Marsh, Richards, Johnson, Roche \& Tremayne (1994) to test children from the age of 12 years to adult, of both genders, on their physical self-concept, physical fitness and Global Self-esteem dimensions. The PSDQ is a multidimensional measure of selfesteem and physical self-perceptions divided into 11 subscales (see Appendix F). One subscale is at the global level (Global Self-esteem), one at the domain level (Global Physical Self-concept) and nine at the subdomain level (appearance, body fat, strength, endurance, flexibility, health, coordination, physical activity and Sport Competence). For the purposes of this study only three subscales were used - Global Self-esteem, global physical self-esteem and sports competence. The questionnaire consisted of 20 hypothetically statements to describe oneself and the subjects were asked to rate themselves, on a 6 point scale, how well each statement matched how they felt about themselves. The six point Likert scale ranged from 1 (false) to 6 (true). Internal consistency estimates 
of reliability were from 0.87 to 0.96 for the 11 subscales (Marsh et al., 1994). Discriminant validity has been confirmed through subsequent studies to do quite well at differentiating the 11 components of physical self-concept between athletes and non-athletes and between genders (Marsh, 1994; Marsh et al., 1995; Marsh, 1998).

To determine the dimensions along which the coaching behaviours pattern themselves, a principal component analysis was performed with a varimax orthogonal rotation. The number of factors was selected with consideration given to the Kaiser criterion $(21.0)$, the scree plot, parallel analysis and previous research results. Pearson correlation coefficients and Cronbach's coefficient alpha were used to estimate test-retest and internal consistency reliability respectively. Comparison of the principal component structures from the $\mathrm{T} 1$ and $\mathrm{T} 2$ responses on the mCBAS questionnaire, exploratory and confirmatory factor analysis, and comparison of the structure of the modified CBAS at T1 with the principal component structure of CFQ also at T1 were used to establish evidence of construct and concurrent validity respectively.

Pearson correlations on the coaching behaviour dimensions and selfconcept dimensions the were conducted to evaluate the ability of the modified CBAS to predict the three self-esteem indices - Global Self-esteem, Global Physical Self-concept, and Sports Competence. The predictive abilities of the other two questionnaires were also included to provide some context within which to evaluate the mCBAS correlations: The original CBAS (using T2 data gathered using the mCBAS questionnaire), and the CFQ (using T1 data). The 
mCBAS predictors were the respective coaching dimensions as determined by the exploratory factor analyses from $\mathrm{T} 1$. Separate principal component analyses were conducted for each gender as factor structures for each were distinct (with T1 and T2 data). 


\section{Results}

The purpose of the present study was to modify the Coaching Behaviour Assessment System by expanding the behavioural dimensions of the measure, improve reliability, provide evidence of construct validity, and examine gender variations in the component structure. Such refinements will allow for a closer examination of the impact that coaching behaviour has on elite adolescent athlete self-perceptions by improving the predictive validity of the measure.

This section starts with a discussion of the exploratory and confirmatory factor analyses as pertaining to the modified Coaching Behaviour Assessment System (mCBAS). This is followed by a discussion of the Coaching Feedback Questionnaire (CFQ) results in an attempt to assess the concurrent validity of mCBAS. Next, the genders differences are assessed with an analysis of variance and a comparison of the separate principal component structures. The section concludes with a discussion of the predictive validity of mCBAS. Exploratory Factor Analysis

The purpose of the Exploratory Factor Analysis (EFA) process was to generate an hypothesised structural model. Data from this study, the pilot project and component analytic structures from prior research were used to determine a hypothesised model for the confirmatory phase of this study. To determine the dimensions along which the coaching behaviours pattern themselves, a principal component analysis was performed with a varimax orthogonal rotation with $\mathrm{T1}$ data. To select the appropriate number of components consideration was given to the Kaiser criterion, the scree plot, parallel analysis and previous research 
results.

Kaiser criteria specifies that a component should not be selected unless its variance exceeds that of one variable. Typically an eigenvalue minimum of $\geq 1.0$ is the suggested threshold (Hayton et al., 2004; Kaiser, 1960; Statsoft Inc., 2004). The Kaiser criteria applied to the T1 data as an upper boundary for the number of components suggested five components.

Scree analysis is a method applied to the graph of the descending eigenvalues from the principal component extraction. Components are included to the point at which the graph line slope begins to reach an equilibrium (Tabachnik \& Fidell, 2007). The scree analysis, although providing no clear break in the diminishing negative slope, suggested five components.

Parallel Analysis determines the number of components by comparison of the real data set to a random set of data with the same sample and variable sizes. Non-trivial components have larger eigenvalues than the random data set (Hayton et al., 2004). A Monte Carlo simulator (a sample size of 265, 19 variables, with 100 replications) also suggested a five component solution (Watkins, 2004).

However, theoretical considerations based on previous studies were more compelling and suggest that there were too many anomalies with the five component solution as suggested by the methods reviewed above. In the five component solution provided by the test data in this study (T1), there were too many cross loadings and the potential fourth and fifth components each possessed an inadequate number of items (C. Davis, personal communication; 
Tabachnik \& Fidell, 2007). Therefore the five component solution was rejected. The four component solution presented by the data also contained an excessive number of cross loaded items and an inappropriate reorganization of two of the three traditionally segregated behavioural dimensions, and so it too was rejected.

It was therefore determined that a three component structure which explained $45.3 \%$ of the variance was most appropriate. This was selected by principal component analysis (PCA) using the $\mathrm{T} 1$ data, with a varimax orthogonal rotation, and a minimum loading threshold of 0.50 (see Table 9). The first component included the Instructional and Supportive Coaching Behaviours, and accounted for $28.1 \%$ of the explained variance (Cronbach's alpha $=0.80$ ). Behaviours included in this dimension are the Instructive Coaching Behaviours (Technical Instruction with Reinforcement, General Technical Instruction, and Mistake-contingent Technical Instruction) and the Supportive Coaching Behaviours (General Encouragement, General Communication, Nurturing, and Reinforcement). This organization of the behaviours into an Instructive group is supported by the pilot project results and previous research (Amorose \& Horn, 2000; Thompson \& Bowker, 2005). The organization of the Supportive Behaviours together is reflected in the pilot results and in the results of Smith et al. (1978), Smoll et al. (1993), Amorose \& Horn (2000), Smith et al., (2005) ${ }^{2}$, and Thompson \& Bowker (2005). Several studies have included both the Supportive

\footnotetext{
${ }^{2}$ Note the errors in reporting of Non-reinforcement on Factor 1 in this table. The table provided here is as was originally published. Convention suggests that the negative value is irrelevant to the magnitude of the loading, and therefore the Non-reinforcement items should have been listed with the other items in Factor 1 and not excluded as the author has done.
} 
and the Instructive Coaching Behaviours together on a single component (Smith et al., 1978, Smoll et al., 1993, Amorose \& Horn, 2000, Smith et al., 2005).

The second component is a completely new dimension of coaching behaviours distinct from all previous research and has been called the Game Coaching Behaviours $\left(9.8 \%\right.$ variance; Cronbach's alpha $\left.=0.78^{3}\right)$. Three of the four behaviours which make up this new dimension (Composed Game Behaviour, Emotional Sideline Behaviour towards Officials and Emotional Sideline Behaviour towards Players) were first added in this study and have never been used in CBAS research before. These three Game Behaviours consistently loaded together in the pilot study, in the three component solution using the T1 data, and in both the four and the five component PCA structures initially considered and rejected (referred to above).

Emotional Sideline Behaviour towards Players refers to emotional outbursts directed specifically towards the subject's team mates during games. Emotional Sideline Behaviour towards Officials is also a game behaviour and refers to emotional outbursts towards officials. The third Game Behaviour Composed Game Behaviour - indicates a calm and relaxed demeanor on the sidelines without emotion outbursts during games.

The fourth behaviour in the Game Behaviour dimension, Mistakecontingent Encouragement, is one of the original CBAS behaviours. Although

\footnotetext{
${ }^{3}$ The calculation of Cronbach's alpha statistic for the Game Behaviour dimension required that items which loaded with a negative valence be recoded to match the valence of the other items within the factor.
} 
contrary to its traditional loading with the Supportive Coaching Behaviours in previous studies, its appearance within the Game Behaviour dimension is consistent in the T1 and T2 principal component structures in this study (see Table 10), and arguably, is a logical addition to the Game Behaviour dimension. Due to the high action environment typical during soccer games, the coach's ability to take time to give Mistake-contingent Technical Instruction is limited, and thus forces reliance upon Mistake-contingent Encouragement. The pace during practices is typically not as frenetic, and so time is available to correct mistakes resulting in more use of Mistake-contingent Technical Instruction. Therefore the loading of Mistake-contingent Encouragement with the Game Behaviours has face validity.

The third component included the Negative Coaching Behaviours Punishment, Punitive Mistake-Contingent Technical Instruction, Nonreinforcement, and Keeping Control (7.4\% variance; Cronbach's alpha $=0.60)$. The relationship between Punishment and Punitive Mistake-Contingent Technical Instruction is consistent with the pilot results and with all previous CBAS and CFQ studies (Allen \& Howe, 1998; Amorose \& Horn, 2000; Smith et al., 1978; Smoll et al., 1993; Smith et al., 2005; Thompson \& Bowker, 2005). Non-reinforcement is associated with Punishment and Punitive MistakeContingent Technical Instruction in Smith et al. (1978) and Smoll et al. (1993).

As part of the exploratory process, a comparison of the principal component structures of the $\mathrm{T} 1$ and $\mathrm{T} 2$ data were done to provide as much insight as possible. This analysis demonstrated that the $\mathrm{T} 1$ and $\mathrm{T} 2$ component 
structures were remarkably similar. The same behaviours made up the same dimensions in each. The most significant differences between the two structures was the location of Non-reinforcement (which loaded on the third component at T1, and on the first component at T2), and the less than threshold presence that characterised all of the Skill Clue Behaviours at both T1 and T2. But regardless of the differences, the similarities of the two structures far out weigh the dissimilarities and provide evidence of test-retest reliability.

This observation is also supported by the correlation matrix of the T1 and T2 components (see Table 11). The Pearson correlations for the Supportive/Instructive dimension $\left(r^{2}=.75, p<.01\right)$, the Game dimension ${ }^{4}\left(r^{2}=\right.$ $.75, p<.01)$, and the Negative Coaching dimension $\left(r^{2}=.66, p<.01\right)$ are large significant values, and so, despite the slight differences in the component structures noted above, further evidence of test-retest reliability is provided here as well.

In summary, there is an overwhelming consistency between the component structures observed in this study and those of previous CBAS studies (see Appendix G). The consistent grouping of the Instructional, Supportive and Negative behaviours from the earliest studies is clearly evident. The Game Behaviours, although unique to this study, have consistently loaded together in the pilot, the T1 and T2 structures. Further support for the consistency of all

\footnotetext{
${ }^{4}$ The calculation of the mean factor score the Game Behaviour dimension required that some item scores be recoded to match the valence of the meaning of the other items within the factor.
} 
three dimensions also comes from the internal consistency estimates of reliability provided by the Cronbach's alpha statistic for both the T1 and T2 data, and from the test-retest reliability provided by the significant Pearson correlations between the T1 and T2 dimensions. Taken together, there is clear evidence of the reliability of mCBAS.

Comparison of the $\mathrm{T} 1$ component structure with the factor structures from previous studies was also done to assist in determining which behaviours should be selected to ultimately make up the structural equation model to be examined in the confirmatory factor analysis phase. Comparison of the component structure from $\mathrm{T} 1$ with those from the pilot study was also done to determine which of the newly added behaviours should be included for the purposes of expanding the behavioural range of mCBAS.

Confirmatory Factor Analysis

A confirmatory factor analysis (PCA) on T2 data was done to provide a statistical determination of the degree to which the retest data matched an hypothesised latent factor structure for the coaching behaviours as represented by the T1 data. To ensure that only appropriate behaviours were included in the final structure, both the PCA results using T1 and T2 data, and the results from the Statistical Package for the Social Sciences Structural Equation Modelling program AMOS 7.0 are utilized. From these analyses, it was determined that several behaviours should be dropped. Equal Playing Time, Positive Skill Clues, Negative Skill Clues and Ignoring Mistakes did not load above the minimum threshold $(20.50)$ in the PCA structure at T1 and so were not considered further. 
Non-reinforcement was also excluded because historically it has loaded equally often with either the Negative Coaching Behaviours (Smith et al., 1978; Smoll et al., 1993) or the Supportive Coaching Behaviours (Thompson \& Bowker, 2005; pilot data, this study). This inconsistency with respect to Nonreinforcement is also reflected in the comparison of the PCA structure of the T1 data versus the PCA structure of the T2 data.

The decision to exclude Keeping Control is based on several unacceptably high standardized residual covariance values found in the AMOS structural equation model results. This approach is consistent with those employed by Byrne (2001) prior to attempting a confirmatory factor analysis evaluation.

Therefore, the latent structure determined to best fit the given theoretical and practical considerations consisted of a three component structure: component 1 - the Instructive and Supportive Coaching Behaviours; component 2 - the Game Behaviours; and component 3 - the Negative Coaching Behaviours - Punishment and Punitive Mistake-Contingent Technical Instruction only (see Figure 3). This structure was analysed by the Structural Equation Modelling technique using the maximum likelihood estimation procedure $(\mathrm{ML})$ provided by the Statistical Package for the Social Sciences AMOS 7.0 program. For the purposes of the CFA only missing values are imputed using the arithmetic mean method.

Results of the Confirmatory Factor Analysis statistical significance testing yielded a $X^{2}$ value of $148.5,(\mathrm{df}=58, p<.0001)$. Notable goodness-of-fit statistics 
are the standardised root mean square residual (std RMR) results of 0.08 , and the goodness-of-fit index (GFI) result of 0.896 which tend to suggest an adequate fit of the model to the data. Additional goodness-of-fit statistics which suggest that the model has merit are the incremental index of fit (IFI $=.907)$, the comparison fit index $(\mathrm{CFI}=.905)$ and the root mean square of approximation (RMSEA $=.088)$. These results give witness to a measure of construct validity of the modified Coaching Behaviour Assessment System but suggest further efforts to improve the measure are necessary (Byrne, 2001).

The Coaching Feedback Questionnaire

A principal component analysis (PCA) of the Coaching Feedback Questionnaire (CFQ) was undertaken at $\mathrm{T} 1$ to assess the concurrent validity of mCBAS. The PCA structure for the CFQ was also determined with varimax orthogonal rotation, and a minimum threshold of 0.50 . The final solution was determined through Kaiser criterion, scree plot, theoretical considerations and parallel analysis (see Table $13^{5}$ ) and consisted of three components explaining $53.8 \%$ of the variance. Component 1 consisted of the Supportive and Instructive Behaviours (Cronbach's alpha $=0.79$ ); Component 2 included the Negative Coaching Behaviours (Cronbach's alpha $=0.80$ ), and Component 3 , has been called the 'No Response' behaviours (Cronbach's alpha $=0.70$ ). These results are virtually identical to the results reported by the previous studies using the 16 item CFQ (Amorose \& Horn, 2000; Smith et al., 2005). The reliability of the CFQ

\footnotetext{
${ }^{5}$ Note that many of the original CBAS behaviours and none of the mCBAS behaviours added for this study exist in the CFQ and so cannot be included in this table.
} 
is evident in the above threshold internal consistency estimates of reliability provided by the Cronbach's alpha statistic $(>0.70)$, and by the similarity of the structure determined by this analysis and the structures reported in previous research (Amorose \& Horn, 2000; Smith et al., 2005).

In relation to the PCA structure of the T1 mCBAS, scrutiny of the first component (F1) of the CFQ structure shows that it is analogous to the first component of the mCBAS structure. The first component of CFQ includes all of the Supportive items available in the CFQ (both Reinforcement items, both Mistake-contingent Encouragement items), and three of the four available Instructive items (both Technical Instruction with Reinforcement, the first of the two Mistake-contingent Technical Instruction items). The only discrepancy between the $F 1$ the CFQ structure and the F1 of the mCBAS structure was the location of the second Mistake-contingent Technical Instruction item of the CFQ structure which loaded on factor 2 (F2) and is discussed further below.

The second CFQ component centred around the ubiquitous twinning of Punishment and Punitive Mistake-Contingent Technical Instruction. This pair of behaviours is located together in both of the CFQ and mCBAS factor structures in this study and in all three previous CFQ studies in their respective Punishment dimension (Allen \& Howe, 1998; Amorose \& Horn, 2000; Smith et al., 2005). Also of note is the inclusion of the second Mistake-contingent Technical Instruction item in this Negative component as noted in the previous paragraph. This anomaly is evident in each of the previous CFQ structures (see Tables 4 and 5). 
The behaviours of the third CFQ component indicate the players' perception of a failure to respond to either player success or failure, and include both the Non-reinforcement and Ignoring Mistakes items. The make up of this final factor is identical or remarkably similar to the findings of previous CFQ studies (Amorose \& Horn, 2000: Smith et al., 2005). In relation to the mCBAS and CBAS studies, however, this third CFQ factor has not been duplicated. But, despite the anomalies, the similarities between the the CFQ and mCBAS in this study clearly outnumber the dissimilarities, and a comparison of the principal component structures of mCBAS and CFQ provide evidence of concurrent validity.

The correlation matrix of the $\mathrm{mCBAS}$ and the CFQ dimensions were also analysed as a further step in evaluating the concurrent validity of mCBAS (Cohen \& Swedlik, 1988). The strong positive correlations between the corresponding Supportive/Instructive Behavioural dimensions $\left(r^{2}=.50, p<.001\right)$, and the corresponding Negative Behavioural dimensions $\left(r^{2}=.55, p<.001\right)$ provide further support for concurrent validity (see Table 14). Beyond the different wording and formats of the two questionnaires, the anomalies between the two structures are largely a function the larger pool of behaviours in the mCBAS and the presence of two items for each behaviour in the CFQ.

To summarize, a comparison of the principal component structure of the Coaching Feedback Questionnaire (CFQ) and the modified Coaching Behaviour Assessment System (mCBAS) at T1 was undertaken to assess the concurrent validity of mCBAS. The favourable comparison of the CFQ structure provided by 
this study and CFQ structures from previous research, plus the high internal consistency estimates of reliability indicate a high degree of reliability of the CFQ on its own. Comparisons of the CFQ and mCBAS dimensional structures, despite anomalies, were also generally favourable. But most notably, the correlation matrix of the CFQ and mCBAS coaching dimensions indicated strong significant correlations between each of the dimensions that the two questionnaires share. Therefore, the comparison of mCBAS and CFQ provides strong evidence of concurrent validity for mCBAS.

\section{Gender Differences}

This section presents the details of the gender analyses. The first section presents the mean differences between self-concept and coaching dimensions by gender. This will be followed by a comparison of the principal component structures at $\mathrm{T} 1$ between the genders, at $\mathrm{T} 2$ between the genders, and a comparison of the genders between $\mathrm{T} 1$ and $\mathrm{T} 2$.

A series of one way analyses of variance were performed on the coaching and the self-concept dimensions to assess the magnitude of the gender differences. Consistent with previous research results, there were no significant gender differences in the means for any of the three self-concept dimensions studied which demonstrates that both male and female elite athletes have the same positive feelings about themselves with regard to these specific dimensions (Marsh et al., 1994; Thompson \& Bowker, 2005). Mean scores for all subjects ranged from a low of $4.99(\mathrm{SD}=0.55)$ for Global Self-esteem to a high of $5.23(\mathrm{SD}=0.72)$ for Sport Competence with the highest score possible $=7$. These 
results indicate that both boys and girls generally feel good about themselves concerning these specific measures of self-concept (see Tables 15 and 16).

Significant gender differences were observed with regard to the coaching dimensions. The girls perceived more Instruction and Supportive behaviours than the boys at both $\mathrm{T} 1(\mathrm{~F}=9.44, p=0.02)$ and $\mathrm{T} 2(\mathrm{~F}=4.72, \mathrm{p}=0.03)$, while the boys perceived more Negative and Skill Clue behaviours than did the girls at both $\mathrm{T} 1(\mathrm{~F}=6.25, p=0.01)$ and $\mathrm{T} 2(\mathrm{~F}=12.85, p<0.001)$. These results are consistent with previous research to the extent of the dimensions shared by the respective studies (Thompson \& Bowker, 2005; Smoll \& Smith, 1989). Also of note are the results from Black and Weiss (1992) in which preferences were measured rather than perceptions, and results demonstrated that the girls enjoyed the sport more if the coaches were more supportive and instructive.

Principal component analysis of T1 data segregated by gender revealed significantly different component structures for each gender. Both structures were determined using Kaiser criteria, scree analysis, parallel analysis and theoretical considerations and each structure possessed three dimensions (varimax orthogonal rotation, a minimum threshold of 0.50 ). The component structure for the female athletes was reflective of the T1 'all subjects' structure and explained $46.1 \%$ of the variance (see Table 17). The first component of the female structure (F1) included the Instructive and the Supportive Coaching Behaviours (Cronbach's alpha $=0.79$ ); the second component $(F 2)$ the Game Coaching Behaviours plus Mistake-contingent Encouragement (Cronbach's alpha =0.78); and the third component (F3) the Negative and the Skill Clues 
Coaching Behaviours (Cronbach's alpha $=0.64$ ).

For the males, the first component of $\mathrm{T} 1$ included the Negative and Game Behaviours (Cronbach's alpha $=0.84$ ); the second component included Supportive Coaching Behaviours (Cronbach's alpha $=0.76$ ); and the third component included the Instructive Coaching Behaviours (Cronbach's alpha = 0.73). This structure explained $50.4 \%$ of the variance (see Table 18) and was the most unique of all of the PCA structures observed.

Contrary to $\mathrm{T} 1$ results, the principal component analysis of $\mathrm{T} 2$ data divided by gender revealed remarkably similar component structures for both girls and boys, and was also reflective of the 'all subjects' structures from both test and retest analyses. The first component for both genders at T2 included the Instructive and the Supportive Coaching Behaviours; the second T2 component included the Game Coaching Behaviours plus Mistake-contingent Encouragement and was also the same for both genders; and the third T2 component included the Negative and the Skill Clues Coaching Behaviours. The female T2 structure explained $51.8 \%$ of the variance, and the male structure explained $54.9 \%$ of the variance (see Table 19 and 20). All structures were determined using Kaiser criteria, scree analysis, parallel analysis and theoretical considerations and each structure possessed three dimensions (varimax orthogonal rotation, a minimum threshold of 0.50 ).

Of note are the high Cronbach's alpha results from all PCA analyses. The internal consistency estimates of reliability provided by the Cronbach's alpha range from 0.84 to 0.64 indicating an acceptable degree of internal consistency. 
The significant Pearson correlations between the T1 and T2 components for both genders (see Tables 21 and 22) indicate a good test-retest reliability. The high degree of similarity between the PCA structures for the girls at both T1 and T2, the boy's structure at T2, and the 'all subjects' structure at both T1 and T2 provide a strong indication of construct validity and indicate a high degree of testretest reliability. It must be noted, that the anomalous component structure of the male subjects at $\mathrm{T} 1$ does not have any corroborating research with which to compare.

To summarize, it is clear that both genders generally have the same positive feelings about themselves with regard to the self-concept dimensions. Alternatively, the genders differed in their perceptions of coaching behaviours: the girls having perceived more Instructive and Supportive Coaching Behaviours, and the boys more of the Negative Behaviours. The comparison of the principal component structures show good internal consistency estimates of reliability at T1 and T2 for both genders. The test-retest reliability was demonstrated by the high Pearson correlations between the T1 and T2 coaching dimensions. And finally the high degree of similarity of all the PCA structures, except the boys at T1, provide strong evidence of construct validity, and a high degree of test-retest reliability as well.

Predictive Validity

This section analyses the predictive value of mCBAS with a discussion of the correlation matrix of the coaching and self-concept dimensions. The predictors were the respective mCBAS coaching dimensions as determined by 
the exploratory factor analysis from $\mathrm{T} 1$, and the dependent variables were the self-concept dimensions from T2. And in an effort to provide a context within which to evaluate these correlations, results from the CFQ (at T1) and the original CBAS (T2) were also included in the correlation matrix. The section concludes with a comparison of the correlations between mCBAS and the selfconcept dimensions by gender.

The correlations between the self-concept and the coaching dimensions demonstrate the predictive value of mCBAS. From Table 23 it can be seen that the Supportive/Instructive dimension has a significant positive correlation with Global Self-esteem ${ }^{6}\left(r^{2}=.23, p<.01\right)$, Global Physical Self-concept $\left(r^{2}=.27, p\right.$ $<.01)$ and Sport Competence $\left(r^{2}=.18, p<.01\right)$. The Game dimension has a significant positive correlation with Global Self-esteem $\left(r^{2}=.17, p<.05\right)$ and Global Physical Self-concept $\left(r^{2}=.21, p<.01\right)$. The Negative Coaching dimension has a significant negative correlation with Global Self-esteem $\left(r^{2}=\right.$ $.22, p<.01)$.

These results are generally supported by previous research (Black \& Weiss, 1992; D'Alessio, 1991; Horn, 1985; Kenow \& Williams, 1999; Smith, Smoll \& Curtis, 1978; Smith \& Smoll, 1990; Smoll, Smith, Barnett \& Everett, 1993) but the considerable differences which exist between these studies with regard to the age, gender and competitive level of the subjects suggest that detailed comparisons between any of these studies should be done with caution.

\footnotetext{
${ }^{6}$ The calculation of the mean factor score for the GSE dimension required that scores for some questions be recoded to match the meaning of the other questions within the factor.
} 
Yet despite these potentially confounding differences between the studies, the significant correlations between the self-concept and the coaching dimensions in this and previous studies demonstrate a measure of predictive value for mCBAS. The significant correlations between the Game Behaviour dimension and the self-concepts at both the global and domain levels further supports a measure of predictive validity for mCBAS.

To give context to these results, the Pearson correlations between the self-concept dimensions and each of the other two coaching behaviour questionnaires was also included. The original CBAS dimensions were determined from a composite of the factor structures from Smith et al. (1978) and Smoll et al. (1993) ${ }^{7}$ and consisted of the Supportive/Structuring dimensions (Reinforcement, Mistake-contingent Encouragement, General Encouragement, General Technical Instruction), the Aversive dimension (Punishment, Punitive Mistake-Contingent Technical Instruction, Non-reinforcement), and Response to Mistakes (Ignoring Mistakes, Mistake-contingent Technical Instruction). This study's T2 results were utilized to create an appropriate data set for the original CBAS dimensional structure.

The CFQ dimensions and data from the T1 portion of this study were used, and consisted of the Positive \& Information Feedback factor (both Reinforcement items, both Mistake-contingent Encouragement items, both

\footnotetext{
${ }^{7}$ Note that all of the necessary behaviours to duplicate the CBAS dimensions were present in mCBAS, both with respect to the wording and order of the questions within the original questionnaire.
} 
Technical Instruction with Reinforcement items, and the first Mistake-contingent Technical Instruction item), the Punishment Oriented Feedback factor (both Punishment items, both Punitive Mistake-Contingent Technical Instruction items, and the second Mistake-contingent Technical Instruction item), and the Nonreinforcement and Ignoring Mistakes factor (both of the Non-reinforcement and Ignoring Mistakes items). This structure is consistent with the structure reported by Amorose and Horn (2000), and virtually identical to the structure reported by Smith et al. (2005).

Results indicate that although moderate, there are significant correlations between at least two self-concept dimensions and a coaching dimension for each of the three questionnaires. It is also relevant that both the original CBAS and the CFQ have one dimension which has no significant correlation with any of the self-concept dimensions studied here, but that the mCBAS has significant correlations between each of its dimensions and at least one of the three selfconcept dimensions.

In summary, this section reported on the ability of mCBAS to predict the self-concepts of elite athletes by analysing correlation matrix of the mCBAS, the original CBAS and the CFQ dimensions against the self-concept dimensions as defined by the Physical Self-Description Questionnaire. The significant correlations between the respective correlation matrices and the self-concept dimensions of the PSDQ indicate that each of the three coaching behaviour assessment devices demonstrated a moderate predictive ability. Of significance with respect to mCBAS was that the addition of the new Game and Supportive 
Behaviours provided a correlation matrix which compared favourably with the matrices of the original CBAS and the CFQ. 
Discussion

The objective of this study was to modify the Coaching Behaviour Assessment System by expanding the behavioural dimensions of the measure, improve reliability, provide evidence of construct validity, and examine gender variations in the component structure. Such refinements will allow for a closer examination of the impact that coaching behaviour has on elite adolescent athlete self-perceptions by improving the predictive value of the measure. To this end, 269 competitive adolescent soccer players completed questionnaires assessing their self-concepts, and their perception and recall of their coach's behaviour during the summer of 2006.

There were five significant findings. Firstly, there are salient additional behaviours that the original Coaching Behaviour Assessment System does not include. The saliency of these behaviours are confirmed by the strong presence of each in the principal component structures, and by the impact these coaching dimensions have on the self-concepts of the players. So, rather than reduce the number of behaviours included in CBAS as the CFQ authors have attempted to do, further attempts should be made to expand the behavioural dimensions of the measure.

The most significant additional behaviours in this study were Composed Game Behaviour, Emotional Sideline Behaviour towards Players, and Emotional Sideline Behaviour towards Officials which together formed the essence of the Game Behaviours dimension. It was clearly demonstrated that this dimension belongs within the CBAS questionnaire with repeated and substantial inclusion in 
the principal component analyses with high loadings, high commonalities as individual behaviours and high internal consistency estimates of reliability provided by the Cronbach's alpha. The resultant goodness of fit statistics within the confirmatory factor analysis process further galvanizes support for the inclusion of Game Behaviours as a dimension within CBAS by demonstrating that the hypothesized factor structure, in which the Game Behaviours were a significant component, has statistical merit.

There is also evidence that the Positive Skill Clues, Negative Skill Clues and Equal Playing Time behaviours should perhaps be included in mCBAS. Despite the inconsistent loading of these behaviours within the principal component structures, several facts suggest that these behaviours, and a potential Skill Clue Behaviour dimension needs further exploration. The high principal component communalities, component loading values, and Pearson correlations between the individual behaviours with the self-concept dimensions suggest that these behaviours are both discernable to the players, and salient to their self-perceptions. A similar situation existed with the Game Behaviours in the pilot study. At that time the data suggested that a distinct dimension may be represented by the two Game Behaviours (Composed Game Behaviour, Emotional Sideline Behaviour). This led to the splitting of the Emotional Game Behaviour into Emotional Sideline Behaviour towards Players, and Emotional Sideline Behaviour towards Officials, and solidified the Game Behaviour dimension in both subsequent surveys. Perhaps by further increasing the number of Skill Clue behaviours, or by rewording these questions to more 
decisively define the essence of each behaviour for the players, a fourth coaching behaviour dimension may be uncovered. Alternately, improving the wording of these questions may allow one or more of these behaviours to load within another of the established factors thereby providing a more consistent loading pattern than was possible in this study.

Adding behaviours to the measure may also cause established behaviours to relocate to other dimensions. The example provided by Mistakecontingent Encouragement is an important case in point. Mistake-contingent Encouragement had been traditionally associated with the Supportive Coaching Behaviours. With the addition of the Game Behaviours in this study, the added dimension appears to have drawn Mistake-contingent Encouragement, to a different location - with the Game Behaviours. This relocation is, arguably, a more suitable dimension for this behaviour: Due to the addition of another supportive behaviour in this study (Nurturing), the structure of the Supportive Coaching dimension did not collapse with its departure but was strengthened by the addition of the new behaviour plus traditional behaviours which had not loaded consistently before. This may have strengthened the two dimensions in the process. This example illustrates why it is possible that the Skill Clue behaviours may provide a more robust Negative Coaching Behaviour dimension as occurred fleetingly in the third component of the T2 PCA structure. Or it may be possible that a new dimension will be established. If additional behaviours load elsewhere, they may provide greater robustness and consistency for an existing dimension in the process, which in turn may improve the reliability and 
validity of the CBAS as a result.

The second significant finding of this study was the improved reliability of the measure. From a technical standpoint, reliability is the proportion of variance that indicates the ratio between the true score variance for a test item and the total variance possible for the same test item (Cohen \& Swerdlik, 1988). The modified CBAS is a one item per behaviour questionnaire and its heterogeneity of items suggested that a test-retest estimate of reliability and an inter-item estimate of reliability as the most appropriate approaches in this regard (the third method, parallel forms is not applicable in this study). To this end, a test-retest and an internal consistency estimate of reliability were both conducted towards providing evidence of reliability.

The survey was given to the same players twice during the 2006 summer soccer season, once in July and a second time, 2 to 4 weeks later before end of the season. A guage of the test-retest reliability was provided by the Pearson correlation matrix of the test and retest components. The very high correlations provide solid evidence of dimensional reliability of the measure.

The preferred method for estimating internal consistency reliability is the Cronbach's alpha coefficient. Cronbach's alpha, also referred to as an inter-item estimate of reliability, refers to the homogeneity of the items within each component in a principal component analysis. In this regard, it is thought of as the mean of all possible split half correlations, corrected by the Spearman-Brown formulae (Cohen \& Swedlik, 1988). Cronbach's alpha values provided by the individual dimensions in this study indicate adequate to excellent intra-item 
reliability not included in research with CBAS to date. These values compare favourably with those found by the studies using CFQ, and are near and above the generally accepted threshold value $(>0.70)$.

The difference between the total and the true score variance is represented as the error variance. Sources of error variance which would occur during the administration of the questionnaire involve the environment and the frame of mind of the subjects at the time. Such issues were potentially profound in this study. Players before practices would be focussing on the task at hand or after practice fatigued by it. The outdoor environment, with variable weather, comings and goings of others in the vicinity, parents hurrying their charges to or from practice, noises and distractions of other nearby games or practices, and biting insects at dusk were significant issues in this regard.

The third concern of this study was to seek evidence of construct validity for CBAS, and in this regard the findings are mixed. Validity of a measure is an assessment derived from relevant information concerning the suitability of inferences drawn from the test results, or how adequately the target construct is actually measured (Cohen \& Swedlik, 1988). In this regard, the present study is a local validation study designed to provide evidence that a modified testing device adequately serves the intended purpose. To this end, this study attempted to evaluate the content of the measure, compare the results of this study to other related studies, and focus on understanding comprehensively the results of this study within a theoretical framework. Succinctly, this study attempted to address the content, criterion-related, construct and predictive 
validity of mCBAS.

Content validity, how adequately CBAS measures the universe of behaviours it purports to measure remains a fundamental question. The original authors proclaimed CBAS to measure the complete array of behaviours that a coach could possibly demonstrate. But this study suggests otherwise. The value of adding the Game Behaviours is clear. There is also the very real possibility that the Skill Clue Behaviours must also be considered as contenders for inclusion as well. More research into this possibility should be the focus of further research.

Criterion-related validity was evaluated by assessing concurrent validity of mCBAS with respect to the CFQ (Cohen \& Swedlik, 1988). The principal component structures and Pearson correlations between the CFQ and the mCBAS coaching dimensions were analysed toward this end. Results of this analysis demonstrate good concurrent validity for mCBAS. The principal component structures were as similar as could be expected considering the wider range of behaviours included in the mCBAS that were not part of the CFQ (see Appendix G). Significant Pearson correlations between the CFQ and the mCBAS coaching dimensions were also supportive of concurrent validity.

Criterion-related validity can also be qualified using a measure of its predictive validity (Cohen \& Swedlik, 1988). In this study the use of the Pearson's correlation coefficients between the mCBAS and the self-concept dimensions was used with some success. Significant Pearson correlations were found for each of the mCBAS coaching behaviour dimensions with at least one 
of the self-concept dimensions. A comparison of the mCBAS correlation matrix with the matrices of the original CBAS and the CFQ dimensions provided evidence that the mCBAS has a predictive validity which compares favourably with the other two questionnaires.

Construct validity - a measure of the degree of the homogeneity or internal consistency of the various construct dimensions, was provided by the Cronbach's coefficient alpha and by a comparison of the principal component structure of this study with the structures observed in previous research (convergent evidence of construct validity). Results show that the dimensional structures found in this study compare favourably with those from earlier studies. This therefore provides evidence of construct validity of the mCBAS.

In summary, evidence of the validity of CBAS is mixed. The content validity is brought into question by the saliency of new behaviours added in this study. In contrast, there is evidence for criterion-related validity in the high degree of similarity of the principal component structures between all sources (concurrent validity), in the number of significant correlations between the mCBAS dimensions and the self-concept dimensions (predictive validity), and in the similarity of the dimensional structures provided by the test-retest results and by comparison with previous research (construct validity).

With regard to gender differences, this study did not provide an hypothesis as very little research has been done to date on gender variations. And so the fourth finding, despite little supporting evidence, posits that there do appear to be significant gender differences. Generally speaking, this study 
indicates that girls perceived more Supportive and Instructive Coaching Behaviours than did the boys, and the boys perceived more Negative Coaching Behaviours. Of the few previous studies available with which to make comparisons (Smoll \& Smith, 1989; Thompson \& Bowker, 2005), only partial support of these findings is provided.

In seeking repeatable principal component structures for each gender, only the structures for the girls offer any real consistency. Comparison of the pilot, T1 and T2 results for the boys demonstrates variation, with only the 'all subjects' structures available to provide a favourable comparison. As no prior studies have compared factor structures, no conclusions will be made here except to suggest that the results from this study may be able to provide a starting point from which future research may continue.

The gender differences may be caused by the differing motives the genders have for participating in sport (Kleiber \& Kirshnit, 1991). The males rank the Game Behaviours as the most salient because it is the competition in games that most reflects their principle motives for participating in sport in the first place - task mastery and social comparison. Whereas, the females, motivated more by affiliative needs, categorise the supportive and Instructive Behaviours together as part of the schema of competitive sports thus placing it as their most salient dimension. The males see instruction as less a part of the schema and more of an option, which if they choose, they can utilize to improve their individual chances to move up in the team pecking order. But it is of little interest otherwise and so loads on the third factor on the male factor structure. The females don't 
completely discount the Game Behaviours and rank it as their second factor. Most notable of the male structure is the absence of the Negative Behaviours as a dimension. Although they perceived more Negative Behaviours than did the girls, they seem to place little, if any currency in them as a dimension.

In the context of competitive team environments boys are far less engaged in the process when not physically active - they may not disrupt the proceedings but certainly are not consistently attentive when the coach is giving instruction. This suggests that for boys the coach's Instructive Behaviours are optional, not part of the social schema as the Instructive Behaviours are for girls. The need to acquire technical skills, or improve their standing in the team pecking order is contingent upon their success in practice and game contests. Intra squad games in practice with team mates are opportunities to beat their team mates and are used as a measure of domain specific self-esteem, or Sport Competence. Thus the coach's skill level clues, whether negative or positive are irrelevant compared to the importance of winning the small sided games in practice and the games within the games during competition. This could also help explain why the game outcomes alone have so little to do with the enjoyment male athletes indicate they feel for participation in sport as a whole.

And finally, the ultimate goal of this study was to improve the predictive value of the measure. CBAS is considered the principal measurement device when the psychosocial development of child athletes are the outcome variables (Horn, 2002), and so the ability of CBAS to predict the self-concepts of adolescent athletes based on the coach's behaviour would seem fundamental. 
Previous studies have found correlations between the coaching dimensions (Instructive Coaching Behaviours; Supportive Coaching Behaviours; Negative Coaching Behaviours) and the self-concept dimensions (Global Self-esteem; Global Physical Self-concept; Sport Competence). In that regard this study is also supportive. However, the addition of the Game Behaviour dimension further enhances the value of the measure. Significant Pearson correlations between the Game Behaviour dimension with Global Self-esteem and Global Physical Self-concept is clear evidence of the predictive value of the measure with these additional behaviours included. Clearly the predictive validity of the mCBAS is favourable in comparison with the original 12 item Coaching Behaviour Assessment System and the 8 item Coaching Feedback Questionnaire. Limitations

The most serious limitation of this study was the relatively small number of subjects taking part. Gender analysis would have been improved if the number of participants was above 200 for each gender. The number of participants also hampered attempts to understand the inconsistent nature of the PCA loadings for the Skill Clue behaviours. With the strong and consistent presence of the Game Behaviours in hand, considerable effort was made to understand the nature of the inconsistencies of the Skill Clue Behaviours without success. There also appeared to be some evidence of age effects within the gender related differences but the small number of subjects made it difficult to make any conclusions.

Also potentially confounding the test-retest reliability was the likeability of 
the coach. Conceivably, this would play a role in the severity of the subject's response for behaviours deemed offensive, and alternatively, the generosity of the responses for likeable coaches for inoffensive behaviours. It is possible that as a season wore on, deteriorating relationships might spur on increasingly negative responses from disaffected players despite unwavering behaviour from the coach. Or, a strengthening relationship between player and coach might result in more positive and less negative scores on items for behaviours deemed respectively inoffensive and offensive.

Another potentially limiting factor is the potential volitility of player mood, especially within the 'win at all costs' culture of elite sport. The expected highs and lows of the typical adolescent mood could potentially be exacerbated by disappointment of losing, or by the elation of winning. It is very possible that this may confound the internal consistency estimates of reliability. For although care was taken to have the players do the questionnaires within the relatively neutral practice environment, it was not always possible to do so. Several of the teams were only available after a game, and the mood of the players may have been buoyant or depressed afterward, which could impact the players' view of the coach, and in turn the scores on the questionnaire.

Extrapolating the lessons learned through this research into future studies presents a variety of opportunities. Firstly, the mechanics of the distribution and return of the questionnaires needs to be improved to inspire more subjects to participate. Future attempts at test-retest methods should require the use of more researchers who would presumably be better able to return repeatedly to 
individual team practices to gather T2 questionnaires from all T1 participants. Player attendance at late season practice was poorer than earlier in the season. Yet despite this, response rates from this study were decidedly improved over results from earlier studies which relied on either mail in or internet conveyed responses. The combination of improved profile within the soccer community (from continuing exposure to the players and clubs), and the act of doing the questionnaire as part of the team practice has enhanced the credibility and support of this type of research within the soccer community, and by the players. Earlier response rates were on the order of three per team (maximum 18 players). This study averaged 6.7 per team for the first survey, and 5.8 per team for the second survey ( 5 teams were not able to participate in the second survey due to the early and unexpected end of the season). This therefore provides validation for the method of garnering subjects, and acknowledges that improvements in this regard are possible and necessary to improve data gathering efficacy.

Another limitation of this study is the strength of the evidence used to evaluate the concurrent validity of mCBAS. Adequate assessment of concurrent validity requires that a parallel measurement device with prior validation be used as the criteria upon which to judge the quality of the results from the target test device. It also requires that the parallel device measure have the same items as the target test measure. But CFQ has not been validated at this writing, and has considerable differences from mCBAS. Most significantly CFQ has only two distinct factor dimensions, whereas the mCBAS has three. This therefore draws 
into question the quality of the suggested concurrent validity claims. Other questionnaires which are available which could be used selectively to evaluate the concurrent validity of the game behaviours include the Coaching Behaviour Questionnaire (Williams et al., 2003), and the Coaching Evaluation Questionnaire (Rushall \& Wiznuk, 1985). These questionnaires do possess specific questions addressing the behaviour of the coach during games, but not however, the proper validation necessary to entirely fulfill the requirements of a properly validated parallel measurement device.

Future research should also delve into age differences. Awareness of the nature of elite sport, of the expectations placed upon the players and their own potential for success within this environment is new for the youngest players. As they become in tune with the process over time, their understanding and expectations grow. To what degree and valence they evaluate the various coaching behaviours, and to what degree and valence they evaluate themselves as a result is an important research goal. Smith, Smoll \& Curtis (1978) arbitrarily segregated players into age groupings and analysed perceptions of coaching behaviour within these arbitrary boundaries. Segregating players according to natural developmental criteria may be more appropriate, but where do these boundaries exist? Cognitive, emotional and social development may create their own natural boundaries which are less discernable than the obvious physiological differences.

Further research is necessary to expand rather than reduce the number of behaviours and dimensions. This study concludes that there are salient 
behaviours beyond the original twelve recognized by the Coaching Behaviour Assessment System. These behaviours are clearly differentiated from the other behaviours and are robustly represented statistically throughout. These additional behaviours need to be analysed and acknowledged by the research community before they can be galvanized within the measurement device.

There are also behaviours which did not fit into the component structure in this study which nevertheless are clearly salient to the players as the strong correlations with self-concept dimensions attest. The Skill Clue behaviours may represent a latent dimension, and must be investigated thoroughly in further research. The highest Pearson correlation between a single behaviour and a self-concept dimension was between the Negative Skill Clue item and Global Self-esteem $(r=0.38, p<0.001)$. Considerable potential for improving the predictive validity of the measure may be possible if one or more questions can more adequately address this attribute. Perhaps a question should address playing time issues by asking how often the coach takes away playing time from the subject after a mistake has been made during games? For this would address playing time in a reactive way, as opposed to the present question which suggests a spontaneous attempt by the coach to provide equal playing time.

The Game behaviours also provide some opportunities to improve the questionnaire. The mCBAS questions concerning emotional outbursts from the sidelines during games suggests that emotion is negative. However, positive emotive behaviour is probably common from the sidelines during games and should be addressed. A question targeting emotional outbursts from the coach 
after a good play on the field would seem prudent to address this issue, and it would also act as a foil to the Compose Sideline Behaviour item. In addition, the present question regarding emotional outbursts toward players should probably include a clear reference to it being a response to a mistake on the field. This may make the question clearly negative and more directly linked to a selfconcept evaluative response as well.

The preliminary literature search for this study yielded few published studies using CBAS to investigate the psychosocial development of adolescent athletes. In retrospect this is disappointing because it is considered the only well tested device available for this kind of research. The device is used to investigate other issues but not necessarily the area of research for which it was intended. Future research must focus on the raison d'etre of the device. With the abundance of literature stating the many benefits of sport for children, it should be expected that this notion be tested empirically before it is accepted universally.

Finally, further research should consider the effects of the gender of the coach. If discernable differences between player self-concept is attributable to gender of the player, perhaps the coach's gender would impact the players' perceptions of the coach's behaviour, and the resultant self-esteem impact as well. Research using CBAS to study the frequency of the various behaviours reported significant differences between male and female coaches (Millard, 1999). This study employed third party observation to measure the behaviours, and these differences may be compounded if the perceptions of the athlete were 
incorporated into the study as well.

In conclusion, the purpose of this study was to modify the Coaching Behaviour Assessment System by expanding the behavioural dimensions of the measure, improve reliability, provide evidence of construct validity, examine gender variations in the component structure and improve the predictive value of the measure. It was hoped that such refinements would allow for a closer examination of the impact that coaching behaviour has on elite adolescent athlete self-perceptions.

The study was in a large part successful in achieving these goals. Additional behaviours, clearly salient to the athletes, provided a coaching behaviour dimension which had not been reported in previous research. Evidence of reliability was established by above threshold internal consistency reliability estimates, by a high degree of similarity of the T1 and T2 component structures, and the high Pearson correlations between the coaching dimensions at T1 and T2. Validity was addressed in several ways with mixed results. Although content validity has been has been questioned by the successful addition of new behaviours, concurrent validity was evident in the favourable comparison of component structures with those reported in previous research, and by the significant correlations between the CFQ, CBAS and mCBAS dimensions. The predictive validity of mCBAS was demonstrated by the correlations between the mCBAS dimensions and the self-concept dimensions. Gender differences were examined without the direction of previous research and several significant differences reported. 
These refinements in the questionnaire should contribute to the confidence associated with mCBAS in the study of the psychosocial impacts of coaching behaviour in adolescent athletes. As a result, more research should be expected on the potential expansion of the salient behaviours, which in turn would provide a more complete picture of the nature of the relationship between a coach's behaviour and the self-perceptions of their adolescent athletes. 


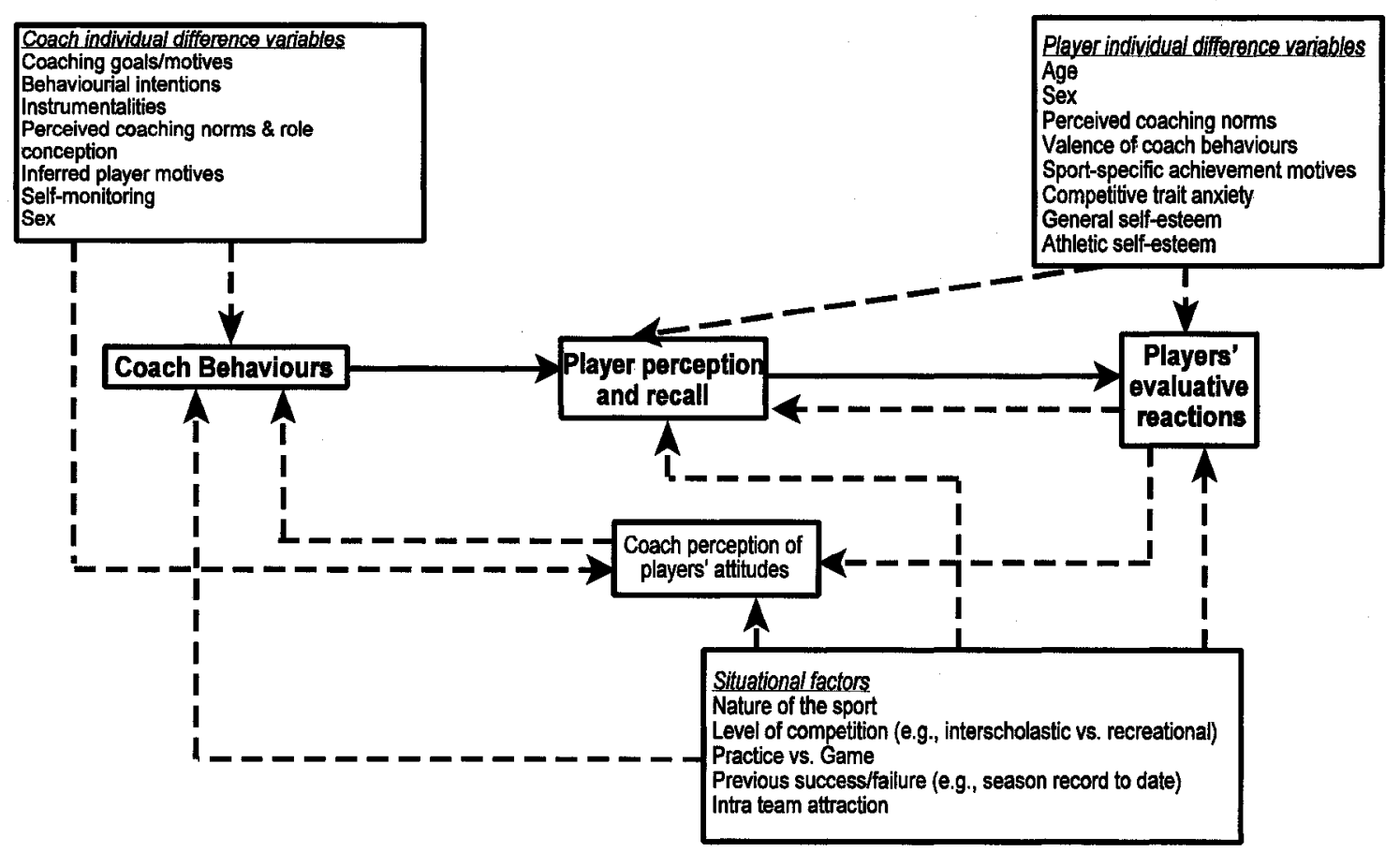

Figure 1. Smoll \& Smith's model of adult leadership behaviours in sport and hypothesized relationships among situational, cognitive, behavioural, and individual difference variables (Smoll \& Smith, 1989). 
Modifications to the CBAS 82

Table 1: Factor analysis structure using varimax rotation reported by Smith, Smoll \& Curtis (1978).

\begin{tabular}{|c|c|c|c|c|}
\hline Variable & $\begin{array}{l}\text { Factor 1: } \\
\text { Supportive/ } \\
\text { structuring }\end{array}$ & $\begin{array}{l}\text { Factor 2: } \\
\text { Aversive }\end{array}$ & $\begin{array}{l}\text { Factor 3: } \\
\text { Response } \\
\text { to mistakes }\end{array}$ & $h^{2}$ \\
\hline General Encouragement & .68 & & & - \\
\hline General Technical Instruction & .61 & & & - \\
\hline Reinforcement & .56 & & & - \\
\hline $\begin{array}{r}\text { Punitive Mistake-Contingent Technical } \\
\text { Instruction }\end{array}$ & & .79 & & - \\
\hline Punishment & & .75 & & - \\
\hline Non-reinforcement & & .52 & & - \\
\hline Ignoring Mistakes & & & -.87 & - \\
\hline $\begin{array}{r}\text { Mistake-contingent Technical } \\
\text { Instruction }\end{array}$ & & & .57 & - \\
\hline Cronbach's $\alpha$ & - & - & - & \\
\hline variance & - & - & - & $45.6 \%$ \\
\hline none (original 12) & none & & & \\
\hline
\end{tabular}


Table 2: Principal component analysis results using varimax rotation reported by Smoll, Smith, Barnett \& Everett (1993).

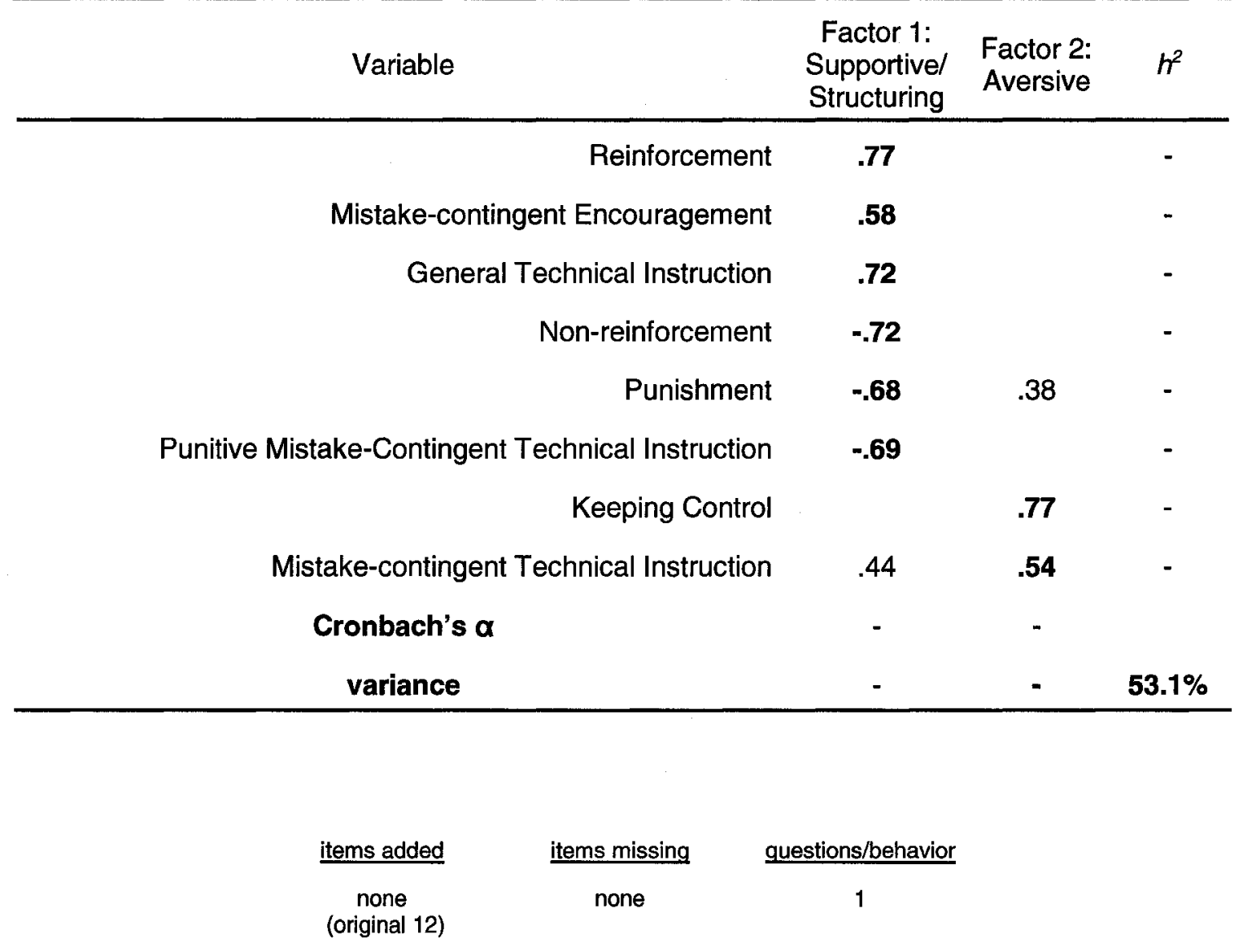


Table 3: Principal-axis factor analysis using varimax rotation reported by Allen \& Howe (1998).

\begin{tabular}{|c|c|c|c|c|c|c|c|c|}
\hline Variable & Factor 1: & Factor 2: & Factor 3: & Factor 4: & Factor 5 : & Factor 6: & Factor $7:$ & $h^{2}$ \\
\hline EM & .72 & & & & & & & - \\
\hline TIM+E & .71 & & & & & & & - \\
\hline TIM+E & .70 & & & & & & & - \\
\hline TIM & .60 & & & & & & & - \\
\hline $\mathrm{T} \mid \mathrm{M}+\mathrm{E}$ & .58 & & & & & & & - \\
\hline EM & .54 & & & & & & & - \\
\hline EM & .49 & & -.46 & & & & & - \\
\hline TIR & & .73 & & & & & & - \\
\hline TIR & .34 & .66 & & & & & & - \\
\hline $\mathrm{R}$ & & .60 & & & & & & - \\
\hline Tir & .34 & .59 & & & & & & - \\
\hline$R$ & & .57 & & & & & & - \\
\hline nvR & .39 & .53 & & & & & & - \\
\hline Tir & & .53 & & & 0.42 & & & - \\
\hline nvR & & .51 & & & & & & - \\
\hline $\mathrm{P}$ & & & .91 & & & & & - \\
\hline nvP & & & .83 & & & & & - \\
\hline$n v P$ & & & .49 & & & & & - \\
\hline $\mathrm{TIM}+\mathrm{P}$ & & & & .70 & & & & - \\
\hline$P$ & & & & .59 & & & & - \\
\hline$T I M+P$ & & & & .58 & & & & - \\
\hline$P$ & & & & .49 & & & & - \\
\hline TIM+P & & & & .49 & & & & - \\
\hline TIR & & .39 & & & .75 & & & $\cdot$ \\
\hline Tir & & .33 & & & .65 & & & - \\
\hline TIM & .36 & & & & .49 & & & $\cdot$ \\
\hline NR & & & & & & .60 & & - \\
\hline NR & & & & & & .54 & & - \\
\hline NR & & & & & & .45 & .32 & - \\
\hline $\mathrm{IM}$ & & & & & & & .73 & - \\
\hline IM & & & & & & & .59 & - \\
\hline IM & & & .39 & & & & .42 & - \\
\hline Cronbach & & 0.85 & 0.86 & 0.80 & 0.67 & 0.78 & 0.63 & 0.59 \\
\hline variance & $22.5 \%$ & $9.5 \%$ & $6.1 \%$ & $4.4 \%$ & $3.4 \%$ & $2.7 \%$ & $2.0 \%$ & $50.6 \%$ \\
\hline \multicolumn{3}{|c|}{ items added to original 12} & \multicolumn{4}{|c|}{$\underline{\text { items missing from original } 12}$} & \multicolumn{2}{|c|}{ questions/behavior } \\
\hline \multicolumn{3}{|c|}{$\begin{array}{l}\text { Technical Instruction with } \\
\text { Reinforcement }\end{array}$} & \multicolumn{4}{|c|}{$\begin{array}{c}\text { Organization, General Encouragement, Keeping } \\
\text { Control, General Communication, General } \\
\text { Technical Instruction }\end{array}$} & \multicolumn{2}{|c|}{3} \\
\hline \multicolumn{9}{|c|}{ 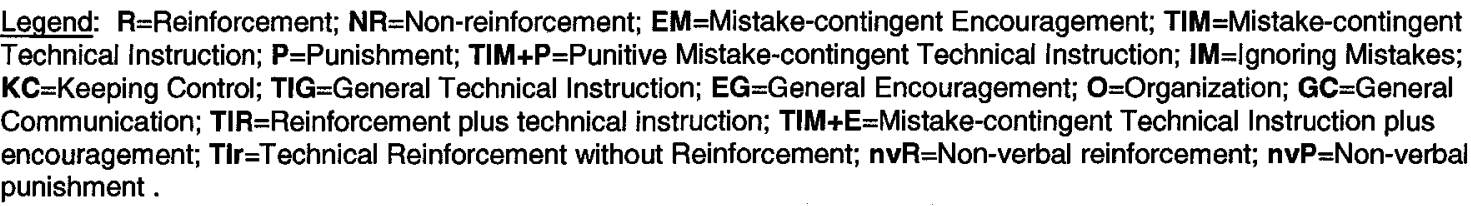 } \\
\hline
\end{tabular}


Table 4: Principal-axis factor analysis results using varimax rotation reported by Amorose \& Horn (2000).

\begin{tabular}{|c|c|c|c|c|}
\hline Variable & $\begin{array}{l}\text { Factor 1: } \\
\text { Positive \& } \\
\text { Information } \\
\text { Feedback }\end{array}$ & $\begin{array}{c}\text { Factor 2: } \\
\text { Punishment } \\
\text { Oriented } \\
\text { Feedback }\end{array}$ & $\begin{array}{c}\text { Factor 3: } \\
\text { Non- } \\
\text { reinforcement } \\
\& \\
\text { Ignoring } \\
\text { Mistakes }\end{array}$ & $h^{2}$ \\
\hline Reinforcement & .65 & & & - \\
\hline Non-reinforcement & -.46 & & .53 & - \\
\hline Technical Instruction with Reinforcement & .78 & & & \\
\hline Technical Instruction with Reinforcement & .72 & & & - \\
\hline Reinforcement & .57 & & & - \\
\hline Non-reinforcement & -.51 & & .58 & - \\
\hline Mistake-contingent Encouragement & .58 & & & - \\
\hline Mistake-contingent Technical Instruction & .46 & & & - \\
\hline Mistake-contingent Encouragement & .58 & & & - \\
\hline Punishment & & .72 & & - \\
\hline $\begin{array}{r}\text { Punitive Mistake-Contingent Technical } \\
\text { Instruction }\end{array}$ & & .76 & & - \\
\hline $\begin{array}{l}\text { Punitive Mistake-Contingent Technical } \\
\text { Instruction }\end{array}$ & & .76 & & - \\
\hline Punishment & & .77 & & - \\
\hline Mistake-contingent Technical Instruction & & .46 & & - \\
\hline Ignoring Mistakes & & & .64 & - \\
\hline Ignoring Mistakes & & & .83 & - \\
\hline Cronbach's & 0.72 & 0.83 & 0.78 & \\
\hline variance & $27.8 \%$ & $14.1 \%$ & $7.9 \%$ & $49.8 \%$ \\
\hline items added to original 12 & \multicolumn{2}{|c|}{ items missing from original 12} & questions/behav & \\
\hline $\begin{array}{l}\text { Technical Instruction with } \\
\text { Reinforcement }\end{array}$ & \multicolumn{2}{|c|}{$\begin{array}{c}\text { Organization, } \\
\text { General Encouragement } \\
\text { Keeping Control } \\
\text { General Communication } \\
\text { General Technical Instruction }\end{array}$} & 2 & \\
\hline
\end{tabular}


Table 5: Principal component factor analysis results using varimax rotation reported Smith, Fry, Ethington \& Li (2005).

\begin{tabular}{|c|c|c|c|c|}
\hline Variable & $\begin{array}{l}\text { Factor 1: } \\
\text { Positive } \\
\text { Feedback }\end{array}$ & $\begin{array}{l}\text { Factor 2: } \\
\text { Punishm } \\
\text { ent }\end{array}$ & $\begin{array}{l}\text { Factor 3: } \\
\text { Ignoring } \\
\text { Mistakes }\end{array}$ & $h^{2}$ \\
\hline Mistake-contingent Encouragement & .71 & & & - \\
\hline Reinforcement & .70 & & & - \\
\hline Reinforcement & .70 & & & - \\
\hline Mistake-contingent Encouragement & .69 & & & - \\
\hline Mistake-contingent Technical Instruction & & .74 & & - \\
\hline $\begin{array}{l}\text { Punitive Mistake-Contingent Technical } \\
\text { Instruction }\end{array}$ & & .64 & & - \\
\hline Punishment & -.43 & .63 & & - \\
\hline Mistake-contingent Technical Instruction & & .53 & & - \\
\hline Punishment & -.54 & .47 & & - \\
\hline $\begin{array}{l}\text { Punitive Mistake-Contingent Technical } \\
\text { Instruction }\end{array}$ & & .46 & & - \\
\hline Ignoring Mistakes & -.37 & & .76 & - \\
\hline Ignoring Mistakes & -.35 & & .73 & - \\
\hline Technical Instruction with Reinforcement & .45 & .44 & .34 & - \\
\hline Technical Instruction with Reinforcement & .56 & .49 & & - \\
\hline Non-reinforcement & -.60 & & & - \\
\hline Non-reinforcement & -.73 & & & - \\
\hline Cronbach's & 0.77 & 0.69 & 0.70 & \\
\hline variance & $26.8 \%$ & $16.1 \%$ & $9.9 \%$ & $52.8 \%$ \\
\hline
\end{tabular}

items added to original 12

Technical Instruction with Reinforcement

\author{
items missing from original 12 \\ Organization, \\ General Encouragement \\ Keeping Control \\ General Communication \\ General Technical Instruction
}

questions/behavior

2 


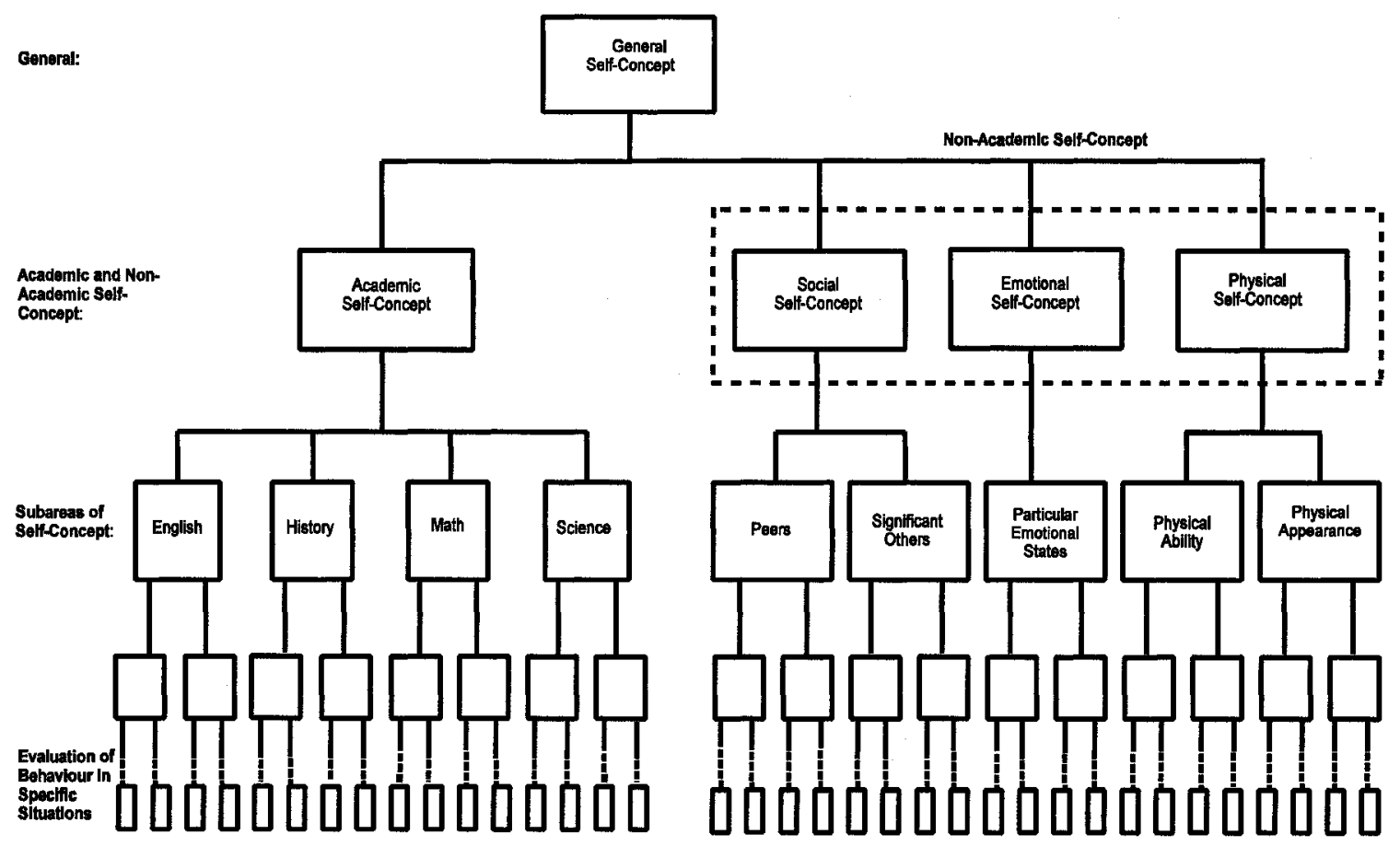

Figure 2: Structure of Self-concept (Shavelson, Hubner, \& Stanton, 1976). 
Table 6: Pilot principal component matrix rotated to the varimax criteria (all subjects).

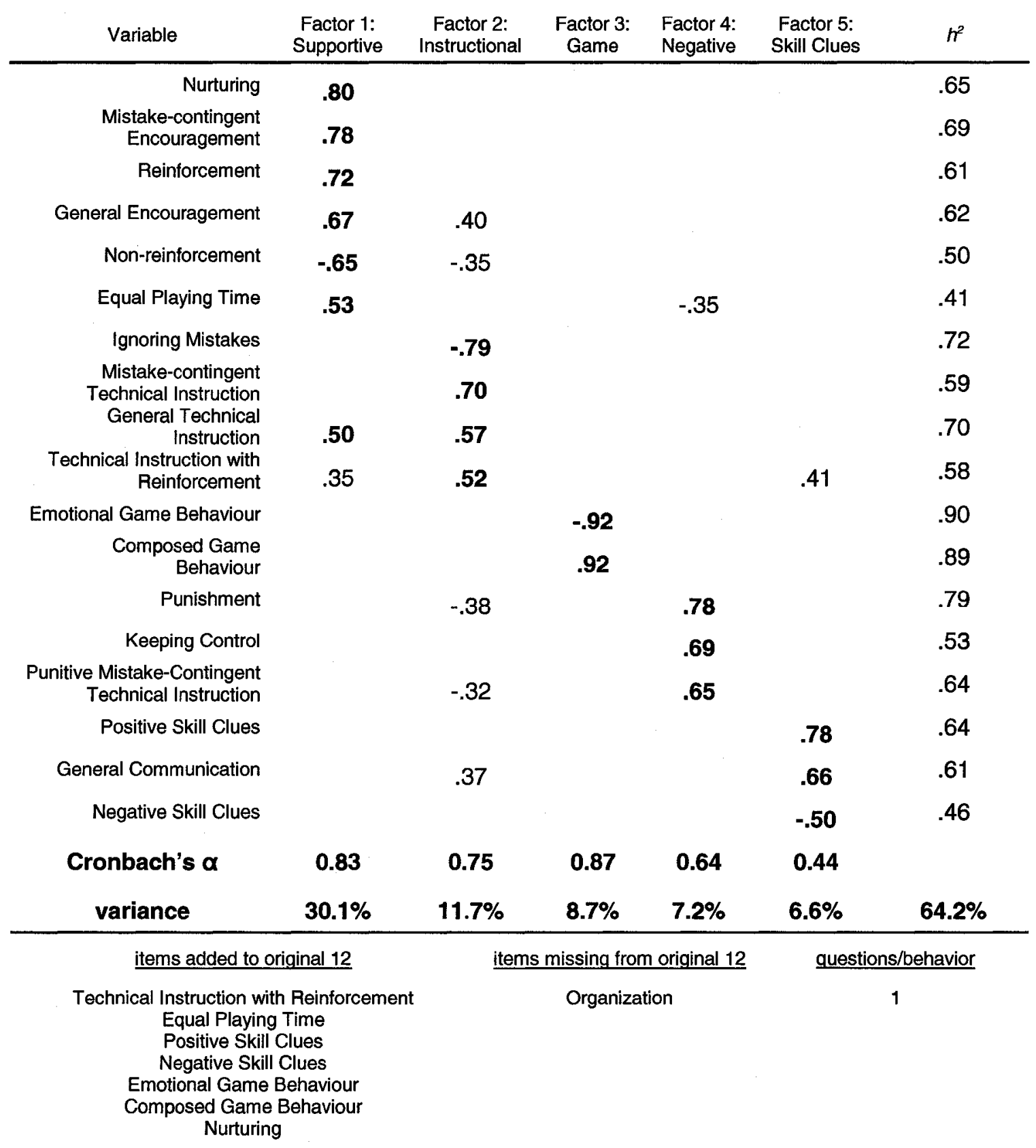


Table 7: Pilot study orthogonal factor structures for female athletes.

\begin{tabular}{|c|c|c|c|c|}
\hline Variable & Factor 1 & Factor 2 & Factor 3 & $h^{2}$ \\
\hline General Encouragement & .78 & & & - \\
\hline Mistake-contingent Encouragement & .72 & & & - \\
\hline General Communication & .70 & .46 & & - \\
\hline Nurturing & .64 & & & - \\
\hline Mistake-contingent Technical Instruction & .63 & & -.36 & - \\
\hline Technical Instruction with Reinforcement & .62 & & & - \\
\hline General Technical Instruction & .58 & -.49 & & - \\
\hline Reinforcement & .55 & -.43 & .37 & - \\
\hline Non-reinforcement & -.54 & .48 & & - \\
\hline Equal Playing Time & .54 & & & - \\
\hline Punishment & & .76 & & - \\
\hline $\begin{array}{r}\text { Punitive Mistake-Contingent Technical } \\
\text { Instruction }\end{array}$ & -.32 & .66 & & - \\
\hline Negative Skill Clues & & -.65 & & - \\
\hline Positive Skill Clues & & .60 & & - \\
\hline Ignoring Mistakes & -.51 & .55 & .37 & - \\
\hline Keeping Control & & & & - \\
\hline Emotional Game Behaviour & & & -.91 & - \\
\hline Composed Game Behaviour & & & .88 & - \\
\hline Cronbach's $\alpha$ & - & - & - & - \\
\hline variance & - & - & - & - \\
\hline items added to original 12 & \multicolumn{2}{|c|}{ items missing from original } & questions/ber & \\
\hline $\begin{array}{c}\text { Technical Instruction with Reinforcement } \\
\text { Equal Playing Time } \\
\text { Positive Skill Clues } \\
\text { Negative Skill Clues } \\
\text { Emotional Game Behaviour } \\
\text { Composed Game Behaviour } \\
\text { Nurturing }\end{array}$ & \multicolumn{2}{|l|}{ Organization } & 1 & \\
\hline
\end{tabular}


Table 8: Pilot study orthogonal factor structures for male athletes.

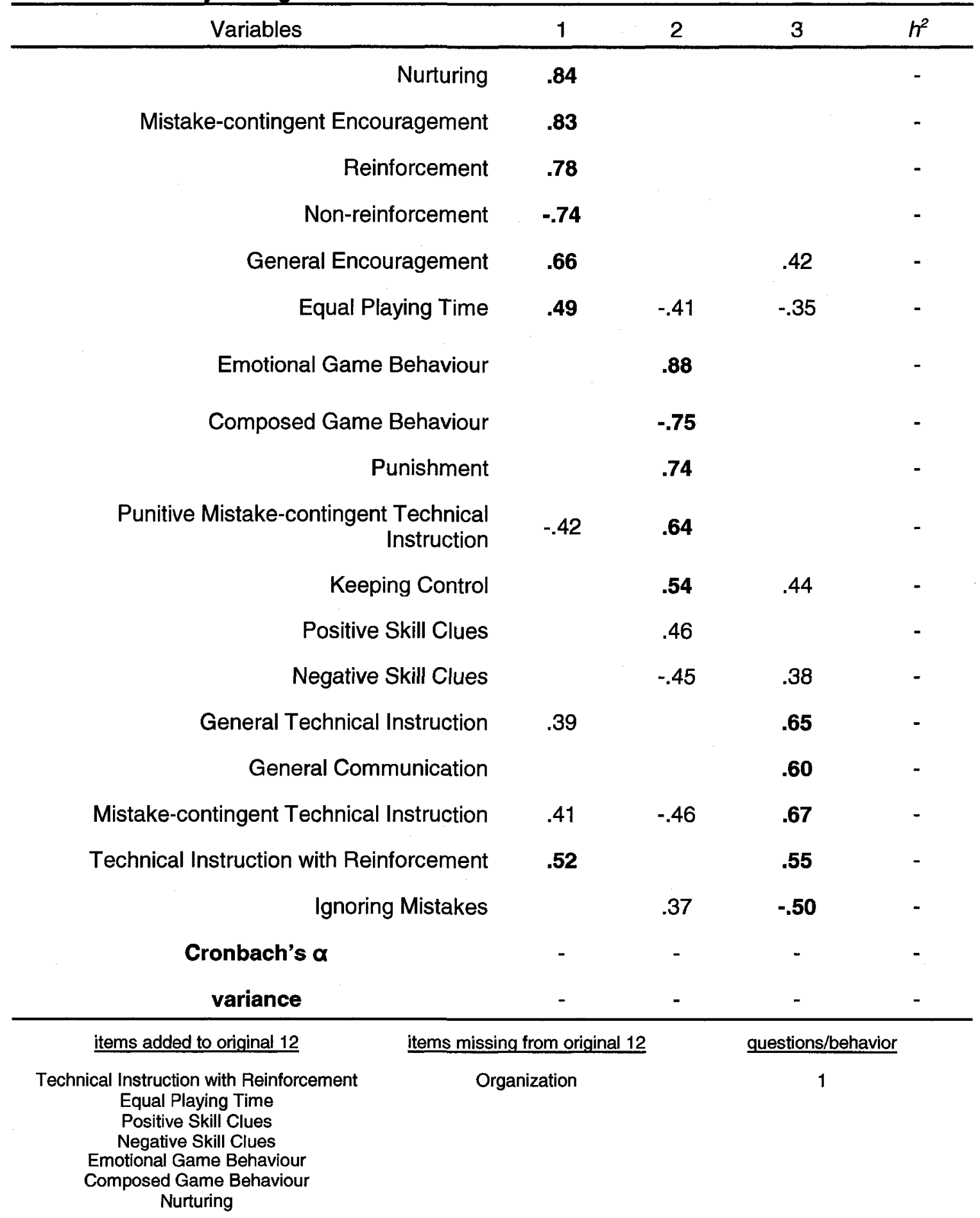


Table 9: Principal component matrix rotated to the varimax criteria for T1 data (all subjects).

\begin{tabular}{|c|c|c|c|c|}
\hline Variable & $\begin{array}{l}\text { Factor 1: } \\
\text { Instructive/ } \\
\text { Supportive }\end{array}$ & $\begin{array}{c}\text { Factor 2: } \\
\text { Game }\end{array}$ & $\begin{array}{l}\text { Factor 3: } \\
\text { Negative }\end{array}$ & $h^{2}$ \\
\hline Technical Instruction with Reinforcement & .77 & & & .43 \\
\hline General Technical Instruction & .67 & & & .48 \\
\hline Mistake-contingent Technical Instruction & .63 & & & .60 \\
\hline General Encouragement & .63 & & -.33 & .50 \\
\hline General Communication & .62 & & & .41 \\
\hline Nurturing & .56 & & & .39 \\
\hline Reinforcement & .51 & & -.42 & .49 \\
\hline Composed Game Behaviour & & .84 & & .74 \\
\hline Emotional Sideline Behaviour towards Officials & & -.76 & & .62 \\
\hline Emotional Sideline Behaviour towards Players & & -.74 & & .63 \\
\hline Mistake-contingent Encouragement & .42 & .52 & & .50 \\
\hline Punitive Mistake-Contingent Technical & & & .69 & .57 \\
\hline Non-reinforcement & -.34 & & .64 & .53 \\
\hline Punishment & & & .59 & .48 \\
\hline Keeping Control & & & .50 & .35 \\
\hline Equal Playing Time & & & -.42 & .25 \\
\hline Negative Skill Clues & & & .40 & .30 \\
\hline Positive Skill Clues & & & & .15 \\
\hline Ignoring Mistakes & & & & .19 \\
\hline Cronbach's $\alpha$ & 0.80 & 0.78 & 0.60 & \\
\hline variance & $28.1 \%$ & $9.8 \%$ & $7.4 \%$ & 45.3 \\
\hline items added to original 12 & sing from original & & questions/behavior & \\
\hline $\begin{array}{c}\text { Technical Instruction with Reinforcement } \\
\text { Equal Playing Time } \\
\text { Positive Skill Clues } \\
\text { Negative Skill Clues } \\
\text { Emotional Game Behaviour towards Players } \\
\text { Emotional Sideline Behaviour towards Officials } \\
\text { Composed Game Behaviour } \\
\text { Nurturing }\end{array}$ & rganization & & 1 & \\
\hline
\end{tabular}


Table 10: Principal component analysis rotated to the varimax criteria for T2 data (all subjects).

\begin{tabular}{|c|c|c|c|c|}
\hline$\underline{\text { Variable }}$ & $\begin{array}{c}\text { Factor 1: } \\
\text { Instructive/ } \\
\text { Supportive }\end{array}$ & $\begin{array}{l}\text { Factor 2: } \\
\text { Game }\end{array}$ & $\begin{array}{l}\text { Factor 3: } \\
\text { Negative/ } \\
\text { Skill clues }\end{array}$ & $h^{2}$ \\
\hline Technical Instruction with Reinforcement & .74 & & & .57 \\
\hline General Encouragement & .69 & & & .53 \\
\hline General Communication & .69 & & & .49 \\
\hline General Technical Instruction & .69 & & & .48 \\
\hline Mistake-contingent Technical Instruction & .69 & & & .55 \\
\hline Reinforcement & .69 & -.40 & & .63 \\
\hline Non-reinforcement & -.60 & & & .53 \\
\hline Nurturing & .58 & -.38 & & .48 \\
\hline Emotional Sideline Behaviour towards Officials & & .78 & & .64 \\
\hline Composed Game Behaviour & .34 & -.75 & & .71 \\
\hline Emotional Sideline Behaviour towards Players & & .71 & & .64 \\
\hline Mistake-contingent Encouragement & .47 & -.49 & & .46 \\
\hline Punitive Mistake-Contingent Technical Instruction & & & .77 & .66 \\
\hline Negative Skill Clues & & & .71 & .56 \\
\hline Punishment & & .40 & .65 & .63 \\
\hline Positive Skill Clues & & & .53 & .35 \\
\hline Ignoring Mistakes & & & .50 & .37 \\
\hline Keeping Control & .36 & .37 & .32 & .38 \\
\hline Equal Playing Time & .42 & & & .20 \\
\hline Cronbach's $\alpha$ & .86 & .75 & .69 & \\
\hline variance & $31.0 \%$ & $12.1 \%$ & $8.7 \%$ & $51.8 \%$ \\
\hline items added to original 12 & \multicolumn{2}{|c|}{ items missing from original 12} & \multicolumn{2}{|c|}{ questions/behavior } \\
\hline $\begin{array}{c}\text { Technical Instruction with Reinforcement } \\
\text { Equal Playing Time } \\
\text { Positive Skill Clues } \\
\text { Negative Skill Clues } \\
\text { Emotional Game Behaviour towards Players } \\
\text { Emotional Sideline Behaviour towards Officials } \\
\text { Composed Game Behaviour } \\
\text { Nurturing }\end{array}$ & \multicolumn{2}{|c|}{ Organization } & \multicolumn{2}{|c|}{1} \\
\hline
\end{tabular}


Table 11: Pearson correlations between the $\mathrm{T} 1$ and $\mathrm{T}_{2}{ }^{\dagger}$ mCBAS dimensions.

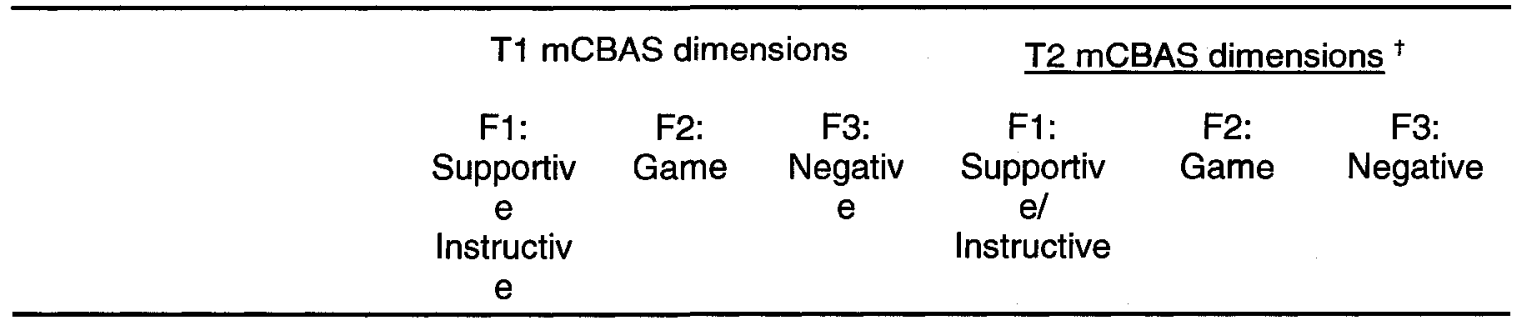

T1 mCBAS

dimensions

F1: Supportive/ Instructive

1

F2: Game $.46^{\star \star} \quad 1$

F3: Negative $\quad-.35^{\star \star} \quad-.44^{\star}$

1

T2 mCBAS

dimensions $^{\dagger}$

\begin{tabular}{|c|c|c|c|c|c|c|}
\hline $\begin{array}{c}\text { F1: Supportive/ } \\
\text { Instructive }\end{array}$ & $.75^{\star \star}$ & $.43^{* *}$ & $-.39^{\star \star}$ & 1 & & \\
\hline F2: Game & $.49^{* *}$ & $.75^{\star *}$ & $-.40^{* *}$ & $-.49^{* *}$ & 1 & \\
\hline F3: Negative & $-.37^{* *}$ & $-.41^{\star *}$ & $.66^{\star *}$ & $-.39^{\star *}$ & $.52^{\star *}$ & 1 \\
\hline
\end{tabular}

${ }^{\star} p,<0.05 ;{ }^{* *} p<0.01$

${ }^{\dagger}$ Note: Coaching Behaviour dimensions utilized the T2 data for behaviours grouped by the T1 principal components analysis dimensions. 


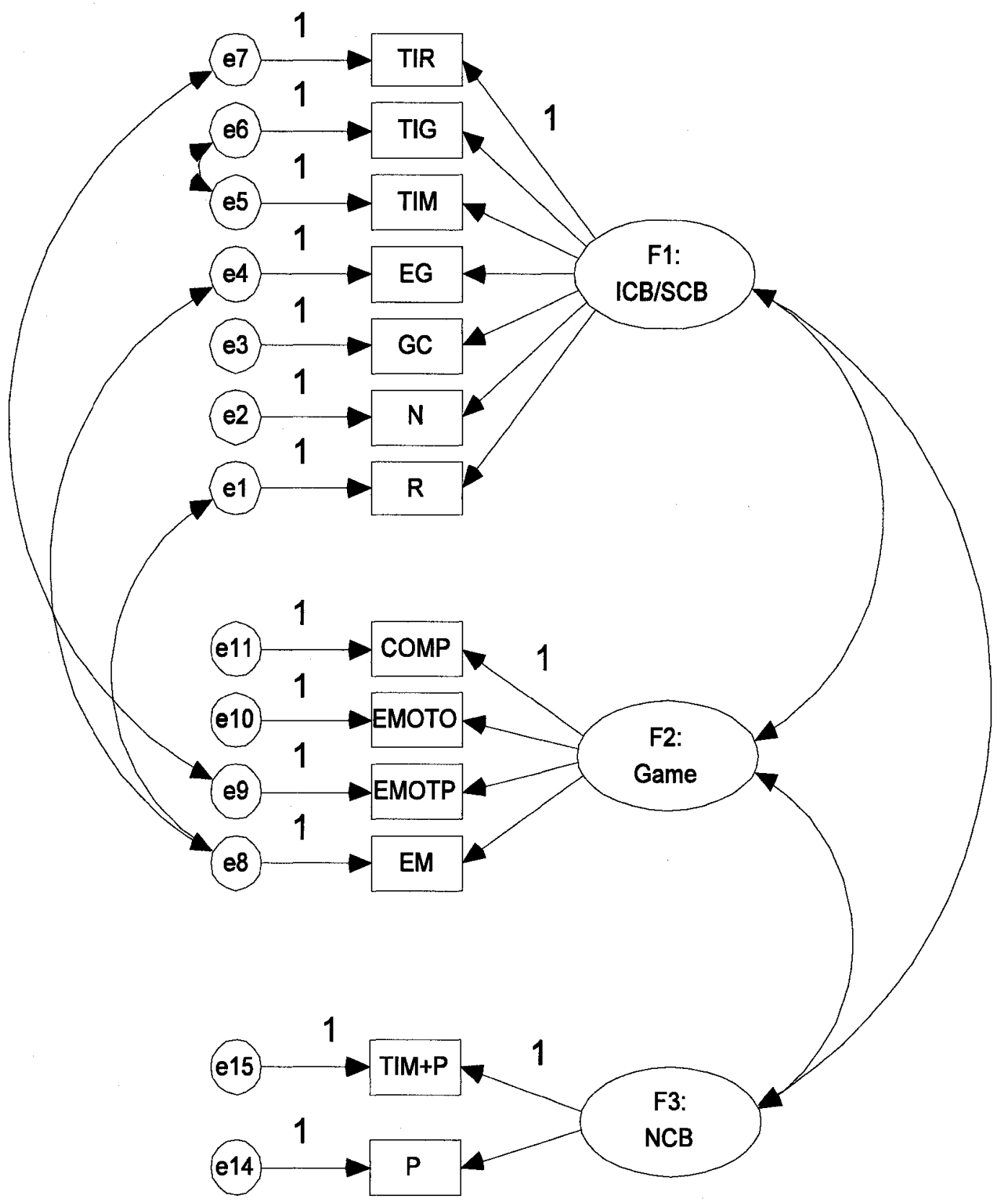

Figure 3: Graphic representation of the proposed dimensional structure of mCBAS behaviours applied to $\mathrm{T} 2$ behaviours. 
Table 12: Goodness-of-Fit statistics summary for the hypothesised model using T2 data.

Minimum Discrepancy (CMIN)

\begin{tabular}{|lrrrrr|}
\hline Model & NPAR & CMIN & DF & P & CMIN/DF \\
\hline Default model & 33 & 148.496 & 58 & 0 & 2.56 \\
Saturated model & 91 & 0 & 0 & & \\
Independence model & 13 & 1030.024 & 78 & 0 & 13.205 \\
\hline
\end{tabular}

Root Mean Square Residual (RMR)

\begin{tabular}{|lrrrr|}
\hline Model & RMR & GFI & AGFI & PGFI \\
\hline Default model & 0.151 & 0.896 & 0.836 & 0.571 \\
Saturated model & 0 & 1 & & \\
Independence model & 0.635 & 0.396 & 0.295 & 0.339 \\
\hline
\end{tabular}

Standardized RMR value $=.075$

Baseline Comparisons

\begin{tabular}{|lrrrrr|}
\hline Model & NFI & RFI & IFI & TLI & CFI \\
\hline Default model & 0.856 & 0.806 & 0.907 & 0.872 & 0.905 \\
Saturated model & 1 & & 1 & & 1 \\
Independence model & 0 & 0 & 0 & 0 & 0 \\
\hline
\end{tabular}

Parsimony-Adjusted Measures

\begin{tabular}{|lrrr|}
\hline Model & PRATIO & PNFI & PCFI \\
\hline Default model & 0.744 & 0.636 & 0.673 \\
Saturated model & 0 & 0 & 0 \\
Independence model & 1 & 0 & 0 \\
\hline
\end{tabular}

Root Mean Square of Approximation (RMSEA)

\begin{tabular}{|lrrrr|}
\hline Model & RMSEA & LO 90 & HI 90 & PCLOSE \\
\hline Default model & 0.088 & 0.071 & 0.106 & 0 \\
Independence model & 0.247 & 0.234 & 0.261 & 0 \\
\hline
\end{tabular}


Table 13: Principal component matrix for CFQ items rotated to the varimax criteria (all subjects).

\begin{tabular}{|c|c|c|c|c|}
\hline Variable & $\begin{array}{l}\text { Factor 1: } \\
\text { Supportive/lnst } \\
\text { ructive }\end{array}$ & $\begin{array}{l}\text { Factor 2: } \\
\text { Negative }\end{array}$ & $\begin{array}{c}\text { Factor 3: } \\
\text { No } \\
\text { response }\end{array}$ & $h^{2}$ \\
\hline Mistake-contingent Encouragement & .71 & -.32 & & .61 \\
\hline Mistake-contingent Encouragement & .68 & & & .54 \\
\hline Reinforcement & .68 & & & .48 \\
\hline Technical Instruction with Reinforcement & .66 & & -.36 & .56 \\
\hline Technical Instruction with Reinforcement & .65 & & & .47 \\
\hline Reinforcement & .59 & & & .41 \\
\hline Mistake-contingent Technical Instruction & .58 & & & .39 \\
\hline Punishment & & .83 & & .71 \\
\hline Punitive Mistake-Contingent Technical Instruction & & .82 & & .67 \\
\hline Punitive Mistake-Contingent Technical Instruction & & .77 & & .60 \\
\hline Punishment & & .77 & & .65 \\
\hline Mistake-contingent Technical Instruction & & .51 & & .27 \\
\hline Ignoring Mistakes & & & .78 & .61 \\
\hline Ignoring Mistakes & & & .78 & .60 \\
\hline Non-reinforcement & -.43 & & .61 & .57 \\
\hline Non-reinforcement & -.43 & & .52 & .49 \\
\hline Cronbach's $\alpha$ & 0.79 & 0.80 & 0.70 & \\
\hline variance & $26.5 \%$ & $17.1 \%$ & $10.2 \%$ & $53.8 \%$ \\
\hline items added to original 12 & \multicolumn{2}{|c|}{ items missing from original 12} & \multicolumn{2}{|c|}{ questions/behavior } \\
\hline Technical Instruction with Reinforcement & \multicolumn{2}{|c|}{$\begin{array}{c}\text { Organization, } \\
\text { General Encouragement } \\
\text { Keeping Control } \\
\text { General Communication } \\
\text { General Technical Instruction }\end{array}$} & \multicolumn{2}{|c|}{2} \\
\hline
\end{tabular}


Table 14: Pearson correlations between the mCBAS and the CFQ dimensions.

\begin{tabular}{|c|c|c|c|c|c|c|}
\hline & \multicolumn{3}{|c|}{ T1 mCBAS dimensions } & \multicolumn{3}{|c|}{ CFQ dimensions } \\
\hline & $\begin{array}{l}\text { F1: } \\
\text { Supportive } \\
\text { Instructive }\end{array}$ & $\begin{array}{l}\text { F2: } \\
\text { Game }\end{array}$ & $\begin{array}{c}\text { F3: } \\
\text { Negative }\end{array}$ & $\begin{array}{l}\text { F1: } \\
\text { Supportive/ } \\
\text { Instructive }\end{array}$ & $\begin{array}{c}\text { F2: } \\
\text { Negative }\end{array}$ & $\begin{array}{c}\text { F3: } \\
\text { No } \\
\text { Response }\end{array}$ \\
\hline \multicolumn{7}{|l|}{$\frac{\mathrm{T} 1 \mathrm{mCBAS}}{\text { dimensions }}$} \\
\hline $\begin{array}{l}\text { F1: Supportive/ } \\
\text { Instructive }\end{array}$ & 1 & & & & & \\
\hline F2: Game & $.46^{\star \star}$ & 1 & & & & \\
\hline F3: Negative & $-.35^{\star \star}$ & $-.44^{* *}$ & 1 & & & \\
\hline \multicolumn{7}{|l|}{$\underline{\mathrm{CFQ} \text { dimensions }}$} \\
\hline $\begin{array}{c}\text { F1: Supportive/ } \\
\text { Instructive }\end{array}$ & $.55^{\star *}$ & $.46^{\star *}$ & $-.28^{\star \star}$ & 1 & & \\
\hline F2: Negative & $-.25^{\star *}$ & $-.37^{\star *}$ & $.50^{\star *}$ & -0.09 & 1 & \\
\hline F3: No Response & $-.37^{\star \star}$ & $-.26^{\star \star}$ & $.48^{* *}$ & $-.25^{\star *}$ & $.24^{\star \star}$ & 1 \\
\hline
\end{tabular}


Modifications to the CBAS 98

Table 15: Means and standard deviations of T1 mCBAS behaviours (all subjects, genders separate).

\begin{tabular}{|c|c|c|c|}
\hline & \multicolumn{3}{|c|}{ Means (SD) } \\
\hline & all subjects & females & males \\
\hline T1 mCBAS dimensions & $(N=265)$ & $(N=144)$ & $(N=121)$ \\
\hline Supportive/Instructive at T1 & $5.23(.94)$ & $5.39(.89)^{* *}$ & $5.04(.96)^{\star *}$ \\
\hline Game at $\mathrm{T} 1$ & $4.18(1.24)$ & $4.07(1.28)$ & $4.30(1.18)$ \\
\hline Negative at $\mathrm{T} 1$ & $3.36(.93)$ & $3.24(.91)^{*}$ & $3.52(.94)^{*}$ \\
\hline T2 mCBAS dimensions & $(N=202)$ & $(N=110)$ & $(N=92)$ \\
\hline Supportive/Instructive at T2 & $5.31(.95)$ & $5.45(.87)^{\star}$ & $5.16(1.02)^{*}$ \\
\hline Game at T2 & $4.32(1.14)$ & $4.35(1.08)$ & $4.26(1.21)$ \\
\hline Negative at T2 & $3.44(1.00)$ & $3.22(.94)^{\star *}$ & $3.70(1.00)^{\star *}$ \\
\hline$\underline{\text { Self-Concept Dimensions }}$ & $(N=201)$ & $(N=110)$ & $(N=91)$ \\
\hline Global Self-esteem & $5.23(0.72)$ & $5.23(0.71)$ & $5.24(0.75)$ \\
\hline Global Physical Self-Concept & $5.04(0.90)$ & $5.01(0.87)$ & $5.08(0.94)$ \\
\hline Sport Competence & $4.99(0.55)$ & $5.06(0.44)$ & $4.91(0.65)$ \\
\hline
\end{tabular}

${ }^{*} \mathrm{p}<.05 ;{ }^{* *} \mathrm{p}<.01$. 
Table 16: ANOVA summary for T1 and T2 mCBAS and Self-Concept dimensions comparing gender.

Variable

T1 Coaching dimensions :

F1: Supportive/Instructive

F2: Game

F3: Negative

between groups
within groups
Total
between groups
within groups
Total

between groups within groups

Total

$\begin{array}{rrrrr}8.03 & 1 & 8.03 & 9.44 & 0.02 \\ 223.71 & 263 & .85 & & \\ 231.74 & 264 & & & \end{array}$

3.53
402.32

405.85

1
263
264

5.29

222.77

228.06

3.53

2.31

0.13

1.53

5.29

.85

6.25

0.01

263

264

T2 Coaching behaviours :

F1: Supportive/Instructive

between groups within groups

Total

4.15

175.97

180.12

$\begin{array}{r}1 \\ 200 \\ 201 \\ \hline\end{array}$

between groups

within groups

Total

.42
261.70

200

201

F3: Negative

between groups

within groups

Total

12.10

188.44

200.55

200

12.10

.94
-94

201

\subsection{5}

.88

4.72

0.03

42

0.32

0.57

1.31

Self-concept dimensions

Self-esteem

between groups

within groups

Total

1.08

59.47

60.55

199

199

200

between groups

within groups

Total

162.9

162.92

1

199

200

between groups

within groups

Total

$$
104.95
$$$$
104.95
$$

104.96

\begin{tabular}{lll}
1.08 & 3.62 & 0.06 \\
.30 & & \\
& & \\
.21 & 0.61 & 0.61 \\
.82 & & \\
.02 & 0.86 & 0.86 \\
.53 & & \\
\hline
\end{tabular}


Modifications to the CBAS 100

Table 17: Principal component matrix of mCBAS results at $\mathrm{T} 1$ rotated to the varimax criteria for female subjects only.

\begin{tabular}{|c|c|c|c|c|}
\hline Variable & $\mathrm{F} 1$ & $\mathrm{~F} 2$ & F3 & $h^{2}$ \\
\hline Mistake-contingent Technical Instruction & .76 & & & .58 \\
\hline Technical Instruction with Reinforcement & .76 & & & .60 \\
\hline General Encouragement & .69 & & & .54 \\
\hline Reinforcement & .58 & & -.42 & .58 \\
\hline General Technical Instruction & .58 & & & .36 \\
\hline General Communication & .54 & & & .35 \\
\hline Nurturing & .54 & & & .38 \\
\hline Ignoring Mistakes & -.36 & & .32 & \\
\hline Emotional Sideline Behaviour towards Players & & -.82 & & .73 \\
\hline Composed Game Behaviour & & .81 & & .71 \\
\hline Emotional Sideline Behaviour towards Officials & & -.70 & & .53 \\
\hline Mistake-contingent Encouragement & .41 & .53 & & .54 \\
\hline Punitive Mistake-Contingent Technical Instruction & & & .70 & .58 \\
\hline Non-reinforcement & -.33 & & .55 & .41 \\
\hline Positive Skill Clues & & & .55 & .34 \\
\hline Keeping Control & & & .54 & .30 \\
\hline Punishment & & -.40 & .54 & .48 \\
\hline Equal Playing Time & & & -.52 & .29 \\
\hline Negative Skill Clues & & & .44 & \\
\hline Cronbach's $\alpha$ & 0.79 & 0.78 & 0.64 & \\
\hline$\%$ variance & $26.1 \%$ & $10.9 \%$ & $9.0 \%$ & $46.1 \%$ \\
\hline
\end{tabular}

items added to original 12

Technical Instruction with Reinforcement

Equal Playing Time

Positive Skill Clues

Negative Skill Clues

Emotional Game Behaviour towards Players

Emotional Sideline Behaviour towards Officials

Composed Game Behaviour Nurturing items missing from original 12

Organization questions/behavior

1 
Table 18: Principal component matrix of $\mathrm{mCBAS}$ results at $\mathrm{T} 1$ rotated to the varimax criteria for males subjects only.

\begin{tabular}{|c|c|c|c|c|}
\hline Variable & $\mathrm{F} 1$ & $\mathrm{~F} 2$ & F3 & $h^{2}$ \\
\hline Emotional Sideline Behaviour towards Officials & .75 & & & .64 \\
\hline Punitive Mistake-Contingent Technical Instruction & .72 & & & .55 \\
\hline Emotional Sideline Behaviour towards Players & .69 & & & .50 \\
\hline Composed Game Behaviour & -.69 & & & .56 \\
\hline Negative Skill Clues & .61 & & -.33 & .49 \\
\hline Equal Playing Time & -.56 & & & .37 \\
\hline Mistake-contingent Encouragement & -.56 & .51 & & .61 \\
\hline Non-reinforcement & .52 & -.41 & & .56 \\
\hline General Encouragement & & .74 & & .60 \\
\hline General Communication & & .68 & .34 & .59 \\
\hline Reinforcement & & .61 & & .52 \\
\hline Punishment & .48 & -.52 & & .51 \\
\hline Positive Skill Clues & & .45 & & .21 \\
\hline Nurturing & -.33 & .38 & .37 & .39 \\
\hline Technical Instruction with Reinforcement & & .40 & .73 & .70 \\
\hline Keeping Control & & & .72 & .55 \\
\hline General Technical Instruction & -.33 & & .67 & .64 \\
\hline Mistake-contingent Technical Instruction & -.40 & & .61 & .54 \\
\hline Ignoring Mistakes & & & -.33 & .17 \\
\hline Cronbach's $\alpha$ & 0.84 & 0.76 & 0.73 & \\
\hline$\%$ variance & $31.9 \%$ & $9.7 \%$ & $8.8 \%$ & $50.4 \%$ \\
\hline items added to original 12 & items missing from original 12 & \multicolumn{3}{|c|}{ questions/behavior } \\
\hline $\begin{array}{c}\text { Technical Instruction with Reinforcement } \\
\text { Equal Playing Time } \\
\text { Positive Skill Clues } \\
\text { Negative Skill Clues } \\
\text { Emotional Game Behaviour towards Players } \\
\text { Emotional Sideline Behaviour towards Officials } \\
\text { Composed Game Behaviour } \\
\text { Nurturing }\end{array}$ & & & 1 & \\
\hline
\end{tabular}


Modifications to the CBAS 102

Table 19: Principal component matrix of mCBAS results at T2 rotated to the varimax criteria for female subjects only.

\begin{tabular}{|c|c|c|c|c|}
\hline Variable & $\mathrm{F} 1$ & F2 & F3 & $h^{2}$ \\
\hline Mistake-contingent Technical Instruction & .74 & & & .60 \\
\hline Technical Instruction with Reinforcement & .70 & & & .58 \\
\hline General Encouragement & .69 & .33 & & .58 \\
\hline General Technical Instruction & .69 & & & .49 \\
\hline Reinforcement & .66 & .48 & & .70 \\
\hline Non-reinforcement & -.63 & -.32 & & .58 \\
\hline General Communication & .55 & & & .39 \\
\hline Ignoring Mistakes & -48 & & & .34 \\
\hline Equal Playing Time & .38 & & & .20 \\
\hline KeepingControl & .34 & -.33 & & .29 \\
\hline Composed Game Behaviour & & .78 & & .65 \\
\hline Emotional Sideline Behaviour towards Officials & & -.76 & & .62 \\
\hline Emotional Sideline Behaviour towards Players & & -.73 & & .73 \\
\hline Nurturing & .46 & .57 & & .54 \\
\hline Mistake-contingent Encouragement & .41 & .49 & & .42 \\
\hline Punitive Mistake-Contingent Technical Instruction & & & .81 & .70 \\
\hline Negative Skill Clues & & & .76 & .60 \\
\hline Punishment & & & .66 & .55 \\
\hline Positive Skill Clues & & & .53 & .29 \\
\hline Cronbach's $\alpha$ & 0.84 & 0.76 & 0.69 & \\
\hline$\%$ variance & $30.0 \%$ & $12.5 \%$ & $9.4 \%$ & $51.8 \%$ \\
\hline items added to original 12 & $\underline{\text { items missing from }}$ & \multicolumn{3}{|c|}{ questions/behavior } \\
\hline $\begin{array}{c}\text { Technical Instruction with Reinforcement } \\
\text { Equal Playing Time } \\
\text { Positive Skill Clues } \\
\text { Negative Skill Clues } \\
\text { Emotional Game Behaviour towards Players } \\
\text { Emotional Sideline Behaviour towards Officials } \\
\text { Composed Game Behaviour } \\
\text { Nurturing }\end{array}$ & Organization & \multicolumn{3}{|c|}{1} \\
\hline
\end{tabular}


Table 20: Principal component matrix of mCBAS results at T2 rotated to the varimax criteria for males subjects only.

\begin{tabular}{|c|c|c|c|c|}
\hline Variable & F1 & F2 & F3 & $h^{2}$ \\
\hline Technical Instruction with Reinforcement & .76 & & & .58 \\
\hline General Communication & .75 & & & .70 \\
\hline General Technical Instruction & .69 & & & .52 \\
\hline Reinforcement & .67 & & & .55 \\
\hline General Encouragement & .67 & & & .49 \\
\hline Nurturing & .63 & -.35 & & .52 \\
\hline Mistake-contingent Technical Instruction & .62 & & & .57 \\
\hline Equal Playing Time & .51 & & & .37 \\
\hline Positive Skill Clues & .50 & .33 & & .39 \\
\hline Keeping Control & .48 & .41 & & .46 \\
\hline Emotional Sideline Behaviour towards Officials & & .78 & & .64 \\
\hline Emotional Sideline Behaviour towards Players & & .76 & & .62 \\
\hline Composed Game Behaviour & .44 & -.66 & & .68 \\
\hline Punishment & & .60 & .56 & .69 \\
\hline Mistake-contingent Encouragement & .47 & -.49 & & .50 \\
\hline Negative Skill Clues & & & .73 & .57 \\
\hline Ignoring Mistakes & & & .66 & .44 \\
\hline Punitive Mistake-Contingent Technical Instruction & & .33 & .65 & .55 \\
\hline Non-reinforcement & -.48 & & .57 & .62 \\
\hline Cronbach's $\alpha$ & 0.84 & 0.78 & 0.67 & \\
\hline$\%$ variance & $32.7 \%$ & $13.5 \%$ & $8.7 \%$ & $54.9 \%$ \\
\hline items added to original 12 & \multicolumn{2}{|c|}{ items missing from original 12} & \multicolumn{2}{|c|}{ questions/behavior } \\
\hline $\begin{array}{c}\text { Technical Instruction with Reinforcement } \\
\text { Equal Playing Time } \\
\text { Positive Skill Clues } \\
\text { Negative Skill Clues } \\
\text { Emotional Game Behaviour towards Players } \\
\text { Emotional Sideline Behaviour towards Officials } \\
\text { Composed Game Behaviour } \\
\text { Nurturing }\end{array}$ & Organization & & \multicolumn{2}{|l|}{1} \\
\hline
\end{tabular}


Modifications to the CBAS 104

Table 21: Pearson correlations between the $\mathrm{T} 1$ and $\mathrm{T}_{2}{ }^{\dagger}$ mCBAS dimensions for female subjects.

\begin{tabular}{|c|c|c|c|c|c|c|}
\hline & \multicolumn{3}{|c|}{ T1 mCBAS dimensions } & \multicolumn{3}{|c|}{$\underline{\text { T2 mCBAS dimensions }}^{\dagger}$} \\
\hline & $\begin{array}{c}\text { F1: } \\
\text { Supportiv } \\
\text { e } \\
\text { Instructiv } \\
\text { e }\end{array}$ & $\begin{array}{l}\text { F2: } \\
\text { Game }\end{array}$ & $\begin{array}{c}\text { F3: } \\
\text { Negativ } \\
\text { e }\end{array}$ & $\begin{array}{c}\text { F1: } \\
\text { Supportiv } \\
\text { e/ } \\
\text { Instructive }\end{array}$ & $\begin{array}{l}\text { F2: } \\
\text { Game }\end{array}$ & $\begin{array}{c}\text { F3: } \\
\text { Negative }\end{array}$ \\
\hline \multicolumn{7}{|l|}{$\frac{\mathrm{T} 1 \mathrm{mCBAS}}{\underline{\text { dimensions }}}$} \\
\hline $\begin{array}{l}\text { F1: Supportive/ } \\
\text { Instructive }\end{array}$ & 1 & & & & & \\
\hline F2: Game & $.43^{\star \star}$ & 1 & & & & \\
\hline F3: Negative & $-.31^{\star *}$ & $-.42^{\star \star}$ & 1 & & & \\
\hline \multicolumn{7}{|l|}{${\frac{\mathrm{T} 2 \mathrm{mCBAS}}{\text { dimensions }^{\dagger}}}^{\dagger}$} \\
\hline $\begin{array}{l}\text { F1: Supportive/ } \\
\text { Instructive }\end{array}$ & $.79^{\star \star}$ & $.39^{\star *}$ & $-.38^{\star *}$ & 1 & & \\
\hline F2: Game & $.44^{* *}$ & $.71^{* *}$ & $-.40^{\star \star}$ & $-.43^{\star \star}$ & 1 & \\
\hline F3: Negative & $-.23^{*}$ & $-.34^{* *}$ & $.64^{* *}$ & $-.36^{* *}$ & $.48^{* *}$ & 1 \\
\hline
\end{tabular}

${ }^{*} p,<0.05 ;{ }^{* *} p<0.01$

${ }^{\dagger}$ Note: Coaching Behaviour dimensions utilized the T2 data for behaviours grouped by the T1 principal components analysis dimensions. 
Modifications to the CBAS 105

Table 22: Pearson correlations between the $\mathrm{T} 1$ and $\mathrm{T}^{\dagger}{ }^{\dagger}$ mCBAS dimensions for male subjects.

\begin{tabular}{|c|c|c|c|c|c|c|}
\hline & \multicolumn{3}{|c|}{ T1 mCBAS dimensions } & \multicolumn{3}{|c|}{$\underline{\text { T2 mCBAS dimensions }}^{\dagger}$} \\
\hline & $\begin{array}{c}\text { F1: } \\
\text { Supportiv } \\
\text { e } \\
\text { Instructiv } \\
\text { e }\end{array}$ & $\begin{array}{l}\text { F2: } \\
\text { Game }\end{array}$ & $\begin{array}{l}\text { F3: } \\
\text { Negativ } \\
\text { e }\end{array}$ & $\begin{array}{c}\text { F1: } \\
\text { Supportiv } \\
\text { e/ } \\
\text { Instructive }\end{array}$ & $\begin{array}{l}\text { F2: } \\
\text { Game }\end{array}$ & $\begin{array}{c}\text { F3: } \\
\text { Negative }\end{array}$ \\
\hline \multicolumn{7}{|l|}{$\frac{\text { T1 mCBAS }}{\underline{\text { dimensions }}}$} \\
\hline $\begin{array}{l}\text { F1: Supportive/ } \\
\text { Instructive }\end{array}$ & 1 & & & & & \\
\hline F2: Game & $.55^{\star \star}$ & 1 & & & & \\
\hline F3: Negative & $-.36^{* *}$ & $-.51^{* *}$ & 1 & & & \\
\hline \multicolumn{7}{|l|}{$\frac{\mathrm{T} 2 \mathrm{mCBAS}}{\underline{\text { dimensions }}^{\dagger}}$} \\
\hline $\begin{array}{l}\mathrm{F} 1: \text { Supportive/ } \\
\text { Instructive }\end{array}$ & $.70^{\star *}$ & $.53^{* *}$ & $-.38^{\star \star}$ & 1 & & \\
\hline F2: Game & $.55^{\star \star}$ & $.82^{* *}$ & $-.39^{\star *}$ & $-.54^{* *}$ & 1 & \\
\hline F3: Negative & $-.45^{*}$ & $-.58^{* *}$ & $.65^{* *}$ & $-.39^{* *}$ & $.56^{\star *}$ & 1 \\
\hline
\end{tabular}

† Note: Coaching Behaviour dimensions utilized the T2 data for behaviours grouped by the T1 principal components analysis dimensions. 
Table 23: Pearson correlations between the original CBAS, the CFQ and the mCBAS dimensions.

\begin{tabular}{|c|c|c|c|}
\hline & \multicolumn{3}{|c|}{ Self-Concept (T2) } \\
\hline & $\begin{array}{l}\text { Global Self- } \\
\text { concept }\end{array}$ & $\begin{array}{c}\text { Global } \\
\text { Physical Self- } \\
\text { concept }\end{array}$ & $\begin{array}{c}\text { Sport } \\
\text { Competence }\end{array}$ \\
\hline \multicolumn{4}{|l|}{ original CBAS dimensions (T2): } \\
\hline F1: Supportive/Structuring & $.19^{\star \star}$ & $.27^{\star *}$ & .13 \\
\hline F2: Aversive & $-.22^{\star \star}$ & -.14 & .01 \\
\hline F3: Response to Mistakes & -.04 & .10 & -.02 \\
\hline \multicolumn{4}{|l|}{ CFQ dimensions (T1): } \\
\hline F1: Positive Feedback & $.22^{\star \star}$ & $.24^{\star *}$ & $.21^{\star *}$ \\
\hline F2: Punishment & -.07 & -.01 & .11 \\
\hline $\begin{array}{r}\text { F3: Non-reinforcement/lgnoring } \\
\text { Mistakes }\end{array}$ & $-.25^{\star \star}$ & $-.20^{\star \star}$ & $-.15^{*}$ \\
\hline \multicolumn{4}{|l|}{ mCBAS dimensions (T2): } \\
\hline F1: Supportive/Instructive & $.23^{\star \star}$ & $.27^{\star *}$ & $.18^{* *}$ \\
\hline F2: Game & $.17^{* *}$ & $.21^{* *}$ & .05 \\
\hline F2:Negative & $-.22^{\star \star}$ & -.12 & .00 \\
\hline
\end{tabular}


References

Allen, J. B., and Howe, B. L. (1998). Player Ability, Coach Feedback, and Female Adolescent Athletes' Perceived Competence and Satisfaction. Journal of Sport \& Exercise Psychology, 20, 280-299.

Amorose, A. J., and Horn, T. S. (2000). Intrinsic Motivation: Relationships With Collegiate Athletes' Gender, Scholarship Status, and Perceptions of Their Coaches' Behaviour. Journal of Sport \& Exercise Psyhchology, 22, 63-84.

Baker, J., Cote, J., \& Hawes, R. (2000). The Relationship Between Coaching Behaviours and Sport Anxiety in Athletes. Journal of Science and Medicine in Sport, 3 (2), 110-119.

Bell, C. C. (1996). Promotion of mental health through coaching competitive sports. Journal of the National Medical Association, 89(8), 517-520.

Black, S. J., \& Weiss, M. R. (1992). The relationship among perceived coaching behaviors , perceptions of ability, and motivation in competitive agegroup swimmers. Journal of sport \& Exercise psychology, 14, 309-325.

Bowker, A., Gadbois, S., \& Cornock, B. (2003). Sports participation and SelfEsteem: Variations as a function of gender and gender orientations. Sex Roles, Vol 49, Nos. 1/2, 47-58.

Bryne, B, M. (2001). Structural Equation Modeling with AMOS: Basic Concepts, Applications, and Programming. Lawrence Erlbaum Associates, Publishers. Mahwah, New Jersey. 
Modifications to the CBAS 108

Chelladurai, P. (1990). Leadership in Sports: A Review. International Journal of Sport Psychology, 21, 328-354.

Chelladurai, P., and Reimer, H. A. (1998). Measurement of Leadership in Sport. In J. L. Duda, Ed.), Advances in Sport and Exercise Psychology Measurement (pp 227-253). Morgantown, WV: Fitness Information Technology, Inc.

Cohen, R. J., and Swerdlik, M. E. (1988). Psychological Testing and Assessment - An Introduction to Tests and Measurement. Mayfield Publishing Company, Mountain View, California.

Coopersmith, S. (1967). The Antecedents of Self-esteem. San Francisco: W. Health. Freeman.

D' Alessio, T. F. (1991). The relationship between high school football coaches' behavior and athletes' perceived self-esteem. Dissertation Abstracts International, $52(12-A), 4260$.

Deci, E. L., \& Ryan, R. M. (1985). Intrinsic Motivation and Self-Determination in Human Behaviour. New York: Plenum Press.

Delaney, W. \& Lee, C. (1995). Self-esteem and Sex Roles Among Male and Female High School Students: Their Relationship to Physical Activity. Australian Psychologist, 30 (2), 84-87.

Dishman, R. K. (1988). Exercise adherence; Its impact on public health. Champaign, IL: Human Kinetics Books.

Feltz, D. (1978). Athletics in the status system of female adolescents. Review of 
Sport and Leisure, 3, 98-108.

Fox, K. R., \& Corbin, C. B. (1989). The Physical Self-Perception Profile:

Development and Preliminary Validations. Journal of Sport and Exercise Psychology, 11, 408-430.

Frederick, C. M., \& Ryan, R. M. (1993). Differences in Motivation for Sport and Exercise and Their Relations with Participation and Mental Health. Journal of Sport Behaviour, 16, 124-145.

Harter, S. (1987). Causes, correlates and the functional role of global self-worth: A life-span perspective. J. Kolligian and R. Sternberg (Eds.). In Perceptions of Competence and Incompetence Across the Life-Span. New Haven, Ct.: Yale University Press.

Harter, S. (1999). The construction of the self: a developmental perspective. New York: Guilford Press.

Horn, T. S. (1985). Coaches Feedback and Changes in Children's Perceptions of Their Physical Competence. Journal of Educational Psychology, 77, 174-186.

Horn, T. S. (2002). Coaching Effectiveness In the Sport Domain. In T. S. Horn (Ed.), Advances in Sport Psychology, (pp 309-354). Champaign, IL: Human Kinetics.

Hayton, J. C., Allen, D. G., and Scarpello, V. (2004). Factor Retention Decisions in Exploratory Factor Analysis: A tutorial on Parallel Analysis. Organizational Research Methods, Vol. 7 No. 2, pp 191-205. 
Modifications to the CBAS 110

Hunter, L., Grenier, S., \& Brink, S. (2001). The Daily. National Longitudinal Survey of Children and Youth: Participation in activities. Retrieved May 30, 2001, from Human Resources Development Canada and Statistics Canada. <http://www.statcan.ca/start.html>. () Minister of Industry, 2000.

Kaiser, H. F. (1960). The application of electronic computers to factor analysis. Educational and Psychological Measurement, 20, 141-151.

Kenow, L. J., \& Williams, J. M. (1992). Relationship between anxiety, selfconfidence, and evaluation of coaching behaviors. Sport Psychologist, 6(4), 344-357.

Kenow, L. J., \& Williams, J. M. (1999). Coach-athlete compatibility and athlete's perception of coaching behaviors. Journal of Sport Behavior, 22(2), 251-259.

Kleiber, D. A., \& Kirshnit, C. E. (1991). Sport involvement and identity formation. In L. Diamant (Ed), Mind-body maturity: Psychological approaches to sports, exercise, and fitness (pp. 193-211). New York, NY: Hemisphere Publishing Corp.

Koivula, N. (1999). Sport participation: Differences in motivation and actual participation due to gender typing. Journal of Sport Behaviour, 22 (3), $360-381$.

Marsh, H. W. (1997). The Measurement of Physical Self-Concept: A Construct Validation Approach. In K. R. Fox (Ed.), The Physical Self: From Motivation to Well-Being. Champaign, IL.: Human Kinetics. 
Marsh, H. W. (1998). Age and gender effects in physical self-concepts for adolescent elite athletes and nonathletes: A multi cohort multi occasion design. Journal of Sport and Exercise Psychology, 20, 237-259.

Marsh, H. W., Jackson, S. A. (1986). Multidimensional Self-Concepts, Masculinity and Femininity as a function of Women's Involvement in Athletes. Sex Roles, 15, 391-415.

Marsh, H. W., Perry, C., Horsely, L., \& Roche, L. (1995). Multidimensional Selfconcept of Elite Athletes: How Do They Differ From the General Population. Journal of Sport and Exercise Psychology, 17, 70-83.

Marsh, H. W., Richards, G. E., Johnson, S., Roche, L., \& Tremayne, P. (1994). Physical Self-Description Questionnaire: Psychometric Properties and a Multitrait-Multimethod Analysis of Relations to existing Instruments. Journal of Sport \& Exercise Psychology, 16, 270-305.

Marsh, H. W., \& Shavelson, R. (1985). Self-Concept: Its Multifaceted, Hierarchical Structure. Educational Psychologist, 20, 107-123.

Martens, R. (1987). Coaches guide to sport psychology. Champaign, IL: Human Kinetics.

Martens, R., \& Gould, D. (1979). Why do adults volunteer to coach children's sport? In G. C. Roberts \& K. M. Newell (Eds.), Psychology of motor behaviour and sport (pp. 79-89). Champaign, IL: Human Kinetics.

Martin, J. E., \& Dubbert, P.M. (1982). Exercise applications and promotion in behavioural medicine: Current status and future directions. Journal of 
Modifications to the CBAS 112

Consulting and Clinical Psychology, 50, 1004-1017.

Millard, L. (1999). Differences in Coaching Behaviours of Male and Female High School Soccer Coaches. Journal of Sport Behaviour, Vol. 19, No. 1, 1931.

Miller, J. L., \& Levy, G. D. (1996). Gender role conflict, gender-typed characteristics, self concepts, and sport socialization in female athletes and nonathletes. Sex Roles, 35 (Nos. 1/2), 111-122.

Paffenberger, R. S., \& Hyde, R. T. (1988). Exercise adherence, coronary heart disease and longevity. In R. K. Dishman (Ed.), Exercise adherence: Its impact on public health (pp. 41-73). Champaign, IL: Human Kinetics.

Richman, E. L. \& Shaffer D. R. (2000). "If you let Mistake-contingent Encouragement play sports" How Might Sport Participation Influence the Self-Esteem of Adolescent Females? Psychology of Women Quarterly, 24, 189-199.

Rushall, B. S., and K. Wiznuk (2003). Athletes' Assessment of the Coach - The

Coach Evaluation Questionnaire. Canadian Journal of Applied Sport Sciences, 10, 157-161.

Ryan, R. M., Frederick, C.M., Lepes, D., Rubio, N. \& Sheldon, K. M. (1997). Intrinsic Motivation and Exercise Adherence. International Journal of Sport Psychology, 28, 335-354.

Scanlan, T. K. (1988). Social evaluation and the competition process: A developmental perspective. In F. L. Smoll, R. A. Matill, \& M. J. Ash 
(Eds.), Children in sport ( $3^{\text {rd }}$ ed.) pp. 135-148. Champaign, IL.: Human Kinetics.

Senkfor, A. J., \& Williams, J. M. (1995). The Moderating Effects of Aerobic Fitness and Mental Training on Stress Reactivity. Journal of Sport Behavior, 18, 130-154.

Shavelson, R. J., Hubner, J. J., \& Stanton, G. C. (1976). Self-concept:

Validation of Construct Interpretations. Review of Educational Research, 46(3), 407-441.

Singer, R.N. (1972). Coaching, athletics, and psychology. New York: McGrawHill.

Siscovick, D. S., LaPorte, R. E., \& Newman, J. M. (1985). The disease-specific benefits and risks of physical activity and exercise. Public Health Reports, 100, 180-188.

Smith, R. E., Smoll, F. L., \& Curtis. B. (1978). Coaching Behaviors in Little League Baseball. In F. L. Smoll \& R. E. Smith (Eds.), Psychological Perspectives in Youth Sports (pp. 173-201). Washington, DC.: Hemisphere.

Smith, R., and Smoll, F. (1990). Self-esteem and children's reactions to youth sport coaching behaviors: A field study of self-enhancement processes. Developmental Psychology, 26 (6), 987-993.

Smith, R. E., Smoll, F. L., and Hunt E. (1977). A System for the Behavioral Assessment of Athletic Coaches. Research Quarterly, Vol. 48, No. 2, 
401-407.

Smith, R. E., Smoll, F. L., Hunt, E., Curtis, B., and Coppel. D. B. (1978). Psychology and the Bad News Bears. In G. C. Roberts and K. M. Newell (Eds.), Psychology of Motor Behavior and Sport. (pp 109-130). Champaign, IL: Human Kinetics,.

Smith, R. E., Zane, N. W. S., Smoll, F. L., and Coppel, D. B. (1983). Behavioral assessment in youth sports: coaching behaviors and children's attitudes. Medicine and Science in Sports and Exercise, Vol 15, No. 3, 208-214.

Smith, S. L., Fry, M. D., Ethington, C. A., and Li, Y. (2005). The Effect of Female Athletes' Perceptions of their Coaches' Behaviours on Their Perceptions of the Motivational Climate. Journal of Applied Sport Psychology, 17, 170-177.

Smoll, F. L., \& Smith, R. E. (1989). Leadership behaviors in sport: A theoretical model and research paradigm. Journal of Applied Social Psychology, 19 (18), 1522-1551.

Smoll, F. L., Smith, R. E., Barnett, N. P., \& Everett, J. J. (1993). Enhancement of children's self-esteem through social support training for youth sport coaches. Journal of Applied Psychology, 78 (4), 602-610.

Soloman, G. B., DiMarco, A. M., Ohlson, C. J., Reece, S. D. (1998). Expectations and Coaching Experience: Is More Better? Journal of Sport Behaviour, Vol. 21, Issue 4, 444-456.

Statsoft, (2004). Principal Components Factor Analysis. Retrieved April 16, 
2004, from http://statsoftinc.com/textbook/stfacan.html .

Tabachnik, B., and Fidell, L. S. (2007). Using Multivariate Statistics (5th ed).

Boston: Pearson/Allyn \& Bacon..

Thompson, G., and Bowker, A. (2005). Perceived Coaching Behaviours and

Self-Esteem in Adolescent Soccer Players. Unpublished manuscript.

Wandzilak, T., Ansorge, C. J., \& Potter, G. (1988). Comparison between

selected practice and game behaviors of youth sport soccer coaches. Journal of Sport Behavior, 11 (2), 78-88.

Watkins, W. M. (2004). Monte Carlo PCA for Parallel Analysis. Retrieved January 17, 2007 from http://www.public.asu.edu/ mwwatkin/Watkins3.html.

Weinberg, R., Tenenbaum, G., McKenzie, A., Jackson, S., Anshel, M., Grove, R., \& Fogarty, G. (2000). Motivation for Youth Participation in Sport and Physical Activity: Relationships to Culture, Self-Reported Activity Levels, and Gender. International Journal of Sport Psychology, 31, 321-346.

Weiss, M. R. (1987). Self-esteem and achievement in Children's Sport and Physical Activity. In D. Gould \& M. R. Weiss (Eds.), Advances in Pediatric sport sciences, Vol 2: Behavioral Issues (pp 87-119). Champaign, IL: Human Kinetics.

Williams, J. M., Jerome, G. J., Kenow, L. J., Rogers, T., Sartain, T. A., and Darland, G. I. (2003). Factor Structure of the Coachng Behavior Questionnaire and Its Relationship to Athlete Variables. The Sport 
Psychologist, 17, 16-34. 
Appendix A.

Description of the CBAS behaviours.

Class 1 - Reactive behaviours

Desirable performance

1. Positive Reinforcement or reward is a positive, verbal or nonverbal, reaction to a good performance or action. It may be toward one or more players, and could be as simple as a pat on the back or congratulations for a play well done.

2. Non-reinforcement is simply no reaction or response to a positive performance or action.

Mistakes/Errors

3. Mistake-contingent Encouragement is the coach's encouragement of a player or players following a mistake or poor performance.

4. Mistake-contingent Technical Instruction is the giving of technical instruction following a mistake by one or more players. Corrective action for the specific mistake is required for this category.

5. Punishment is a negative verbal or nonverbal reaction by the coach towards a player(s) in response to poor performance or a mistake. This may be a sarcastic remark or a demonstration of disgust towards a player(s) after an error.

6. Punitive Mistake-contingent Technical Instruction is technical instruction following a mistake or poor performance along with a negative verbal or nonverbal reaction to a mistake by one or more players.

7. Ignoring Mistakes is no reaction to a mistake made by one or more players Misbehaviours

8. Keeping Control are actions or directions intended to maintain order when player conduct is considered unruly or inattentive.

Game related

\section{Class 2 - Spontaneous behaviours}

9. General Technical Instruction is instructional information intended to impart sport specific techniques or strategies and is not elicited by an immediately preceding mistake or poor performance

10. General Encouragement is supportive behaviour, either verbal or nonverbal, not immediately following a mistake or specific action by the player(s) and not involving specific technical instruction.

11. Organization is administrative in nature, not intended to influence play. immediately. Includes assigning positions, housekeeping required and announcing the next game or practice.

Game irrelevant

12. General Communication is non-game related communications with players. This includes joking around, conversations concerning issues not related to sports.

Coaching Behaviour Dimensions

The list of 12 individual behaviours is also divided into three groups by the underlying nature of the behaviour. These categories according to type are frequently differentiated from each other during factor analysis and despite their loose affiliation are consistently discussed as such throughout the research literature.

(a) Reinforcement/reward, Mistake-contingent Encouragement, Mistake-contingent Technical Instruction and occasionally General Encouragement are often referred to as the Supportive Coaching Behaviours.

(b) General Technical Instruction and Mistake-contingent Technical Instruction are referred to as the Instructive Coaching Behaviours.

(c) Punishment, Punitive Mistake-contingent Technical Instruction, and occasionally Non-reinforcement are referred to as the Negative Coaching Behaviours, Some 
Modifications to the CBAS

authors refer to punishment and Punitive Mistake-contingent Technical Instruction as criticism. 


\section{Appendix $B$. \\ Description of the mCBAS behaviours.}

1. Reinforcement or reward is a positive, verbal or nonverbal, reaction to a good performance or action. It may be toward one or more players, and could be as simple as a pat on the back or congratulations for a play well done.

2. Non-reinforcement is simply no reaction or response to a positive performance or action.

3. Mistake-contingent Encouragement is the coach's encouragement of a player or players following a mistake or poor performance.

4. Mistake-contingent Technical Instruction is the giving of technical instruction following a mistake by one or more players. Corrective action for the specific mistake is required for this category.

5. Punishment is a negative verbal or nonverbal reaction by the coach towards a player(s) in response to poor performance or a mistake. This may be a sarcastic remark or a demonstration of disgust towards a player(s) after an error.

6. Punitive Mistake-contingent Technical Instruction is technical instruction following a mistake or poor performance along with a negative verbal or nonverbal reaction to a mistake by one or more players.

7. Ignoring Mistakes is no reaction to a mistake made by one or more players

8. Keeping Control are actions or directions intended to maintain order when player conduct is considered unruly or inattentive.

9. General Technical Instruction is instructional information intended to impart sport specific techniques or strategies and is not elicited by an immediately preceding mistake or poor performance

10. General Encouragement is supportive behaviour, either verbal or nonverbal, not immediately following a mistake or specific action by the player(s) and not involving specific technical instruction.

11. Organization is administrative in nature, and is not intended to influence play immediately. It includes such things as assigning positions, housekeeping and announcing the next game or practice.

12. General Communication is non-game related communications with players. This includes joking around, conversations concerning issues not related to sports.

13. Technical Instruction with Reinforcement is the giving of technical instruction following a good performance or action with a positive, verbal or nonverbal reaction.

14. A coach may play certain players a lot less than other players. This is called Uneven Playing Time.

15. During a game, a coach may play certain players a lot more than other players. This is called Preferential Playing Time.

16. Equal Playing Time is whether the coach provides about the same amount of playing time for each player. It can be over the course of a single game or over the course of the whole season.

17. Over the course of a game and the season a coach may give Uneven Playing Time to the same players all the time. This is called Player Specific Uneven Playing Time.

18. Positive Skill Clues are verbal or nonverbal clues that allow the subject to conclude that he or she has a better skill level than the other players on the team.

19. Negative Skill Clues are verbal or nonverbal clues that allow the subject to conclude that he or she has a poorer skill level than the other players on the team.

20. Emotional Sideline Behaviour towards Players specifically refers to the frequency that the coach has emotional outburst towards the subject 's team mates during games. 
21. Emotional Sideline Behaviour towards Officials specifically refers to the frequency that the coach has emotional outburst towards game officials during games.

22. A coach who is calm and relaxed on the sidelines and has their emotions under control during games demonstrates Composed Sideline Behaviour.

23. A coach is Nurturing when interacting on a personal level with the players, demonstrating individual attention and caring for each player's feelings, problems and injuries.

24. When coaches interact well with their players and give each player individual attention, care about how the players feel, and are interested in the players as individuals, ask about injuries and problems, and listen to the responses. This is called Nurturing Behaviour.

25. The degree to which a player liked how she/he was treated was simply asked in the same terms. 


\section{Appendix C. \\ Modified Coaching Behaviour Assessment System. About your team head coach}

We want to know how well you remember what kinds of things your head coach does, and we want to know how often your head coach does theses things during practices and games. In answering the questions, think only about your team head coach.

1. The first thing is called reward. Coaches reward or praise athletes when they do something well or try really hard. Some coaches give a lot of reward while others do not. How often does your coach reward you for good plays or effort? Circle the number that indicates how often your coach rewards you.

7 - Almost always

6 - Very often

5 - Quite often

4- Sometimes

3 - Seldom

2 - Hardly ever

1 - Never

2. Nonreward is when a coach does not reward or praise an athlete after he/she makes a good play or tries hard. In other words, the coach ignores it. Circle the number that indicates how often your coach does not reward you when he/she should have.

7 - Almost always

6 - Very often

5 - Quite often

4 - Sometimes

3 - Seldom

2 - Hardly ever

1 - Never

3. Sometimes athletes screw-up and make mistakes. Some coaches give a lot of encouragement after mistakes. For example, he/she might say, "That's OK, don't worry about it. You'll get it next time." Other coaches don't give their athletes much encouragement after they make a mistake. Circle how often your coach gives you encouragement after mistakes.

7 - Almost always

6 - Very often

5 - Quite often

4 - Sometimes

3 - Seldom

2 - Hardly ever

1 - Never

4. Another thing a coach might do after a mistake is show or tell the athlete how to do it right. For example, a football coach might tell or show a player the right way to tackle after he misses the ball carrier. This is called corrective instruction. Circle how often your coach does this with you.

7 - Almost always

6 - Very often

5 - Quite often

4 - Sometimes

3 - Seldom 


\section{Modifications to the CBAS}

2 - Hardly ever

1 - Never

5. Punishment includes things like yelling at an athlete who has made a mistake.

Punishment is also saying or doing something that hurts an athlete's feelings, or embarrasses him/her. Circle how often your coach does this with you.

7 - Almost always

6 - Very often

5 - Quite often

4 - Sometimes

3 - Seldom

2 - Hardly ever

1 - Never

6. Sometimes a coach will show you how to correct a mistake, but in an unpleasant, punishing way. This is a combination of corrective instruction and punishment. For example, a basketball coach might angrily say, "Pass the ball, don't dribble so much, Dummy!" Circle how often your coach does this with you.

7 - Almost always

6 - Very often

5 - Quite often

4 - Sometimes

3 - Seldom

2 - Hardly ever

1 - Never

7. Sometimes when you make a mistake, coaches say or do nothing. They simply ignore mistakes. Circle how often your coach does this with you.

7 - Almost always

6 - Very often

5 - Quite often

4 - Sometimes

3 - Seldom

2 - Hardly ever

1 - Never

8. The next thing is called keeping control. Coaches do this when their athletes are misbehaving or not paying attention. For example, if athletes are fooling around, a coach might say, "Knock it off and pay attention." How often does your coach do that?

7 - Almost always

6 - Very often

5 - Quite often

4 - Sometimes

3 - Seldom

2 - Hardly ever

1 - Never

9. Some coaches do a lot of teaching. A coach might give instructions, not because a mistake has been made, but just to show athletes how to do things correctly. How often does your coach give you instructions?

7 - Almost always

6 - Very often 


\section{Modifications to the CBAS}

5 - Quite often

4 - Sometimes

3 - Seldom

2 - Hardly ever

1 - Never

10. Coaches don't only give encouragement after mistakes. They may do it any time, even when things are going well. For example, a coach may clap his/her hands and shout encouragement at any time during practices and games. How often did your coach give you encouragement?

7 - Almost always

6 - Very often

5 - Quite often

4 - Sometimes

3 - Seldom

2 - Hardly ever

1 - Never

11. Some coaches talk or joke with their athletes a lot. They might talk about school, professional sports, vacations, or about when they used to be an athlete. This is called general communication. Circle how often your coach does this with you.

7 - Almost always

6 - Very often

5 - Quite often

4 - Sometimes

3 - Seldom

2 - Hardly ever

1 - Never

12. Sometimes along with praise for a good play, a coach will repeat instructions that were given in practice that resulted in the good play. For example, after an athlete has made a good play using a move that was taught during practice the coach will say "That was a great play! You kept your head down and your body over the ball when you made that shot." How often does your coach give praise and repeat instructions from practice?

7 - Almost always

6 - Very often

5 - Quite often

4 - Sometimes

3 - Seldom

2 - Hardly ever

1 - Never

13 The next item is equal playing time. Think about the amount of playing time individual players get during a single game or over the course of the whole season. There are coaches who try to give the same amount of playing time to all players. It may not be equal over the course of one game, but over the whole season playing time is evened out so everyone gets about the same amount of playing time. Circle how often your coach tries to do this?

7 - Almost always

6 - Very often

5 - Quite often

4 - Sometimes

3 - Seldom 
2 - Hardly ever

1 - Never

14 The next item is positive skill level clues. Coaches may try to treat all players the same. But sometimes they slip up and give clues that your skill level is better than the other players. The clues could be something your coach has said or done, or it could be demonstrated by giving you more playing time than other players. How often does your coach give clues that the quality of your play is better than the other players.

7 - Almost always

6 - Very often

5 - Quite often

4 - Sometimes

3 - Seldom

2 - Hardly ever

1 - Never

15 The next item is negative skill level clues. Despite a coach best intentions there are times when they slip up and give clues that your skill level is worse than the other players. These clues could be something your coach has said or done, or it could be demonstrated by giving you less playing time than your team mates. How often does your coach give clues that the quality of your play is worse than the other players.

7 - Almost always

6 - Very often

5 - Quite often

4 - Sometimes

3 - Seldom

2 - Hardly ever

1 - Never

16. During games, coaches may have strong emotional outbursts when they are stressed out about how your team mates are playing during the game. They get too emotional and yell angrily at your team mates from the sidelines. How often does your coach have emotional outbursts towards players on your team during games.

7 - Almost always

6 - Very often

5 - Quite often

4 - Sometimes

3 - Seldom

2 - Hardly ever

1 - Never

17. During games, coaches may have strong emotional outbursts towards the referees when they are stressed out about things that are happening during the game. They get too emotional and yell angrily at the referee or assistant referees. How often does your coach have emotional outbursts towards the referees during games.

7 - Almost always

6 - Very often

5 - Quite often

4 - Sometimes

3 - Seldom 


\section{Modifications to the CBAS}

2 - Hardly ever

1 - Never

18. During games some coaches are calm and relaxed on the sidelines. Their emotions are under control. This is called a composed sideline presence. Circle the number corresponding to how often your coach is calm and relaxed during games?

7 - Almost always

6 - Very often

5 - Quite often

4 - Sometimes

3 - Seldom

2 - Hardly ever

1 - Never

19. Some coaches interact well with their players and give each player individual attention. They care about how the players feel, and are interested in the players as individuals. They ask about injuries and problems, and listen to the responses. They are concerned about the health and safety of each player. How often does your coach demonstrate this kind of behaviour with you?

7 - Almost always

6 - Very often

5 - Quite often

4 - Sometimes

3 - Seldom

2 - Hardly ever

1 - Never 


\section{Appendix D. \\ The Pilot Coaching Behaviour Assessment System. \\ About your team head coach}

We want to see how well you remember what kinds of things your head coach did. We also want to know how often your coach did things during practices and games. In answering the questions, think only about the actions of your team head coach.

1. The first thing is called Reward. Coaches reward or praise athletes when they do something well or try really hard. Some coaches give a lot of Reward while others do not. How often did your coach Reward you for good plays or effort? Circle the number that indicates how often your coach Rewarded you.

7 - Almost always

6 - Very often

5 - Quite often

4 - Sometimes

3 - Seldom

2 - Hardly ever

1 - Never

2. Nonreward is when a coach does not reward or praise an athlete after he/she makes a good play or tries hard. In other words, the coach ignores it. Circle the number that indicates how often your coach did not reward you when he/she should have.

7 - Almost always

6 - Very often

5 - Quite often

4 - Sometimes

3 - Seldom

2 - Hardly ever

1 - Never

3. Sometimes athletes screw-up and make mistakes. Some coaches give a lot of encouragement after mistakes. For example, he/she might say, "That's OK, don't worry about it. You'll get it next time." Other coaches don't give their athletes much encouragement after they make a mistake. Circle how often your coach gave you encouragement after mistakes.

7 - Almost always

6 - Very often

5 - Quite often

4 - Sometimes

3 - Seldom

2 - Hardly ever

1 - Never

4. Another thing a coach might do after a mistake is show or tell the athlete how to do it right. For example, a football coach might tell or show a player the right way to tackle after he misses the ball carrier. This is called corrective instruction. Circle how often your coach did this with you.

7 - Almost always

6 - Very often

5 - Quite often

4 - Sometimes

3 - Seldom 
2 - Hardly ever

1 - Never

5. Punishment includes things like yelling at an athlete who has made a mistake.

Punishment is also saying or doing something that hurts an athlete's feelings, or embarrasses him/her. Circle how often your coach did this with you.

7 - Almost always

6 - Very often

5 - Quite often

4 - Sometimes

3 - Seldom

2 - Hardly ever

1 - Never

6. Sometimes a coach will show you how to correct a mistake, but in an unpleasant, punishing way. This is a combination of corrective instruction and punishment. For example, a basketball coach might angrily say, "Pass the ball, don't dribble so much, Dummy!" Circle how often your coach did this with you.

7 - Almost always

6 - Very often

5 - Quite often

4 - Sometimes

3 - Seldom

2 - Hardly ever

1 - Never

7. Sometimes when you make a mistake, coaches say or do nothing. They simply ignore mistakes. Circle how often your coach did this with you.

7 - Almost always

6 - Very often

5 - Quite often

4 - Sometimes

3 - Seldom

2 - Hardly ever

1 - Never

8. The next thing is called keeping control. Coaches do this when their athletes are misbehaving or not paying attention. For example, if athletes are fooling around, a coach might say, "Knock it off and pay attention." How often did your coach do that?

7 - Almost always

6 - Very often

5 - Quite often

4 - Sometimes

3 - Seldom

2 - Hardly ever

1 - Never

9. Some coaches do a lot of teaching. A coach might give instructions, not because a mistake has been made, but just to show athletes how to do things correctly. How often did your coach give you instructions?

7 - Almost always 


\section{Modifications to the CBAS}

6 - Very often

5 - Quite often

4 - Sometimes

3 - Seldom

2 - Hardly ever

1 - Never

10. Coaches don't only give encouragement after mistakes. They may do it any time, even when things are going well. For example, a coach may clap his/her hands and shout encouragement at any time during practices and games. How often did your coach give you encouragement?

7 - Almost always

6 - Very often

5 - Quite often

4 - Sometimes

3 - Seldom

2 - Hardly ever

1 - Never

11. The next thing is called organization. This includes things like keeping practices running smoothly, making sure the equipment is in the right place, announcing substitutions -- in other words, keeping things organized. How often did your coach do things like that?

7 - Almost always

6 - Very often

5 - Quite often

4 - Sometimes

3 - Seldom

2 - Hardly ever

1 - Never

12. Some coaches talk or joke with their athletes a lot. They might talk about school, professional sports, vacations, or about when they used to be an athlete. This is called general communication. Circle how often your coach did this with you.

7 - Almost always

6 - Very often

5 - Quite often

4 - Sometimes

3 - Seldom

2 - Hardly ever

1 - Never

13. Sometimes along with praise for a good play, a coach will repeat instructions that were given in practice that resulted in the good play. For example, after an athlete has made a good play using a move that was taught during practice the coach will say "That was a great play! You kept your head down and your body over the ball when you made that shot." How often did your coach give praise and repeat instructions from practice?

7 - Almost always

6 - Very often

5 - Quite often

4 - Sometimes

3 - Seldom

2 - Hardly ever 
1 - Never

14. During a game, a coaches may play certain players a lot less than other players. This is called uneven playing time. How often does your coach give you a lot less playing time than other players?

7 - Almost always

6 - Very often

5 - Quite often

4 - Sometimes

3 - Seldom

2 - Hardly ever

1 - Never

15 During a game, a coaches may play certain players a lot more than other players. This is called preferential playing time. Circle how often your coach gave you a lot more playing time than other players?

7 - Almost always

6 - Very often

5 - Quite often

4 - Sometimes

3 - Seldom

2 - Hardly ever

1 - Never

16 The next item is equal playing time. Think about the amount of playing time individual players get during a single game or over the course of the whole season. There are coaches who try to give the same amount of playing time to all players. It may not be equal over the course of one game, but perhaps over the whole season playing time is evened out so everyone gets about the same amount of playing time. Circle how often does your coach tries to do this?

7 - Almost always

6 - Very often

5 - Quite often

4 - Sometimes

3 - Seldom

2 - Hardly ever

1 - Never

17. Over the course of a game and the season a coach may give uneven playing time to the same players all the time. This is called player specific uneven playing time. How much playing time does your coach give you in relation to your team mates?

7 - I play more than anyone else

6 - a few of us get more playing time than the others

5 - I get about the average amount of playing time

4 - a few of us get less playing time than the others

3 - I play less than everyone else

2 - I rarely or never play.

1 - everyone plays about the same amount of time

18 The next item is positive skill level clues. Coaches usually try to treat all players the same. But sometimes they slip up and give clues that your skill level is better than the other players. How often does your coach give skill level clues that the quality of your play is better 


\section{Modifications to the CBAS}

than the other players.

7 - Almost always

6 - Very often

5 - Quite often

4 - Sometimes

3 - Seldom

2 - Hardly ever

1 - Never

19 The next item is negative skill level clues. Despite a coach best intentions there are times when they slip up and give clues that your skill level is worse than the other players. How often does your coach give clues that the quality of your play is worse than the other players.

7 - Almost always

6 - Very often

5 - Quite often

4 - Sometimes

3 - Seldom

2 - Hardly ever

1 - Never

20 During games, coaches may have strong emotional outbursts when they are stressed out about what is going on during the game. They get too emotional angry and yell loudly from the sidelines. How often does your coach have emotional outbursts during games.

7 - Almost always

6 - Very often

5 - Quite often

4 - Sometimes

3 - Seldom

2 - Hardly ever

1 - Never

21 During games some coaches are calm and relaxed on the sidelines. Their emotions are under control. This is called a composed sideline presence. Circle the number corresponding to how often your coach is calm and relaxed during games?

7 - Almost always

6 - Very often

5 - Quite often

4 - Sometimes

3 - Seldom

2 - Hardly ever

1 - Never

22 Some coaches interact well with their players and give each player individual attention. They care about how the players feel, and are interested in the players as individuals. They ask about injuries and problems, and listen to the responses. They are concerned about the health and safety of each player. How often does your coach demonstrate this kind of behaviour with you?

7 - Almost always

6 - Very often

5 - Quite often

4 - Sometimes

3- Seldom 
2 - Hardly ever

1 - Never

$23 \quad$ l like the way my coach treats me.

7 - Almost always

6 - Very often

5 - Quite often

4 - Sometimes

3 - Seldom

2 - Hardly ever

1 - Never 


\section{Modifications to the CBAS}

\section{Appendix E.}

Coaching Feedback Questionnaire

Directions: Listed below are six examples of the feedback your high school coach might have given to you after you had a successful performance in a game or practice. Please rate each statement in terms of how typical it was of the kind of feedback your high school coach gave you after you had a successful performance.

1. "Good play!" Not at all Typical

2. Coach ignores your good performance or play.

$$
1
$$$$
2
$$$$
3
$$$$
4
$$

3. "Way to go! You really extended your elbow that time."1

23

4

4. "Great play. Now you're keeping your eyes on the ball.1

3

4

5

5. "Excellent work in practice today."

1

2

3

$4 \quad 5$

6. Coach doesn't say anything to you about your good performance or play.

2

$4 \quad 5$

Directions: Listed below are ten examples of the type of feedback your high school coach might have given you if you made a mistake or committed an error in a game or practice. Please rate each statement in terms of how typical it was of the kind of feedback your high school coach gave you after a performance error or poor play.

1. "That's O.K. Keep working at it!" Not at all Typical

1. "That's O.K. Keep working at it! 123

2. Coach ignores your error or poor performance.

3. "That was a really stupid play." 12

3

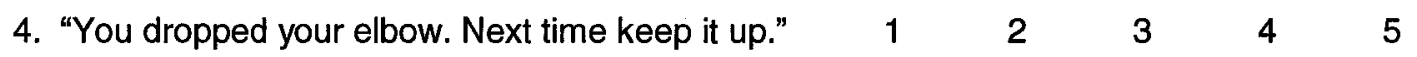

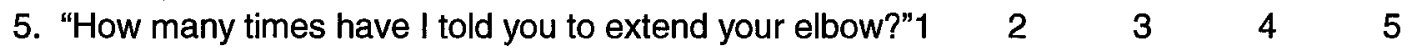

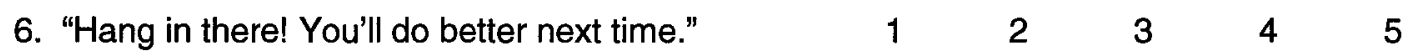

7. Coach doesn't say anything to you about your error or poor performance.

8. "Your technique looks lousy!" Keep your head up."

9. "That play sucked."

1

10. "No, that's not right, you need to work on a faster release."1

2

\section{2}

$\begin{array}{lll}3 & 4 & 5\end{array}$

2

$\begin{array}{lll}3 & 4 & 5 \\ 3 & 4 & 5\end{array}$

$3 \quad 4 \quad 5$




\section{Appendix F. \\ Physical Self Description Questionnaire}

Age

; Male or Female

This a chance to look at yourself. It is not a test. There are no right answers and everyone will have different answers. Be sure that your answers show how you feel about yourself. Please do not talk about your answers with anyone else. We will keep your answers private.

The purpose of this study is to see how people describe themselves physically. In the following pages you will be asked to think about yourself physically. For example, how good looking you are, how strong you are, how good you are to sports, whether you exercise regularly, whether you are physically coordinated, whether you get sick very often and so forth. Answer each sentence quickly as you feel now. Please do not leave any sentence blank.

When you are ready to begin, please read each sentence and decide your answer. There are six possible answers for each question - 'true', 'false', and four answers in between. There are six number net to next sentence, one for each of the answers. The answers are written at the top of the numbers. Choose your answer to a sentence and put a circle around the number under the answer you choose. DO NOT say you answer aloud or talk about it with anyone else.

Before you start there are three examples below. I have already answered two of the three sentences to show you now to do it. In the third one you must choose your own answer and circle it.

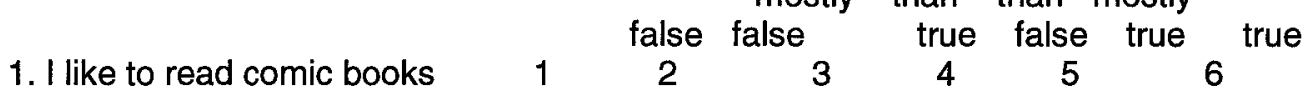

I put a circle around the number 6 under the answer 'true'. This means that I really like to read comic books. If I did not like tread comic books very much, I would have answered 1 ('false') or 2 (mostly false'))
2. In general, I am neat and tidy.
12
34
5
6

( I answered 'more false than true' because I am definitely not very neat, but I am not really messy either.)
3. I like to watch TV.
12
3
4
56

(For this sentence you have to choose the answer that is best for you. First you must decide if the sentence is 'true' or false' for you, or somewhere in between. If you really like to watch TV a lot, you would answer 'true' by putting a circle around the last number ' 6 '. If you hate watching TV you would answer 'false' by circling the first number ' 1 '. If you do not like TV very much, but you watch it sometimes, you might decide to circle '2' ('mostly false') or ' 3 ' ('more false than true').)

If you want to change an answer you have marked you should cross out the circle and put a new circle around another number on the same line. For all sentences be sure that your circle is on the same line as the sentence you are answering. You should have only one answer circled for each sentence. Do not leave out any sentences, even if you are not sure which number to circle. 


\section{Modifications to the CBAS}

If you have any questions please call me at 592-6267 or email your question to <gdthompson@igs.net>. Otherwise begin. 


more more
false true
mostly than than mostly
false false true false true true

1. Other people think I am good at sports.1

2

34

5

6

2. I am satisfied with the kind of person I am physically. 1

3. Overall, most things I do turn out well. 1

4. I am good at most sports.

12

5. Physically, I am happy with myself. 1

6. I don't have much to be proud of. 2

7. Most sports are easy for me. 1

2

3

2

34

5

6

8. I feel good about the way I look and what I can do physically.

2

34

5

6

9. I feel that my life is not very useful.

10. I have good sports skills.

11. Physically I fee good about myself.

12. Overall, l'm no good.

12

$3 \quad 4$

56

56

$\begin{array}{llll}3 & 4 & 5 & 6\end{array}$

13. I am better at sports than most of my friends.

$\begin{array}{llllll}1 & 2 & 3 & 4 & 5 & 6\end{array}$

14. I feel good about who I am and what I can do physically.

$\begin{array}{lllllll} & 1 & 2 & 3 & 4 & 5 & 6 \\ \begin{array}{l}\text { 15. Most things I do, I do well. } \\ \text { 16. I play sports well. }\end{array} & 1 & 2 & 3 & 4 & 5 & 6 \\ \text { 17. I feel food about who I am physically. } & 1 & 2 & 3 & 4 & 5 & 6\end{array}$

18. Overall, I have a lot to be proud of.

19. Overall, I'm a failure.

12

3

4

56

20. Nothing I do ever seems to turn out right.

$\begin{array}{llllll}1 & 2 & 3 & 4 & 5 & 6\end{array}$

21. I would do well in a test of physical endurance and stamina.

xix 


\section{Modifications to the CBAS}

$\begin{array}{lllllll} & 1 & 2 & 3 & 4 & 5 & 6 \\ \text { 22. I don't have much to be proud of. } & 1 & 2 & 3 & 4 & 5 & 6\end{array}$

23. I am sick so often that I cannot do all the things I want to do.

$$
\begin{array}{llllll}
1 & 2 & 3 & 4 & 5 & 6
\end{array}
$$

24. I am good at co-ordinated movements.

$\begin{array}{lllll}2 & 3 & 4 & 5 & 6\end{array}$

25. I get exercise or activity three or four times a week that makes me huff and puff and lasts at least 30 minutes.

$\begin{array}{llllll}1 & 2 & 3 & 4 & 5 & 6\end{array}$

26. I have too much fat on my body. $\quad \begin{array}{llllll}1 & 2 & 3 & 4 & 5\end{array}$

$\begin{array}{llllllll}\text { 27. Most sports are easy for me. } & 1 & 2 & 3 & 4 & 5 & 6\end{array}$

28. I feel good about the way I look and what I can do physically.

$\begin{array}{llllll}1 & 2 & 3 & 4 & 5 & 6\end{array}$

29. I'm better looking than most of my friends.

$\begin{array}{llllll}1 & 2 & 3 & 4 & 5 & 6\end{array}$

30. I am stronger than most people my age.

$\begin{array}{lllllll}\text { 31. My body is stiff and inflexible. } & 1 & 2 & 3 & 4 & 5 & 6\end{array}$

32. I could jog 5 kilometres without stopping.

$\begin{array}{lllllll}1 & 2 & 3 & 4 & 5 & 6\end{array}$

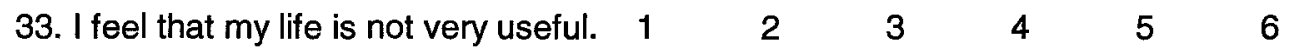

$\begin{array}{lllllll}\text { 34. I hardly ever get sick. } & 1 & 2 & 3 & 4 & 5 & 6\end{array}$

35. I can perform movements smoothly in most physical activities.

$\begin{array}{llllll}1 & 2 & 3 & 4 & 5 & 6\end{array}$

36. I do physically active things (like jogging, dancing, bicycling, aerobics, gym or swimming) at least three times a week.

$\begin{array}{lllll}2 & 3 & 4 & 5 & 6\end{array}$

$\begin{array}{llllllll}\text { 37. I am overweight. } & 1 & 2 & 3 & 4 & 5 & 6\end{array}$

$\begin{array}{lllllll}\text { 38. I have good sports skills. } & 1 & 2 & 3 & 4 & 5 & 6\end{array}$

39. Physically, I feel good about myself. $1 \quad 2 \quad \begin{array}{lllll}3 & 2 & 4 & 5 & 6\end{array}$

$\begin{array}{llllllll}\text { 41. I am weak and have no muscles. } & 1 & 2 & 3 & 4 & 5 & 6\end{array}$

42. My body parts bend and move in most directions well.

$\mathbf{x X}$ 
Modifications to the CBAS

$\begin{array}{llllll}1 & 2 & 3 & 4 & 5 & 6\end{array}$

43. I think that I could run a long way without getting tired.

$\begin{array}{llllllll}\text { 44. Overall, I'm no good. } & 1 & 2 & 3 & 4 & 5 & 6 \\ \text { 45. I get sick a lot. } & 1 & 2 & 3 & 4 & 5 & 6\end{array}$

46. I find my body handles co-ordinated movements with ease.

$\begin{array}{lllllll}1 & 2 & 3 & 4 & 5 & 6\end{array}$

47. I do lots of sports, dance, gym or other physical activities.

$\begin{array}{lllllll} & 1 & 2 & 3 & 4 & 5 & 6 \\ \text { 48. My stomach is too big. } & 1 & 2 & 3 & 4 & 5 & 6\end{array}$

49. I am better at sports than most of my friends.

$\begin{array}{llllll}1 & 2 & 3 & 4 & 5 & 6\end{array}$

50. I feel good about who I am and what I can do physically.

$\begin{array}{llllllll}51.1 \text { am good looking. } & 1 & 2 & 3 & 4 & 5 & 6\end{array}$

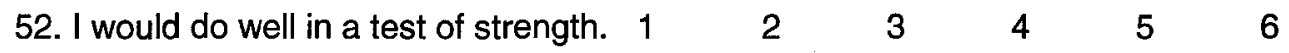

53. I think that I am flexible enough for most sports.

$\begin{array}{llllll}1 & 2 & 3 & 4 & 5 & 6\end{array}$

54. I can be physically active for a long period of time without getting tired.

55. Most things | do, I do well. $\quad \begin{array}{lllllll} & 1 & 2 & 3 & 4 & 5 & 6\end{array}$

56. When I get sick it takes me a long time to get better. $\begin{array}{cccccc}1 & 2 & 3 & 4 & 5\end{array}$

57. I am graceful and co-ordinated when I do sports and activities.

$1 \quad 2 \quad 3 \quad 4 \quad 5 \quad 6$

58. I do sports, exercise, dance or other physical activities almost every day.

$\begin{array}{llllllll}1 & 2 & 3 & 4 & 5 & 6\end{array}$

59. Other people think that I am fat. $\quad \begin{array}{lllllll}1 & 2 & 3 & 4 & 5 & 6\end{array}$

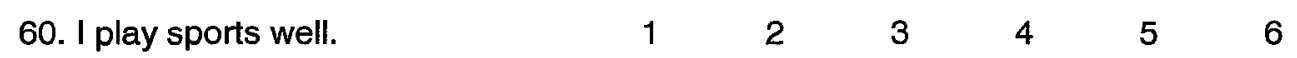

61. I feel good about who I am physically. $\begin{array}{rlllllll}1 & 2 & 3 & 4 & 5 & 6\end{array}$

62. Nobody thinks that I'm good looking. $1 \quad 2 \quad 3 \quad \begin{array}{llllll}4 & 3 & 5 & 6\end{array}$

xxi 
Modifications to the CBAS

63. I am good at lifting heavy things. $\quad \begin{array}{lllllll}1 & 2 & 3 & 4 & 5 & 6\end{array}$

64. I think that I would perform well on a test measuring flexibility.

$\begin{array}{llllll} & 2 & 3 & 4 & 5 & 6\end{array}$

65. I am good at endurance activities like distance running, aerobics, bicycling,

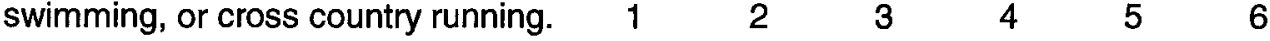

66. Overall, I have a lot to be proud of. $11 \quad 2 \quad \begin{array}{llllll}3 & 4 & 4 & 5 & 6\end{array}$

67. I have to gender orientation to the doctor because of illness more than other people of my age.

$1 \quad 2 \quad 3 \quad 4 \quad 5 \quad 6$

$\begin{array}{lllllll}\text { 68. Overall, I am a failure. } & 1 & 2 & 3 & 4 & 5 & 6\end{array}$

69. I usually stay healthy even when my friends get sick.

$\begin{array}{llllll}1 & 2 & 3 & 4 & 5 & 6\end{array}$

70. Nothing I do ever seems to turn out right.

$\begin{array}{llllll}1 & 2 & 3 & 4 & 5 & 6\end{array}$

xxii 
Appendix G

Comparison of dimensional structures from all sources.

CBAS and mCBAS.

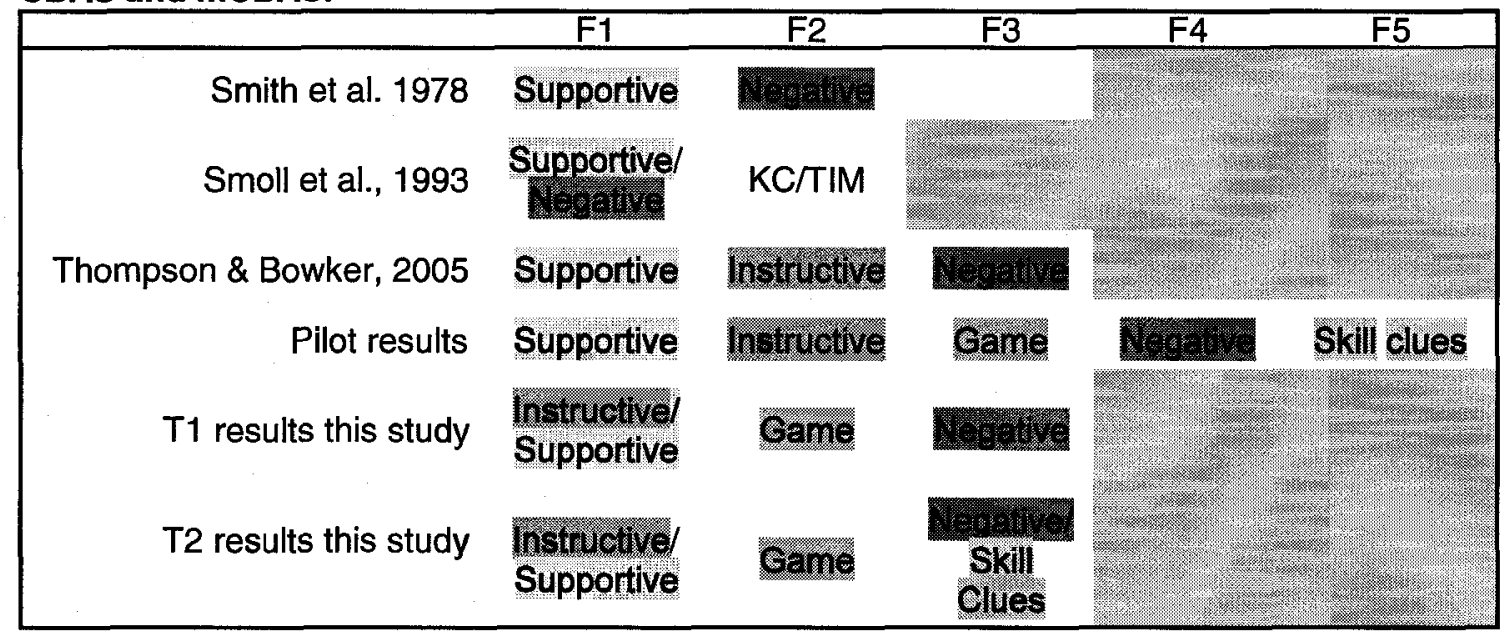

CFQ results only.

\begin{tabular}{|c|c|c|c|}
\hline 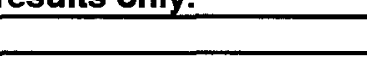 & $F 1$ & $F 2$ & F3 \\
\hline Amorose \& Horn, 2000 & $\begin{array}{l}\text { Supportive/ } \\
\text { Instructive }\end{array}$ & & IM \\
\hline Smith et al., 2005 & Supportive & (5) & NR \\
\hline T2 results this study & $\begin{array}{l}\text { Supportive/ } \\
\text { linstructive }\end{array}$ & & $\begin{array}{l}\mathrm{IM} / \\
\mathrm{NR}\end{array}$ \\
\hline
\end{tabular}

xxiii 
Male subjects only.

\begin{tabular}{|lccc|}
\hline & F1 & F2 & F3 \\
\hline Pilot results & Supportive & Game/ & Instructive \\
T1 results this study & Game & Supportive & Instructive \\
T2 results this study & $\begin{array}{c}\text { lnstructive/ } \\
\text { Supportive }\end{array}$ & Game & Defint \\
\hline
\end{tabular}

Female subjects only.

\begin{tabular}{|c|c|c|c|}
\hline & $\mathrm{F} 1$ & $\mathrm{~F} 2$ & F3 \\
\hline Pilot results & $\begin{array}{l}\text { Supportive/ } \\
\text { Instructive }\end{array}$ & Skill clues & Came \\
\hline T1 results this study & $\begin{array}{l}\text { Instructive/ } \\
\text { Supportive }\end{array}$ & Same & Skill clues \\
\hline T2 results this study & $\begin{array}{l}\text { Instructive/ } \\
\text { Supportive }\end{array}$ & Came & \\
\hline
\end{tabular}

xxiv 